\title{
DIGITALCOMMONS
}

@WAYNESTATE-

Wayne State University

Wayne State University Dissertations

$1-1-2017$

\section{Flexural Creep Behavior Of Adhesively Bonded Metal And Composite Laminates}

Hasan M. Nuwayer

Wayne State University,

Follow this and additional works at: https://digitalcommons.wayne.edu/oa_dissertations

Part of the Mechanical Engineering Commons

\section{Recommended Citation}

Nuwayer, Hasan M., "Flexural Creep Behavior Of Adhesively Bonded Metal And Composite Laminates" (2017). Wayne State University Dissertations. 1854.

https://digitalcommons.wayne.edu/oa_dissertations/1854

This Open Access Dissertation is brought to you for free and open access by DigitalCommons@WayneState. It has been accepted for inclusion in Wayne State University Dissertations by an authorized administrator of DigitalCommons@WayneState. 


\title{
FLEXURAL CREEP BEHAVIOR OF ADHESIVELY BONDED METAL AND COMPOSITE LAMINATES
}

by

\author{
HASAN NUWAYER \\ DISSERTATION \\ Submitted to the Graduate School \\ of Wayne State University, \\ Detroit, Michigan \\ in partial fulfillment of the requirements \\ for the degree of \\ DOCTOR OF PHILOSOPHY
}

2017

MAJOR: MECHANICAL ENGINEERING

Approved By:

Advisor

Date 
(c) COPYRIGHT BY

HASAN NUWAYER

2017

All Rights Reserved 


\section{DEDICATION}

To my parents and all my family members for their encouragement and support. 


\section{ACKNOWLEDGMENTS}

Funding of this research was supported by the Libyan Ministry of Education under doctoral program. The author wishes to express his deep gratitude and appreciation to Dr. Golam Newaz for his strong support and valuable suggestions throughout the course of this study.

I also thank my dissertation committee members, Dr. E. O. Ayorinde, Dr. Christopher Eamon and Dr. Leela Arava for their suggestions and constructive criticism.

I would like to thank Wayne State University, College of Engineering machine shop crew for their work in preparing the flexural creep testing setup.

The author is very grateful to his parents and wife for their blessing and support. 


\section{TABLE OF CONTENTS}

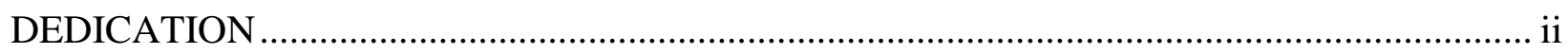

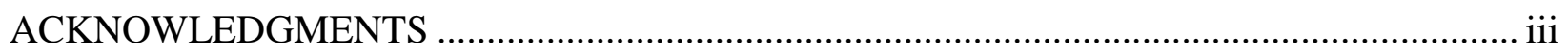

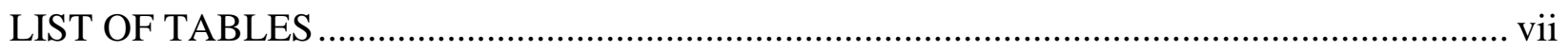

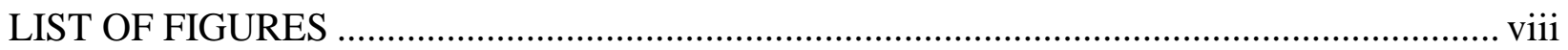

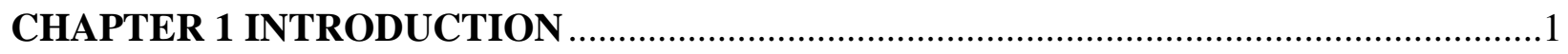

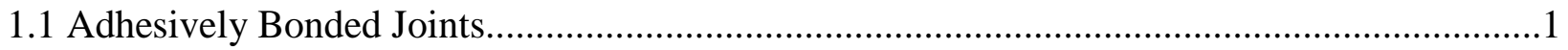

1.1.1 Advantages of Adhesively Bonded Joints ................................................................

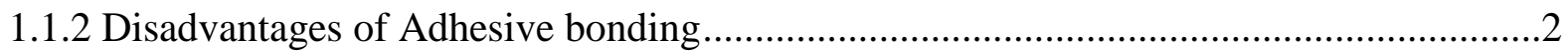

1.2 Design Aspects of Adhesively Bonded Structures .................................................................

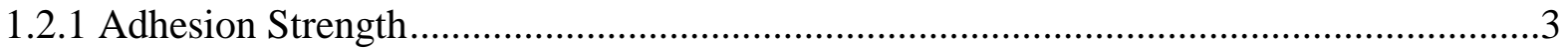

1.2.2 Adhesive Layer Stresses ........................................................................................

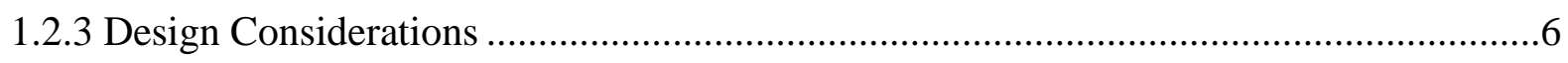

1.3 Key Issues in Modeling Adhesively Bonded Composites .......................................................

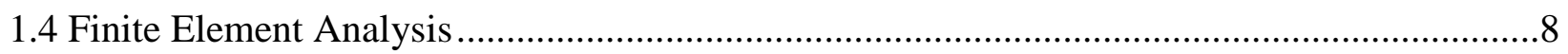

CHAPTER 2 LITERATURE SURVEY AND OBJECTIVES ……....................................

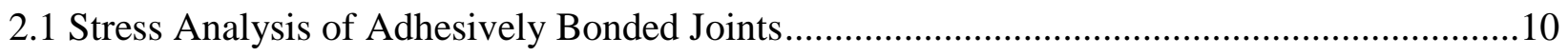

2.1.1 Analytical Modeling of Adhesively Bonded Joints .......................................................11

2.1.2 Numerical Modeling of Adhesively Bonded Joints.....................................................18

2.2 Modeling Approaches of Creep in Adhesively Bonded Joints ...............................................19

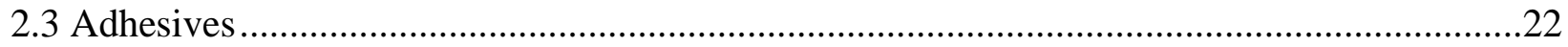

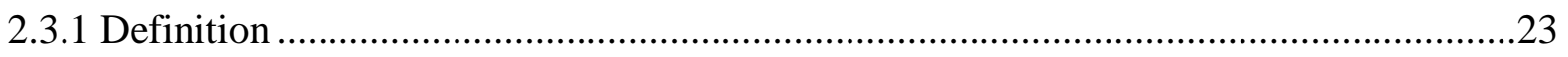

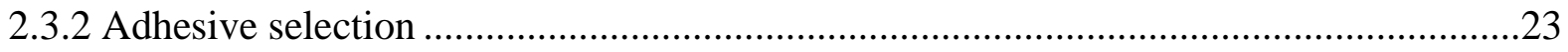


2.3.3 Adhesives classification.

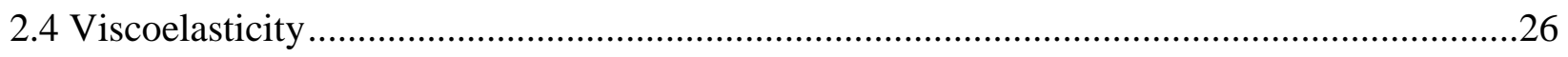

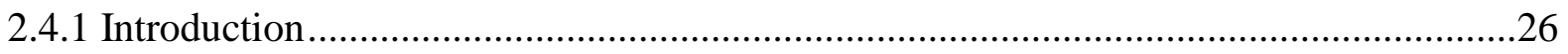

2.4.2 Characterization of viscoelastic materials mechanical properties .............................29

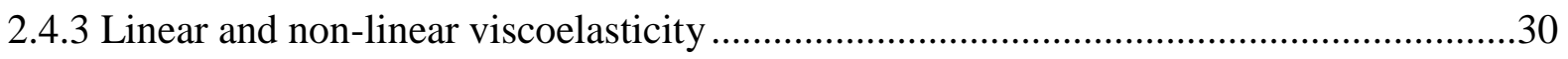

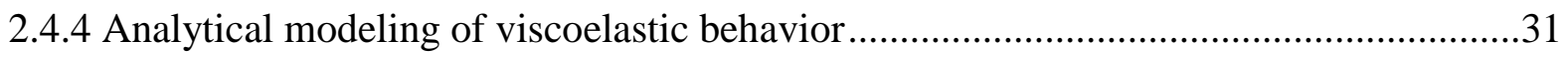

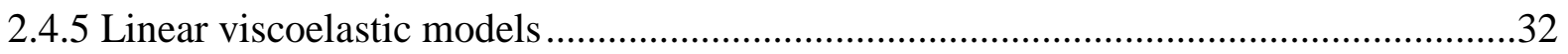

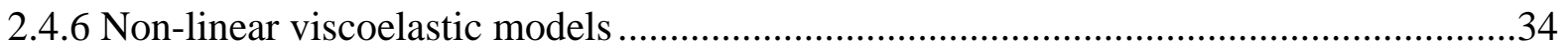

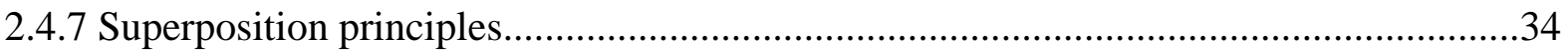

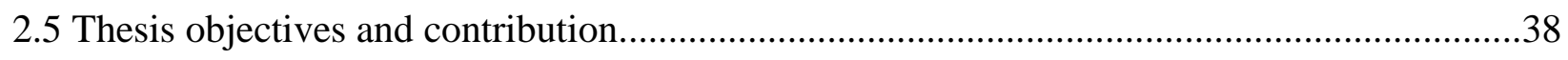

2.5.1. Lap shear versus flexural time dependent behavior...............................................39

CHAPTER 3 THEORETICAL AND ANALYTICAL CONSIDERATIONS .....................40

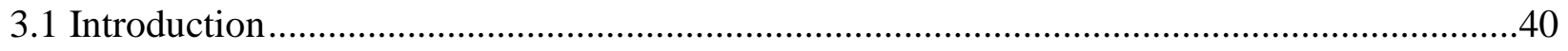

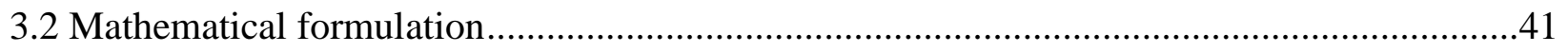

3.3 Sensitivity of the adhesively bonded beam to the adhesive shear modulus .........................47

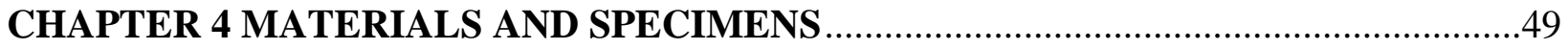

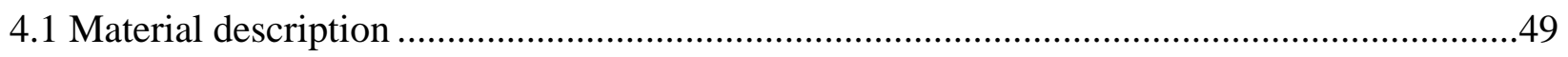

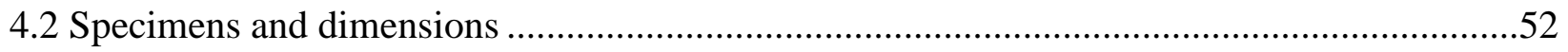

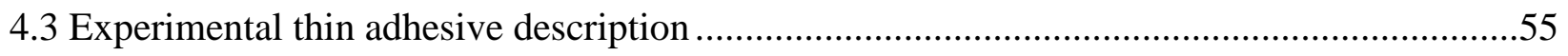

4.4 Preparation of adherends surfaces for adhesive bonding ..............................................56

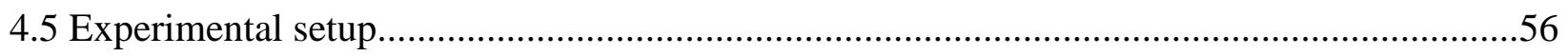

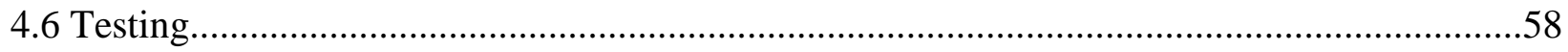

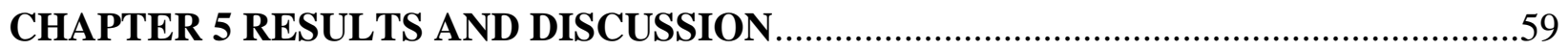




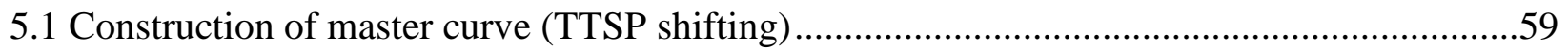

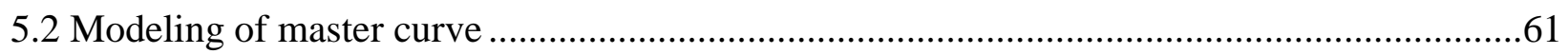

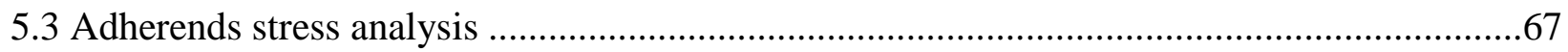

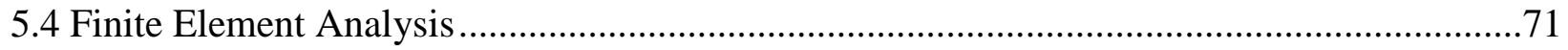

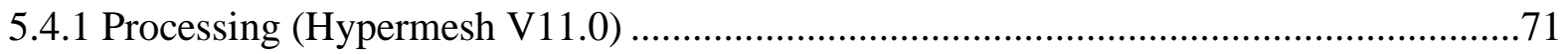

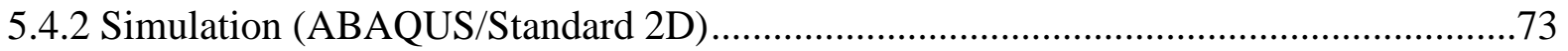

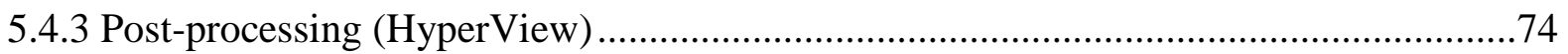

CHAPTER 6 CONCLUSION AND RECOMENDATIONS ..........................................78

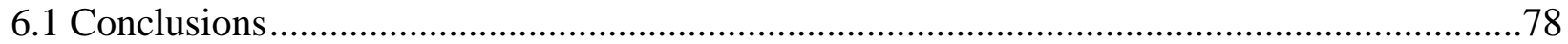

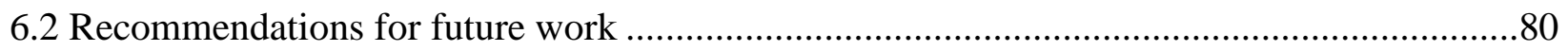

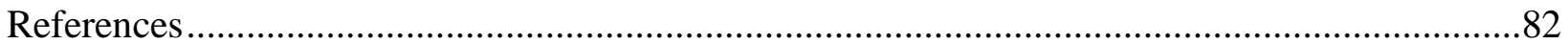

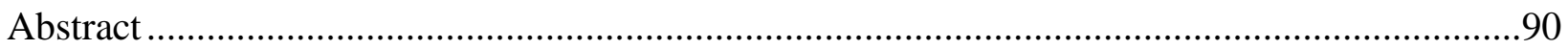

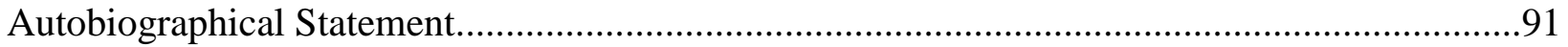




\section{LIST OF TABLES}

Table 2.1: Adhesive development history …....................................................................22

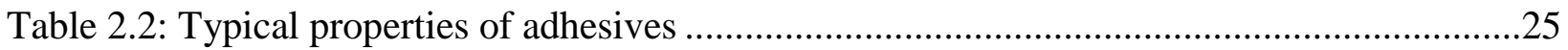

Table 4.1: Tensile, flexural and shear properties of adherends ............................................52

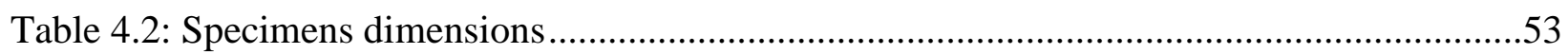

Table 5.1: Horizontal shift factor versus temperature .......................................................60

Table 5.2: Bonding adhesive Prony series parameters .........................................................64 


\section{LIST OF FIGURES}

Figure 1.1: Shear stress in single lap joint SLJ ...............................................................4

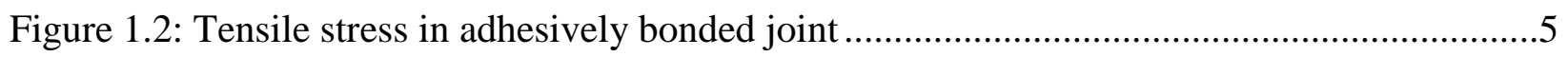

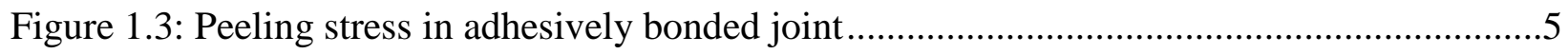

Figure 1.4: Compression stress in adhesively bonded joint..................................................6

Figure 2.1: Single lap joint (a) Rigid adherends, (b) Flexible adherends .................................10

Figure 2.2: Shear and peel stress distribution along the SLJ overlap ....................................11

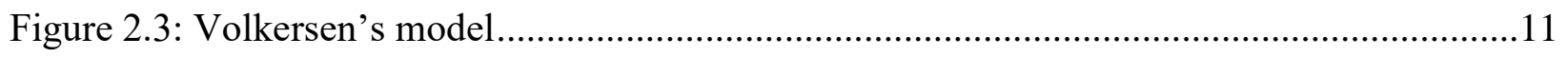

Figure 2.4: Volkersen's model shear stress distribution along the SLJ overlap .........................12

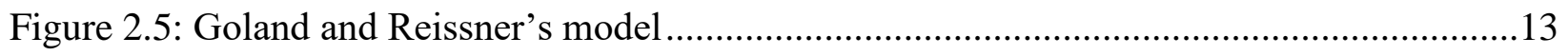

Figure 2.6: Goland and Reissner's model shear and peeling stress distribution along overlap.....13

Figure 2.7: Hart-smith model (Plasticity in the adhesive and shear stress strain curve) ..............17

Figure 2.8: Typical structural adhesive lap joints subjected to axial load ...............................21

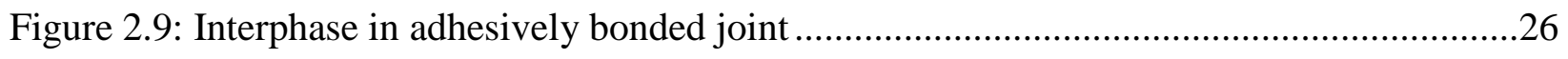

Figure 2.10: Conformational rate versus temperature .....................................................28

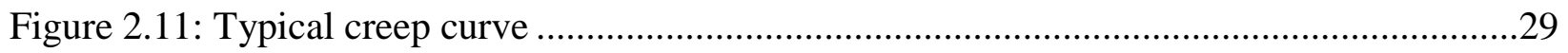

Figure 2.12: Stress relaxation under constant strain ..................................................... 30

Figure 2.13: Linear and nonlinear viscoelastic behavior at different times $\left(\mathrm{t}_{1}, \mathrm{t}_{2}, \mathrm{t}_{3}\right) \ldots \ldots \ldots \ldots \ldots \ldots . . . . . . .11$

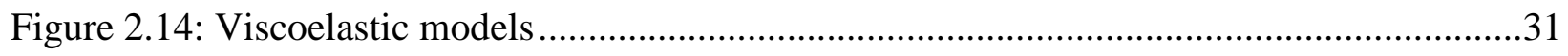

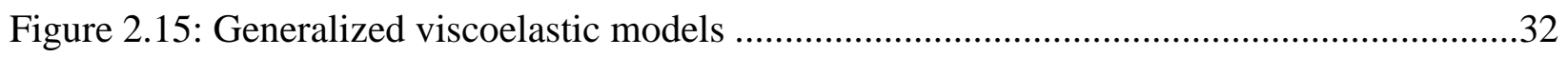

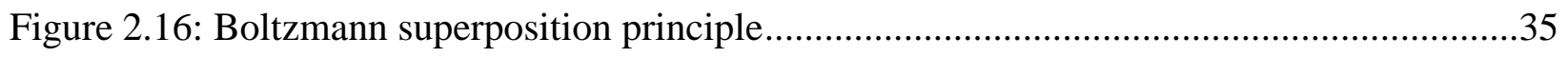

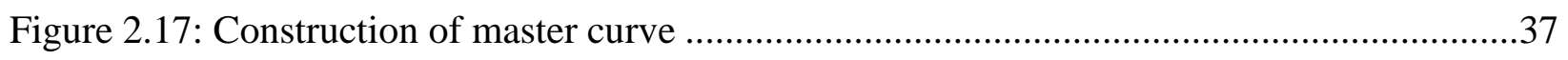

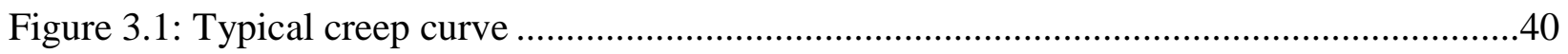


Figure 3.2: Three point bending of adhesively bonded beam.............................................41

Figure 3.3: Linear viscoelastic adhesives creep behavior....................................................41

Figure 3.4: Three-point bending-cantilever beam analogy ..............................................44

Figure 3.5: Cantilever beam cut along the mid-plane of the adhesive layer..............................44

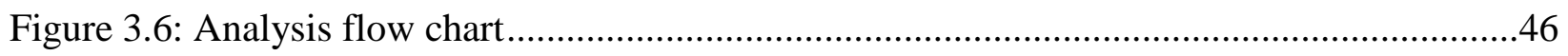

Figure 3.7: Adhesion factor versus adhesive shear modulus ............................................47

Figure 3.8: The composite action between adhesive and adherends .....................................48

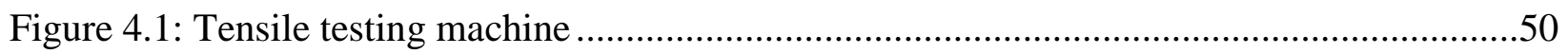

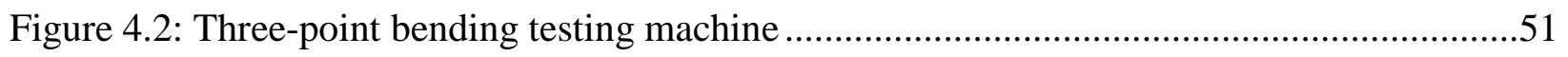

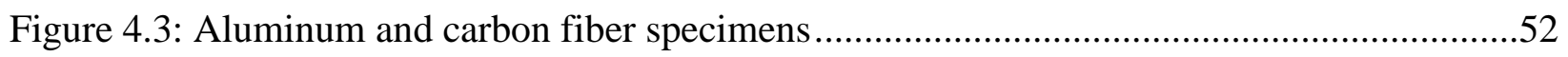

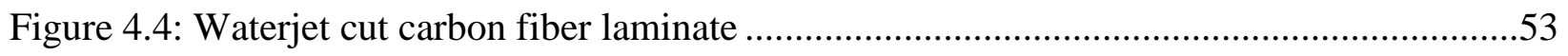

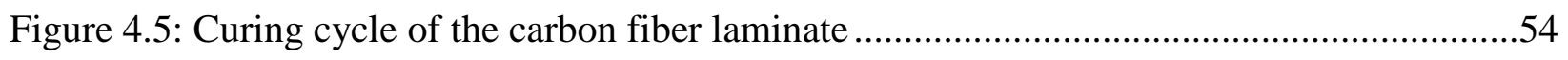

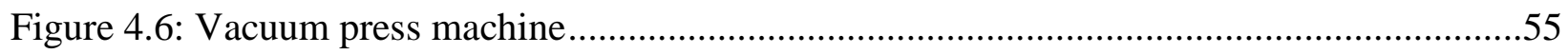

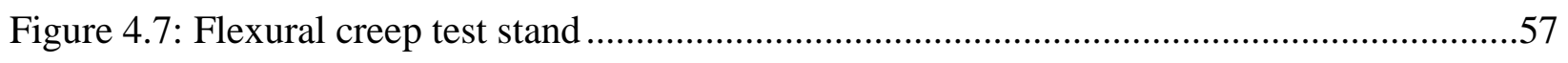

Figure 4.8: Flexural creep testing setup drawing ..........................................................58

Figure 5.1: Individual creep curves and master curve ......................................................59

Figure 5.2: Horizontal shift factor versus temperature ..................................................60

Figure 5.3: Long-term bonded beam stiffness versus creep time .......................................61

Figure 5.4: Analytical modeling of master curve ............................................................64

Figure 5.5: Variation of bonded beam stiffness versus creep time .........................................65

Figure 5.6: Percentage decrease in bonded beam stiffness versus creep time..........................65

Figure 5.7: Adhesion factor versus creep time ...........................................................66

Figure 5.8: Shear stress variation along the adhesive bond line ...........................................66 
Figure 5.9: Maximum adhesive shear stress versus creep time

Figure 5.10: Infinitesimal element of adhesively bonded joint .68

Figure 5.11: Normal stress vs span at upper and lower aluminum composite beam surfaces.......69

Figure 5.12: Axial stress vs span at upper and lower carbon fiber composite beam surfaces.......70

Figure 5.13: Variation of axial stress across composite beam thickness at mid-span (FEM) .......70

Figure 5.14: 2D finite element model for adhesively Bonded Aluminum Beam ...........................72

Figure 5.15: 2D finite element model for adhesively Bonded Carbon Fiber Beam .......................73

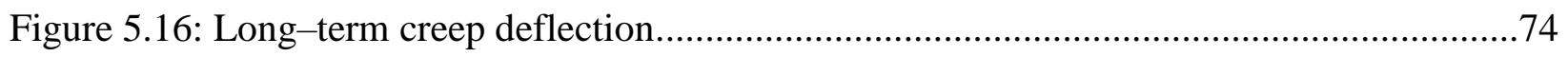

Figure 5.17: In plane shear stress versus adhesive bond line ……...............................................

Figure 5.18: FEM, normal (compressive) adhesive stress distribution along the bond line...........76

Figure 5.19: Mid-span lower adherend lower surface tensile stress versus creep time .................76 


\section{CHAPTER 1 INTRODUCTION}

\subsection{Adhesively Bonded Joints}

There is a rapid growth in the application of adhesive bonding in aeronautical, aerospace and automotive industries to replace the conventional joining techniques such as welding, riveting or bolting. This growth is motivated by the need for bonding composite structures made from light weight carbon or glass fiber composites as adhesives are the only way to join disparate materials to one another. The application of structural adhesives eliminates sudden change of stresses, lowers stresses acting across joined region, uniformly distributes the load, increases load carrying capacity and eliminates stress concentration. The result is a reduced overall weight of the structure, lower cost, improved long-term durability, improved fatigue resistance, increased stiffness of the structure and improved safety. Another promising application is the damping properties of the adhesive that may enhance the damping capacity of the whole structure. However, adhesives are viscoelastic in nature and when put under load they exhibit time dependent behavior. The gradual decrease in their stiffness leads to continuous decrease in load bearing performance and subsequently redistribution of the stresses and strains within the structure. Another negative point is the complex stress state of adhesive joints that makes it difficult to predict its long-term behavior including failure and deformations. Viscoelasticity is a mix of elastic and viscoelastic behavior with deformation depending on load, time and temperature. Many materials will undergo some level of deformation called creep if put under constant stress over a period of time. Increasing the temperature of the material will speed up the processes, and the time dependent response of the material decreases. Even though the use of adhesive materials started long time ago, most of the adhesives being used today were developed 
during the last century. Developments in this field continue to meet the different requirements and applications in industry.

\subsubsection{Advantages of Adhesively Bonded Joints Over Other Joining Methods}

- The possibility of joining substrates with different materials, geometries and size.

- Avoid galvanic corrosion that comes as a result of joining dissimilar metals with different galvanic potential.

- No deformation to the substrates being adhesively bonded and reduction in manufacturing cost.

- Adhesive joining will not make any mechanical damage to the bonded substrates, the structure of the material is protected.

- Use of adhesive joints means high product design flexibility

- Lower structure weight, this is directly related to the reduction in fuel consumption and $\mathrm{CO} 2$ emissions to the environment.

- Improved fatigue and impact resistance of the structure by using elastic adhesives, this means increased life cycle and reliability of the structure.

- Stresses are distributed over larger areas which means less stress concentrations in the bond connection.

- The use of adhesive joints reduces the vibration and noise.

- Reducing the need for many mechanical components such as rivets, screws, washers, etc that needed in the traditional way of structure bonding.

\subsubsection{Disadvantages of Adhesive Bonding}

- The adhesive in adhesive joint bonding needs some time to cure and the bonded structure cannot immediately put under load. 
- The long-term behavior is affected by many factors like ultraviolet light, moisture and chemicals.

- There is a need for adherends surface preparation before the application of the adhesive to achieve a good adhesion.

- Difficult to disassemble the adhesive joint and my lead to the destruction of the substrates.

- Environmental concern in dealing with adhesives during the production, application and waste management.

- There is a need for special processes to be followed during the different stages starting from design to maintenance of the adhesive joint.

\subsection{Design Aspects of Adhesively Bonded Structures}

Many complex shape products manufactured today came as a result of the use of composite materials instead of the traditional materials. Another important aspect is the reinforcement of structures by bonding pre-manufactured structure components with a high strength adhesive. The following is the aspects that need to be considered in the design or rehabilitation of adhesively bonded structure.

\subsubsection{Adhesion Strength}

To achieve high strength bonding the following steps should be followed:

- The surface of the adherend should be dry and clean from any contaminates. This will help the epoxy adhesive flow and wet the surface.

- The adhesive should have enough time to cure in place and the structure should be free from any stresses until the adhesive is fully cured. 
- Proper selection of the adhesive. Epoxy structural adhesive should be used when high strength bonding is needed.

\subsubsection{Adhesive Layer Stresses}

The bonding adhesive layer is subjected to many stresses that can lead to the failure of the joint if not considered properly during the design stage.

\section{- Shear Stress}

This kind of stress arises when the applied forces are at the same line with the adhesive layer as in single lap joint (SLJ) Figure1.1. In general, adhesively bonded structures are good in resisting shear stresses. The in-plane shear stress is not uniform along the adhesive layer and it is maximum at the far ends of the joint. In plane adhesive shear stress decreases with increase in bond line thickness.

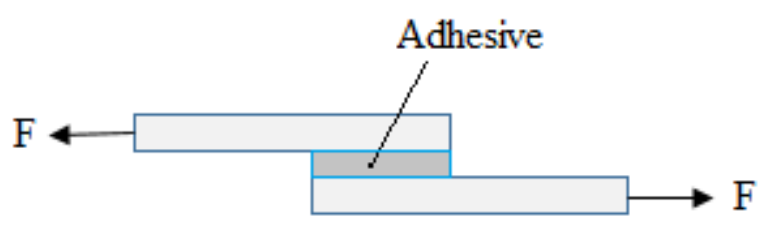

Figure: 1.1 Shear stress in SLJ.

\section{- Tensile Stress}

Tensile stress is created as a result of applying load normal to the surface Figure 1.2. It may cause an adhesive failure of the structure at a stress far below the adhesive strength. It is important to select adhesive with high adhesion strength to the adherend to withstand this kind of stress. 


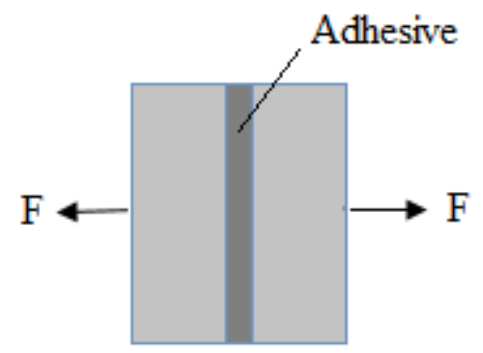

Figure:1.2 Tensile stress in adhesively bonded joint.

\section{- Peel Stress}

Peel stress occurs as a result of forces trying to pull the bonded structure apart Figure 1.3. As a result of this kind of loading, all the stress is concentrated in a very small bond area and very high tensile stress is generated at the interface with the two adherends pulling apart. The adhesive should be ductile enough to allow for distribution of the load along the adhesive layer. Peel stress can be generated as a result of bending of the adhesively bonded structure. Due to the high concentrated tensile load created on the edge of the bond line as a result of the peeling stress, it is important to avoid this kind of stress during the design stage. This can be done by using mechanical fasteners to prevent peel stress from starting at the edge of the bond line. In the real adhesively bonded structure it is rare to have a pure kind of stress. Applying tensile stress for example, may cause the structure to bend and peeling stress will be created.

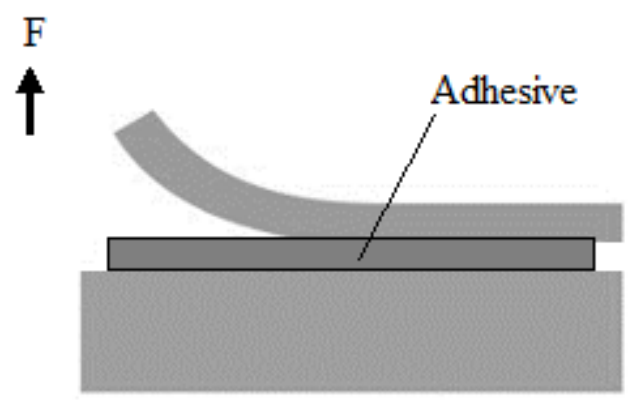

Figure:1.3 Peeling stress in adhesively bonded joint. 


\section{- Compression Stress}

In compression loading the adhesive is used as chocking material and as a support to the mechanical mounting system Figure 1.4. In this kind of loading it is important to select adhesive with proper compressive strength. The compressive stress should be well below the compression strength of the adhesive to avoid creep failure as a result of constant stress on the bond line. More care should be taken if the structure is exposed to high temperatures.

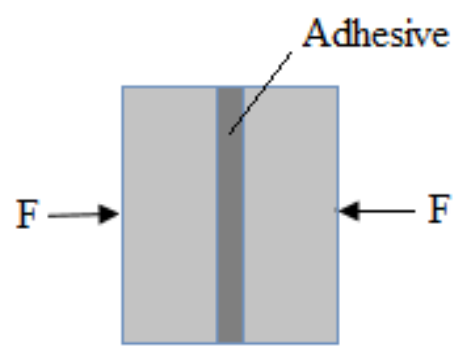

Figure: 1.4 Compression stress in adhesively bonded joint.

\subsubsection{Design Considerations}

The above discussed shear, tensile, peel and compression stresses should be considered carefully and for a good adhesively bonded structure design the following recommendations should be followed:

- Adhesively bonded structures are good in resisting shear loading. Most of the load should be directed to shear.

- Try to avoid peel stress and improve peel resistance by using adhesive with lower stiffness and higher elongation.

- In most loading situations, it is unlikely to have pure tensile stress. 
- High stiffness structural epoxy adhesive is recommended for fastener bonding, high concentrated stress and chocking.

- Bonding surface area should be maximum and for good resistance to peel stress the width of the bonded area should be maximized.

- Adhesive thickness depends on adhesive properties and application.

In order to optimal properties, epoxy adhesive should be properly cured. Adhesive properties highly depend on the curing process.

\subsection{Key Issues in Modeling Adhesively Bonded Composites}

The long-term response of adhesively bonded composites depends on many different variables such as, adhesive mechanical properties, type of adherends used, adherends surface preparation, interaction between the adhesive and the adherend, temperature and relative humidity, kind and magnitude of applied stresses. Many studies have been done on the effects of these variables by Kinloch, [1], Plecnik,J.M.,et al(1980) [2], Mc Murray, M.K. and Amagi,S.(1999)[3],Gardner, D.J. et al., (2006) [4],Curley, A., et al.,(1998) [5]. W.R.Broughton et al., (1999) [6-13] performed series of creep experiments on adhesively bonded joints to investigate the effect of multiple variables such as temperature and humidity on time to failure of adhesively bonded joints. He conducted T-peel, single lap joint and tapered strap joint tests. S. Roy and J.N.Reddy (1986) [14] investigated the nonlinear viscoelastic behavior of adhesively bonded joints. They developed FEM model based on Schapery's single integral constitutive law. Delale and Erdogan (1981) [15] studied the single lap joint assuming linear viscoelastic adhesive and extended their study to the time temperature effect. Botha, Jones and Brinson (1983) [16] used FEM approach to perform nonlinear viscoelastic stress analysis on adhesively bonded joint, Henriksen, Becker, et al. (1984) [17] extended their viscoelastic stress analysis of adhesively bonded joint to include 
moisture diffusion, Yadagiri and Papi Reddy (1985) [18] studied the viscoelastic behavior of nearly incompressible solids.

\subsection{Finite Element Analysis}

The finite element method is a very powerful numerical technique that widely used in structural analysis to simulate the response of any structure shape to various loading and boundary conditions. Finite element method long time used to study the stress distribution along the adhesive bond. Carver, D. et al., (1971) [19] and Adams, R. et al., (1973) [20]. It is now extensively used in the analysis and design of the adhesively bonded joints due to its ability to deal with complicated geometries, material and geometrical nonlinearity. Another factor is the advances in the computing speed and memory size. A good finite element analysis of adhesively bonded joint needs a good description of the geometry, a good modeling of the material behavior under stress and proper simulation of the various loading and boundary conditions. The use of finite element method to model adhesively bonded joints helps optimizing product performance, improves the efficiency in using the materials, reduces the time needed for both, design processes and evaluation of design alternatives. Along the years, many analytical and finite element models were developed to study the behavior of adhesively bonded joints under different types of loading. Results from analytical solutions were compared with the finite element analysis and experimental results. Many linear and nonlinear finite element analyses were performed on different kinds of adhesive joints to study the adhesive stresses and strains. In order to have a good finite element results, it is important to consider the following factors: the differences in the mechanical properties within the adhesive joint, moisture and heat effect (hygro-thermal behavior), stress concentrations at certain regions of the adhesive joint and the low adhesive thickness compared with the thickness of the adherends. There is a need for high 
degree of freedom in the adhesive joint which means a very fine mesh is required. A good finite element analysis should account for the bending effects, shear of the adherends and the nonlinear behavior of the adhesive. It is important to take into account the nonlinearity of the material and geometry in finite element analysis in order to get good results. Adams, R. and N. Peppiatt, (1973-1974) [20-21]. 


\section{CHAPTER 2 LITERATURE SURVEY AND OBJECTIVES}

\subsection{Stress Analysis of Adhesively Bonded Joints}

Analyzing the stresses in the adhesively bonded joint is a complicated issue due to the complexity of the stresses in the adhesive bond line. The difference in the mechanical properties and material mismatch are the reason behind the stress concentrations at the adhesive adherend interface. The simplest adhesively bonded joint stress analysis Figure. 2.1(a) based on the assumption that the adherends are rigid and adhesive is subjected to uniform shear stress given by,

$\tau=\frac{P}{b l}$

Where, $P$ is the applied force, $b$ is the joint width and $l$ is the overlap length. This analysis is based on many simplifications and considered not realistic even though it is used by ASTM and ISO standard to roughly predict the adhesive shear strength.

(a)

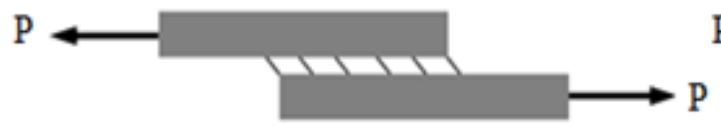

(b)

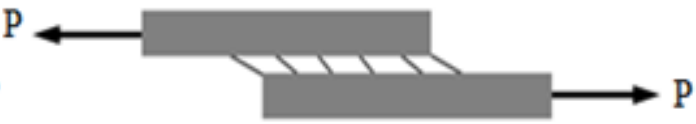

Figure 2.1: Single lap joint: (a) Rigid adherends-constant shear stress, (b) Flexible adherends-not constant shear.

In Figure 2.1(b), the adherends are assumed elastic and their extension reaches its maximum value near to their loaded end. This means that the generated shear stress is not uniform and 
highest at the overlap ends. In addition, there is the rotation of the adherends as a result of the moment generated by the loading forces that leads to peeling stresses in the adhesion bond line Figure 2.2.

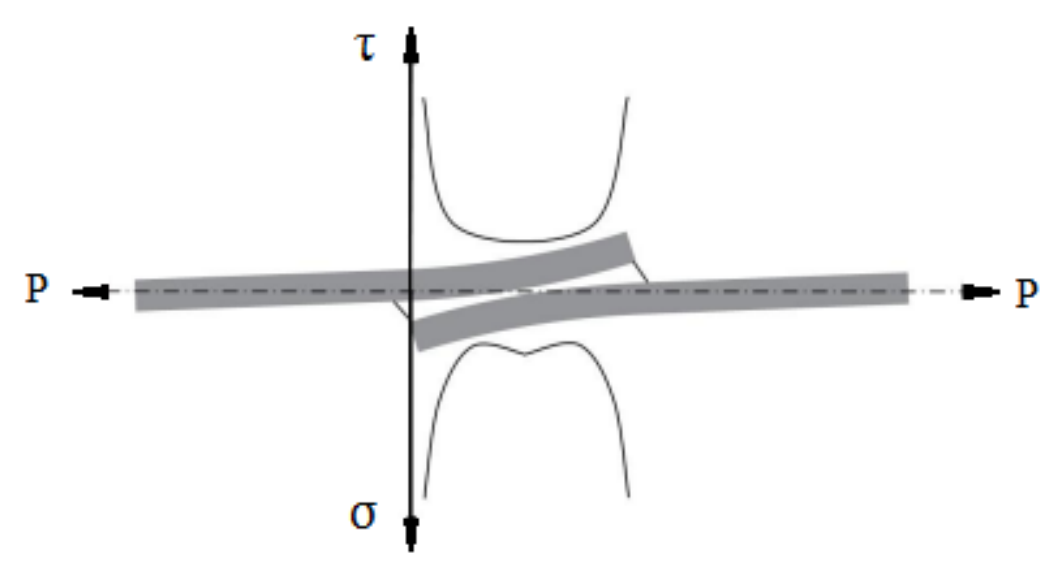

Figure 2.2: Shear and peel stress distribution along the SLJ overlap.

In literature, there are many analytical and numerical models to analyze the state of stress in the adhesive bond line.

\subsubsection{Analytical Modeling of Adhesively Bonded Joints}

- Volkersen's model

The first known analytical model by Volkersen. [22]

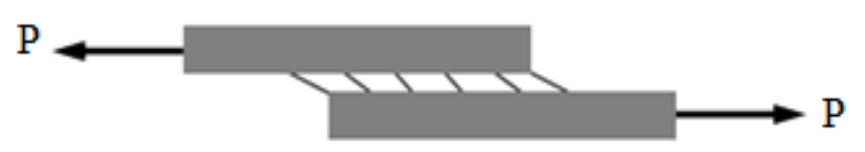

Figure 2.3: Volkersen's model. 
This model assumes that the adhesive deforms only in shear and the adherends are elastic and deform in tension. The shear stress distribution along the overlap is not uniform and is given by,

$$
\tau=\frac{P \omega \cosh (\omega X)}{2 b l \sinh (\omega / 2)}+\left(\frac{\psi-1}{\psi+1}\right) \frac{\omega \sinh (\omega X)}{2 \cosh (\omega / 2)}
$$

Where,

$\mathrm{P}$ is the applied force, $t_{1}$ and $t_{2}$ are the upper and lower adherend thickness respectively, $G_{a}$ is the adhesive shear modulus, $l$ is the overlap, $X$ is the distance from the middle of the overlap, $E_{1}$ and $E_{2}$ the upper and lower adherend elastic modulus respectively.

$$
E=E_{1}=E_{2}, \quad \omega^{2}=(1+\psi) \varphi, \quad \psi=\frac{t_{1}}{t_{2}}, \quad \varphi=\frac{G_{a} l^{2}}{E t_{1} t_{2}}
$$

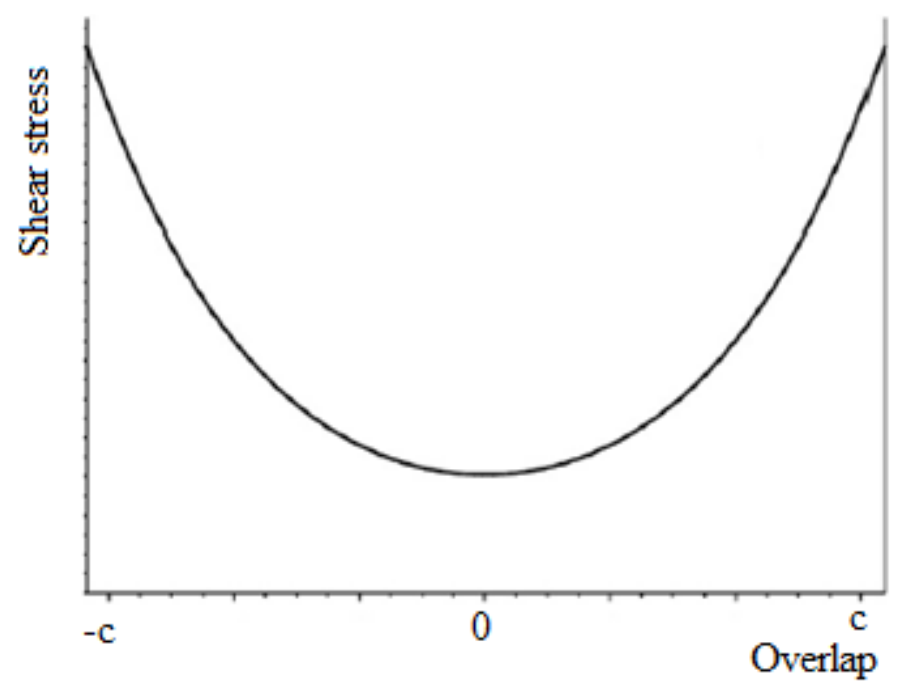

Figure 2.4: Volkersen's model shear stress distribution along the SLJ overlap.

The shear stress is maximum at the ends of the overlap and much lower at the middle. This model does not account for the bending as a result of force eccentricity. 


\section{- Goland and Reissner's model}

This model [23] can be seen as improvement to Volkersen's model because it considered the adhesive peeling stress as a result of applied force path eccentricity. Figure 2.5 shows the SLJ subjected to tensile force per unit width $\bar{P}$.

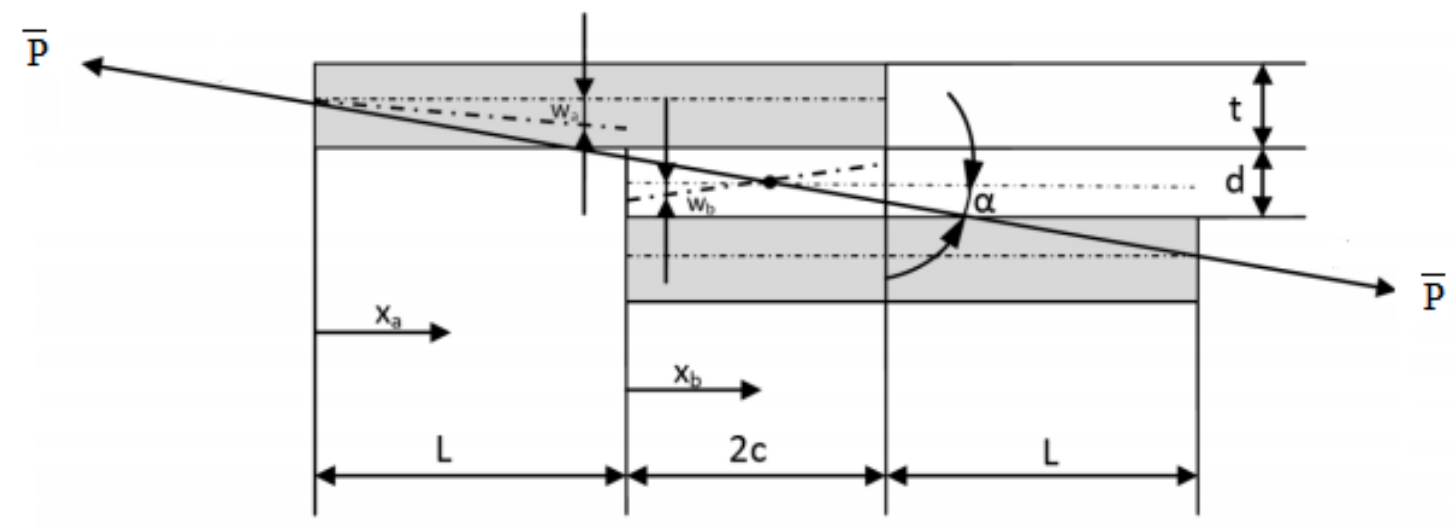

Figure 2.5: Goland and Reissner's model.

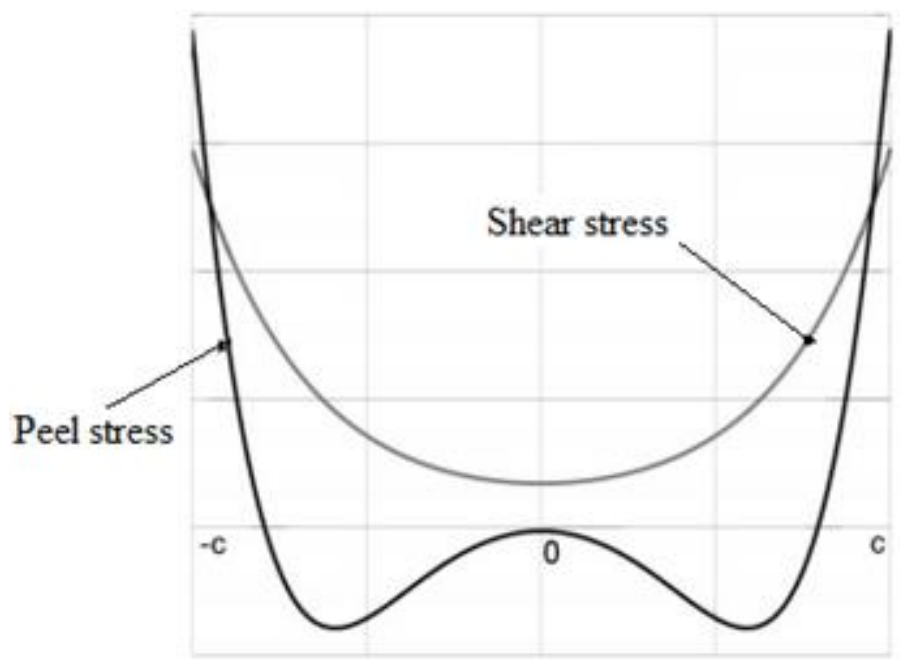

Figure 2.6: Goland and Reissner's model shear stress distribution and peeling stress along the SLJ overlap.

The shear stress distribution along the overlap is given by, 
$\tau=-\frac{1}{8} \frac{\bar{P}}{c}\left(\frac{\beta c}{t}(1+3 k) \frac{\cosh ((\beta c / t)(x / c)}{\sinh \left(\frac{\beta c}{t}\right)}+3(1-k)\right)$

Where,

$\bar{P}$ is the tensile force per unit width, $c$ is the half of the overlap and $t$ is the adherend thickness.

$\beta^{2}=8 \frac{G_{a}}{E} \frac{t}{t_{a}}$

$k=\frac{\cosh \left(u_{2} c\right)}{\cosh \left(u_{2} c\right)+2 \sqrt{2} \sinh \left(u_{2} c\right)}$

$u_{2}=\sqrt{\frac{3\left(1-v^{2}\right)}{2} \frac{1}{t}} \sqrt{\frac{\bar{P}}{t E}}$

The peel stress distribution along the overlap is given by,

$$
\begin{aligned}
& \sigma=\frac{1}{\Delta} \frac{\bar{P}}{c^{2}} t[\left(R_{2} \lambda^{2} \frac{k}{2}+\lambda k^{\prime} \cosh (\lambda) \cos (\lambda)\right) \cosh \left(\frac{\lambda x}{c}\right) \cos \left(\frac{\lambda x}{c}\right) \\
&\left.\left.+\left(R_{1} \lambda^{2} \frac{k}{2}+\lambda k^{\prime} \sinh (\lambda) \sin (\lambda)\right)\right) \sinh \left(\frac{\lambda x}{c}\right) \sin \left(\frac{\lambda x}{c}\right)\right]
\end{aligned}
$$

Where,

$\lambda=\gamma \frac{c}{t}$

$\gamma^{4}=6 \frac{E_{a}}{E} \frac{t}{t_{a}}$

$E_{a}$ is the adhesive Young's modulus,

$k^{\prime}=\frac{k c}{t} \sqrt{3\left(1-v^{2}\right) \frac{\bar{P}}{t E}}$

$R_{1}=\cosh (\lambda) \sin (\lambda)+\sinh (\lambda) \cos (\lambda)$

$R_{1}=\cosh (\lambda) \sin (\lambda)-\sinh (\lambda) \cos (\lambda)$ 
$\Delta=\frac{1}{2}(\sin (2 \lambda)+\sinh (2 \lambda))$

And the middle point of the overlap is the origin of the $x$-coordinate. Both Volkersen's model [22] and Goland and Reissner's model [23] were strong contributions toward understanding the stress in adhesively bonded joints, but they have the following negative points:

- Both models did not consider the change in stress across the adhesive thickness especially at the area of adherend adhesive interface where failure is more expected.

- The maximum adhesive shear stress occurs at the ends of the overlap which is a violation of the stress-free condition. This overestimation of the adhesive shear stress leads to underestimation of failure load prediction.

- The through thickness shear and normal strains of the adherends were neglected. These strains can be important in composite adherends.

\section{- Harth-Smith's model}

This model gives an analytical solution to the elastic shear and peel stress of the adhesive along the SLJ overlap [24]. It also considered adhesive shear stress plasticity by dividing the overlap into a central elastic region of length $d$ and two outer plastic regions each of length: $\left(\frac{l-d}{2}\right)$.

The shear stress distribution along the overlap is given by,

$$
\tau=A_{2} \cosh \left(2 \lambda^{\prime} x\right)+C_{2}
$$

Where,

$$
\begin{aligned}
& \lambda^{\prime}=\sqrt{\left[\frac{1+3\left(1-v^{2}\right)}{4}\right] \frac{2 G_{a}}{t_{a} E t}} \\
& A_{2}=\frac{G_{a}}{t_{a} E t}\left[\bar{P}+\frac{6\left(1-v^{2}\right) M}{t}\right] \frac{1}{2 \lambda^{\prime} \sinh \left(2 \lambda^{\prime} c\right)}
\end{aligned}
$$


$C_{2}=\frac{1}{2 c}\left[\bar{P}-2 \frac{A_{2}}{2 \lambda^{\prime}} \sinh \left(2 \lambda^{\prime} c\right)\right]$

$M=\bar{P}\left(\frac{t+t_{a}}{2}\right) \frac{1}{1+\xi c+\left(\xi^{2} c^{2} / 6\right)}$

$\xi^{2}=\frac{\bar{P}}{D}$

$D=\frac{E t^{3}}{12\left(1-v^{2}\right)}$

The peel stress distribution along the overlap is given by,

$\sigma=A \cosh (\chi x) \cos (\chi x)+B \sinh (\chi x) \sin (\chi x)$

Where,

$\chi^{2}=\frac{E_{a}}{2 D t_{a}}$

$A=-\frac{E_{a} M[\sin (\chi c)-\cos (\chi c)]}{t_{a} D \chi^{2} e^{(\chi c)}}$

$B=\frac{E_{a} M[\sin (\chi c)-\cos (\chi c)]}{t_{a} D \chi^{2} e^{(\chi c)}}$

Shear stress distribution along the elastic region is given by,

$\tau=A_{2} \cosh \left(2 \lambda^{\prime} x\right)+\tau_{2}(1-K)$

Shear strain distribution along the plastic region is given by,

$\gamma=\gamma_{e}\left\{1+2 K\left[\left(\lambda^{\prime} x^{\prime} \tanh \left(\lambda^{\prime} d\right)\right]\right\}\right.$

Where $\tau_{P}$ is the plastic adhesive shear stress and

$A_{2}=\frac{K \tau_{P}}{\cosh \left(\lambda^{\prime} d\right)}$

The following equations are used to solve for $K$ and $d$ :

$\frac{\bar{P}}{l \tau_{P}}\left(\lambda^{\prime} l\right)=2 \lambda^{\prime}\left(\frac{l-d}{2}\right)+(1-K)\left(\lambda^{\prime} d\right)+K \tanh \left(\lambda^{\prime} d\right)$ 


$$
\begin{aligned}
& {\left[1+3 k\left(1-v^{2}\right)\left(1+\frac{t_{a}}{t}\right)\right] \frac{\bar{P}}{\tau_{P}} \lambda^{2}\left(\frac{l-d}{2}\right)=2\left(\frac{\gamma_{P}}{\gamma_{e}}\right)+K\left[2 \lambda^{\prime}\left(\frac{l-d}{2}\right)\right]^{2}} \\
& 2\left(\frac{\gamma_{P}}{\gamma_{e}}\right)=K\left(\left[2 \lambda^{\prime}\left(\frac{l-d}{2}\right)+\tanh \left(\lambda^{\prime} d\right)\right]^{2}-\tanh ^{2}(\chi d)\right)
\end{aligned}
$$

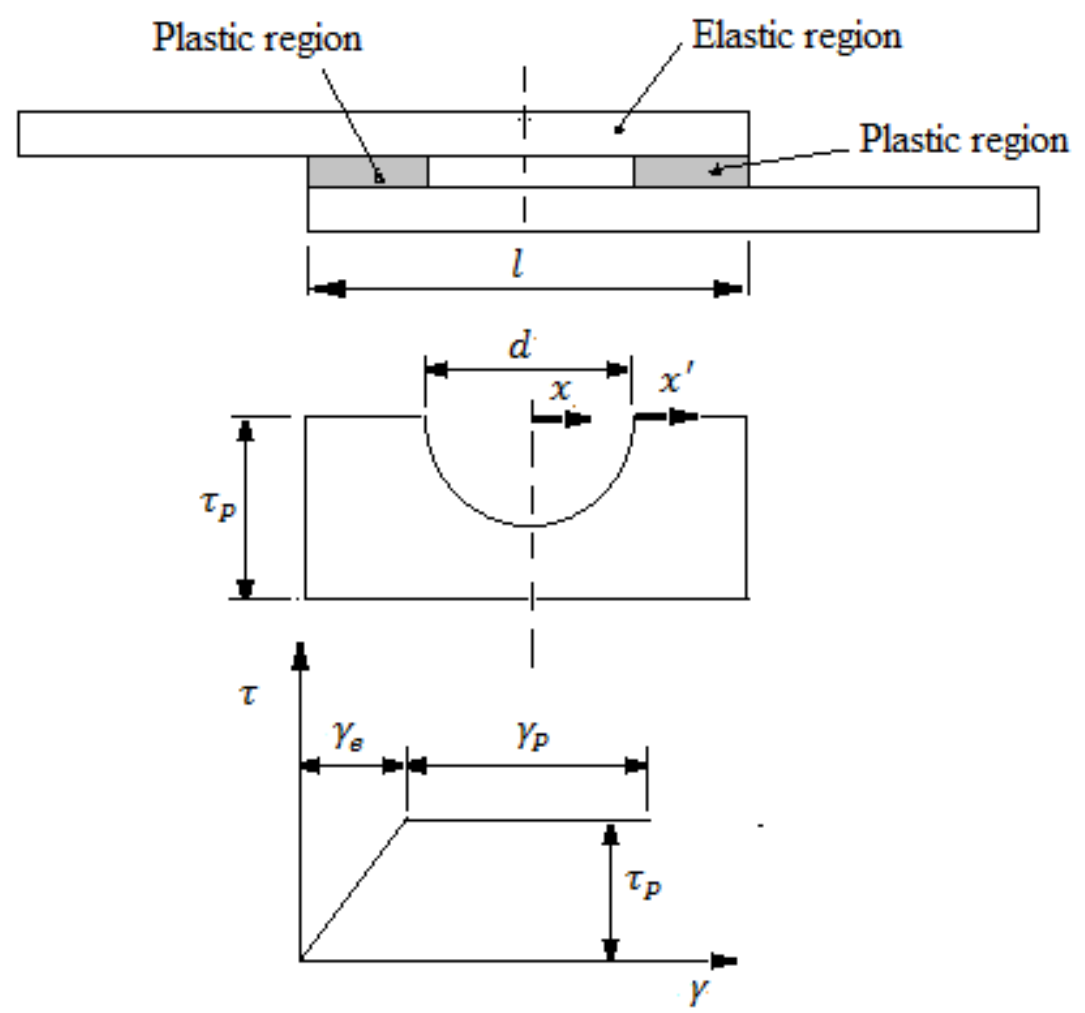

Figure 2.7: Hart-Smith's model (Plasticity in the adhesive and shear stress strain curve). [24]

\section{- Bigwood and Cocombe model}

This model [25] is an improvement to Goland and Reissner model to work with other types of adhesively bonded joints other than tensile loaded SLJ. These connection configurations include tubular joints, T-peel joints, SLJ with transverse load and L-joints. The analysis then extended to deal with the case of adhesive nonlinear behavior [26]. 


\section{- Other analytical analysis contributions}

Many researchers tried to develop models that can deal with adhesive joints with compositeadherends or adherends that are different in material properties and thickness[26-39]. However, general solutions result more complicated equations that need to be solved numerically.

\subsubsection{Numerical Modeling of Adhesively Bonded Joints}

Finite element method FEM is widely used to simulate the stresses and strains in the adhesively bonded joints. Rao et al [40] proposed 2D adhesive elements that are 6-noded iso-parametric elements to model the adhesive. The proposed adhesive elements are compatible with the eight node iso-parametric quadratic elements used to model the adherends. The proposed elements cannot model the nonlinear adhesive behavior or the joint combined loading. Yadagiri [41] modified Rao's 2D element model to deal with normal and longitudinal stresses and adhesive linear viscoelastic behavior.

Reddy and Roy [42] developed 2D element model where they used elastic solids formulations by Lagrange to deal with geometric and material nonlinearity. Their analysis covered the viscoelastic behavior and the thermal moisture effects. Amijima and Fujii [43] developed simple 1D element model to calculate the adhesive normal and shear stresses and takes in to account the bending effects. This model deals only with linear material behavior. Carpenter [44] proposed 2D adhesive element model to simulate the viscoelastic behavior of adhesively bonded lap joints using Laplace transformations where inverse transforms were numerically calculated. [45-46] developed a 2D model to calculate the distribution of shear and normal stresses for different bonded arrangements and to deal with the condition of nearly zero adhesive thickness. This analysis accounts for adherends with different materials and thickness. Edlund and Klarbring 
[47] developed a general 2D element model that deals with both material and geometrical nonlinearity. All the last approaches used 2D elements in their analysis and can be applied only to simple joints. Many other studies were performed based on 3D elements. Tong and Sun [48] proposed 6,16 and 18 node 3D adhesive elements model to analyze bonded repairs of curved structures. Andruet et al. [49] developed 2D and 3D elements model based on shell and solid elements that allows the analysis of complicated bonded structures. Goncalves et al. [50] proposed 3D element model to predict the stresses at the interface between the adhesive and the adherends in the adhesive joints. This approach introduced interface element which can be used with brick solid elements from the ABAQUS software.

All the above models are complicated and not widely used in industry. This means that there is a need for more simple approaches.

\subsection{Modeling Approaches of Creep in Adhesively Bonded Joints}

Proper design of adhesively bonded joint needs a good understanding of the stress strain in the adhesive bond and many models were developed for this purpose. Adhesives are polymeric materials and they show time dependent behavior under stress. This means that the issue of creep behavior should be addressed at the early stages of design of adhesive joint for any structural application. Most of adhesives are linear viscoelastic at low and moderate stress levels and tend to behave nonlinear with increasing stresses due to gradual decrease in stiffness [51]. In literature, there are many experimental and numerical studies to investigate the linear and nonlinear adhesive behavior. There are also some analytical models (viscoelastic and viscoplastic) to analyze the stresses and strains in adhesively bonded joints. The simplest and well known viscoelastic models developed by Voigt and Maxwell [52]. Other models based on springs and dashpots combinations were used to predict the linear viscoelastic response of the 
material under different loading conditions. The springs and dashpots are to model the elastic and viscous components of the viscoelastic material, respectively. Feng et al. [53] developed a model to simulate the long-term behavior of epoxy adhesives. This model based on series of short-term accelerated tests at different temperatures and construction of the master curve using time temperature superposition principle (TTSP). Master curve then modeled using physics based coupling model. Dean [54] modeled the nonlinear creep behavior of polypropylene using a system of four springs and damping elements. Yu et al. [55] studied the creep behavior of epoxy adhesives. They unified theory and viscoelastic models in their simulations. Majda and Skrodzewicz [56] simulated the nonlinear creep behavior of epoxy adhesives at room temperature using modified Burgers spring and dashpot model. Yu et al. [57] used empirical method to determine creep compliance function of viscoelastic adhesive contact models. Roseley et al. [58] used two Kelvin-Voight models in series arrangement to improve the simulation of the creep behavior of three epoxy adhesives that have glass transition temperature between $30^{\circ} \mathrm{C}$ and $60^{\circ} \mathrm{C}$. Chiuand Jones [59] used a unified constitutive model to study the time dependent characteristics of thermoset adhesive that widely used in the bonded repair of aircraft structures. Duncan and Maxwell [60] evaluated the use of newly developed measurement technique to study the creep, stress relaxation and properties of flexible adhesives. Dean and Broughton [61] developed analytical model to characterize the nonlinear creep behavior of rubber toughened adhesives. Their model used for both bulk adhesives and bonded joints and adapted for use with finite element software package ABAQUS. Pandey et al. [62] conducted nonlinear finite element analysis of adhesively bonded joints using elasto-viscoplastic model to describe the adhesive material behavior. The adherends were assumed linear elastic and Ramberg-Osgood relation [63] used to describe the stress-strain relation of the adhesive. Mortensen and Thomsen [64] used a 


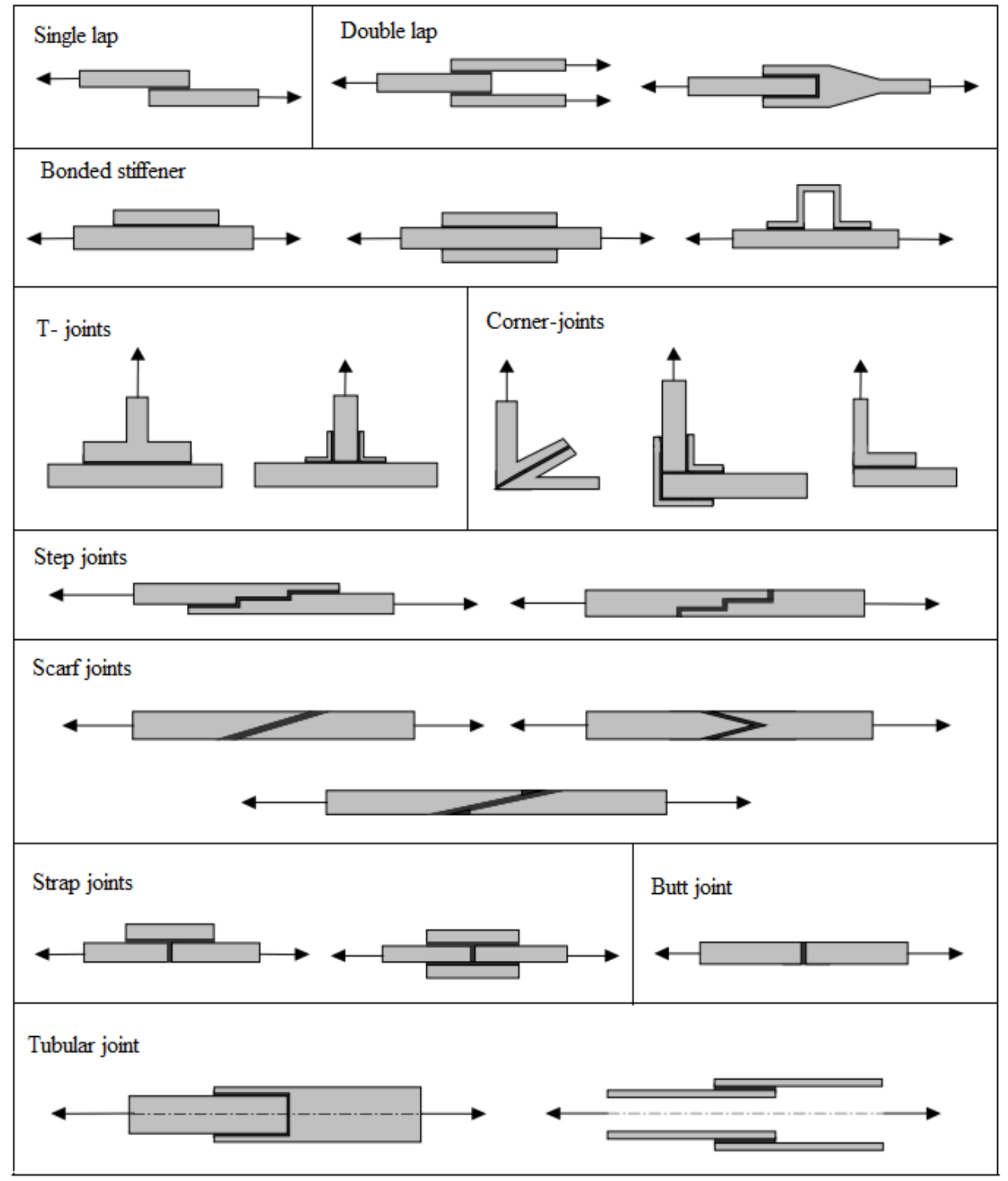

Figure 2.8: Typical structural adhesive lap joints subjected to axial load. [1] 
developed unified approach for the analysis and design of adhesively bonded composite laminates.

\subsection{Adhesives}

Humans used adhesives very long time ago. Early adhesives were made from natural materials like vegetables, bones, hide and other animal substances.

Table 2.1 Adhesives development history. [65]

\begin{tabular}{|c|c|}
\hline Adhesive & $\begin{array}{l}\text { Development } \\
\text { period }\end{array}$ \\
\hline Phenol-formaldehyde, Casein glues & 1910 \\
\hline $\begin{array}{l}\text { Cellulose ester, Alkyd resin, Cyclized rubber in adhesives } \\
\text { Poly-chloroprene (Neoprene), Soybean adhesives }\end{array}$ & 1920 \\
\hline $\begin{array}{l}\text { Urea-formaldehyde, Pressure sensitive tapes, Phenolic resin adhesive films, } \\
\text { Polyvinyl acetate wood glues }\end{array}$ & 1930 \\
\hline $\begin{array}{l}\text { Nitrile-phenolic, Chlorinated rubber, Melamine formaldehyde, Vinyl- } \\
\text { phenolic, AcrylicPolyurethanes }\end{array}$ & 1940 \\
\hline Epoxies, Cyanoacrylates, Anaerobics, Epoxy alloys & 1950 \\
\hline Polyimide, Poly-benzimidazole, Poly-quinoxaline & 1960 \\
\hline $\begin{array}{l}\text { Second-generation acrylic, Acrylic pressure sensitive, Structural } \\
\text { polyurethanes }\end{array}$ & 1970 \\
\hline $\begin{array}{l}\text { Tougheners for thermoset resins, Waterborne epoxies, Waterborne contact } \\
\text { adhesives, Formable and foamed hot melts, Polyurethane modified epoxy }\end{array}$ & 1980 \\
\hline Curable hot melts, UV and light cure systems & 1990 \\
\hline
\end{tabular}


It was only the last century when many new kinds of synthetic (polymeric and elastomeric resins) adhesives were developed and widely used. The development of new adhesives is continuing due to advances in technology and changing needs.

\subsubsection{Definition}

Adhesive is a substance that used to bond two or more surfaces together and resist their separation due to its tensile and shear strength. The following are the most common characteristics of adhesives:

- Good in load distribution and transfer within the assembly components.

- Increase the bonding carrying capacity and strength of the structure.

- Bonding of dissimilar adherend materials due to adhesive cohesion to many substances.

- Adhesives have high damping capacity to dynamic vibrations and impact.

\subsubsection{Adhesive Selection}

- The temperature and humidity range of service.

- Chemical and UV light exposure.

- Type of adherends.

\subsubsection{Adhesives Classification}

- According to origin.

- Natural adhesives.

They are produced from natural resources such as vegetables and animals.

- Synthetic adhesives. 
They are produced from non-organic resources like epoxy, acrylic, polyurethane and cyanoacrylate polymers. Their mechanical, physical and chemical properties are much better than natural adhesives and as a result they are much widely used in industry.

- According to the number of components needed to cure the adhesive.

- One component adhesive.

This kind of adhesives need external source to be cured. This source can be UV light, heat or moisture. As an example, moisture cured polyurethane, silicones and cyanoacrylates adhesives.

- Two or more component adhesive.

Adhesives from two or more substances chemically react and cross link. As an example, two component epoxy, two component polyurethane and acrylates adhesives.

- According to post cure structure of the adhesive.

- Thermoplastic Adhesives.

- Elastomer Adhesives.

- Thermoset Adhesives.

- According to curing type of the adhesive.

- Physically cured adhesives such as pressure sensitive and contact adhesives.

- Chemically cured adhesives such as polyurethane, epoxy and acrylates adhesives.

- According to the mechanical properties of the adhesive.

- Elastic adhesives with high fracture strain such as one component moisture cured polyurethane and silicone adhesives.

- Rigid adhesives that have high impact resistance and low elasticity, such as epoxy adhesives, anaerobic adhesives and heat cured one component polyurethane. 
Table 2.2 Typical properties of adhesives. [66]

\begin{tabular}{|c|c|c|c|}
\hline & Comments & $\begin{array}{c}\text { Service } \\
\text { temperature }{ }^{\circ} \mathrm{C}\end{array}$ & Cure \\
\hline Epoxy & $\begin{array}{l}\text { High strength and temperature } \\
\text { resistance, relatively low cure } \\
\text { temperatures, easy to use, low cost }\end{array}$ & $\begin{array}{l}-40 \text { to }+100 \\
(180 *)\end{array}$ & $\begin{array}{l}\text { One part epoxies cure } \\
\text { with temperature. Two } \\
\text { part epoxies cure at } \\
\text { room temperature } \\
\text { (cure can be } \\
\text { accelerated with } \\
\text { temperature) }\end{array}$ \\
\hline Cyanoacrylates & $\begin{array}{l}\text { Fast bonding capability to plastic } \\
\text { and rubber but poor resistance to } \\
\text { moisture and temperature }\end{array}$ & -30 to +80 & $\begin{array}{l}\text { Fast cure (second or } \\
\text { minute) upon exposure } \\
\text { to moisture at room } \\
\text { temperature }\end{array}$ \\
\hline Anaerobics & $\begin{array}{l}\text { Designed for fastening and sealing } \\
\text { applications in which a tight seal } \\
\text { must be formed without light, heat } \\
\text { or oxygen, suitable for bonding } \\
\text { cylindrical shapes }\end{array}$ & -55 to +150 & $\begin{array}{l}\text { Cure in the absence of } \\
\text { air or oxygen at room } \\
\text { temperature }\end{array}$ \\
\hline Acrylics & $\begin{array}{l}\text { Versatile adhesives with capabilities } \\
\text { of fast curing and tolerate dirtier and } \\
\text { less prepared surfaces }\end{array}$ & -40 to +120 & $\begin{array}{l}\text { Cure through a free } \\
\text { radical mechanism }\end{array}$ \\
\hline Polyurethanes & $\begin{array}{l}\text { Good flexibility at low temperatures } \\
\text { and resistant to fatigue, impact } \\
\text { resistance, and durability }\end{array}$ & -200 to +80 & Room temperature \\
\hline Silicones & $\begin{array}{l}\text { Excellent sealant for low stress } \\
\text { applications, high degree of } \\
\text { flexibility, and very high } \\
\text { temperature resistance, capability to } \\
\text { seal or bond materials of various } \\
\text { natures, long cure times, and low } \\
\text { strength }\end{array}$ & $\begin{array}{l}-60 \text { to }+300 \\
\left(350^{\dagger}\right)\end{array}$ & Room temperature \\
\hline Phenolics & $\begin{array}{l}\text { Good strength retention for short } \\
\text { periods of time, limited resistance to } \\
\text { thermal shocks }\end{array}$ & $\begin{array}{l}-40 \text { to }+175 \\
\left(260^{\dagger}\right)\end{array}$ & $\begin{array}{l}\text { Cure with temperature } \\
\text { and high pressure }\end{array}$ \\
\hline Polyimides & $\begin{array}{l}\text { Thermal stability, dependent on a } \\
\text { number of factors, difficult } \\
\text { processability }\end{array}$ & $\begin{array}{l}-40 \text { to }+50 \\
\left(300^{\dagger}\right)\end{array}$ & $\begin{array}{l}\text { Cure with temperature } \\
\text { and high pressure }\end{array}$ \\
\hline Bismaleimides & Very rigid, low peel properties & $\begin{array}{l}-50 \text { to }+200 \\
\left(230^{\dagger}\right)\end{array}$ & $\begin{array}{l}\text { Cure with temperature } \\
\text { and high pressure }\end{array}$ \\
\hline
\end{tabular}

* With different filler materials; †intermittent. 


\subsection{Viscoelasticity}

\subsubsection{Introduction}

There is a big difference between metals and viscoelastic materials in their response to longterm loading. Beside fatigue which is a common source for mechanical structures failure due to long-term cyclic loading, viscoelastic materials have another problem which is the time dependence behavior of the mechanical properties. Degradation with time of the stiffness and strength may cause premature failure of the structure without any signs, like cracks that usually precede fatigue failure. Viscoelastic properties are highly affected by temperature, moisture, aging and other factors.

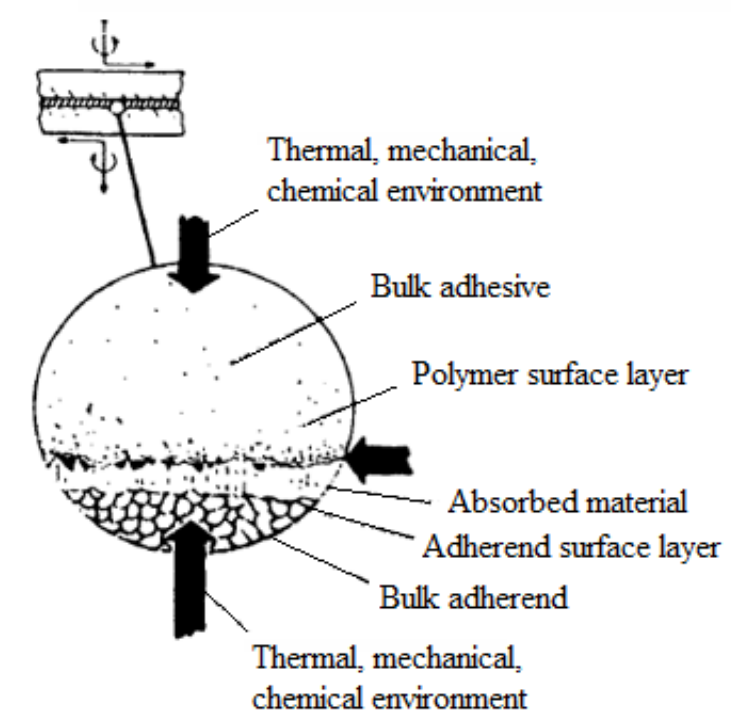

Figure 2.9: Interphase in adhesively bonded joint. [67]

It is also directly related to the molecular structure of the material which makes the deformation, failure and fracture process of the viscoelastic materials more complicated and totally different from metals. Adhesives which are viscelastic in nature have another durability problem in addition to fatigue and time dependent behavior. This problem is a result of the adhesive- 
adherend interface Figure 2.9. In reality, there is no defined interface line between the adhesive and the adherend but a diffuse zone from the adherend surface, adherend surface and any absorbed matter to form what is known as the interphase zone. This interphase zone is strongly related to the durability of the adhesive joint. [67]. It is difficult to perform long-term laboratory testing to cover the life span of many composite structures because of their long service life. As an example, airplanes, cars, bridges are designed to serve for decades. For this reason, there is a need for short time scale testing to predict the longer time scale performance. This means that from the design stage there is a need for reliable procedure to predict the life span and the deformation, stiffness and strength change with time under severe conditions of temperature, moisture and other factors. Glass transition temperature $\mathrm{T}_{\mathrm{g}}$ (different for each polymeric material) is the temperature of transition from the hard and brittle "glassy" state into the soft and ductile "rubbery" state as the temperature increases. This means that temperature is a very important factor in the deformation of polymeric materials. Depending on the material temperature relative to $\mathrm{T}_{\mathrm{g}}$ polymeric material can be glassy, rubbery or viscoelastic. Both glassy and rubbery stages show elastic, instantaneous, reversible and time independent strains under stress. In the glassy stage, the material temperature is far below $\mathrm{T}_{\mathrm{g}}$ and the rate of conformational change 'a change in the shape of a macromolecule, often induced by environmental factors' is very slow Figure 2.10 and the deformation comes as a result of changing of the lengths and angles of the atomic bonds. Glassy polymeric material can endure only little strains before brittle fracture. On the other hand, rubbery polymeric material temperature is far above $T_{g}$, the rate of conformational change is very high (instantaneous) Figure 2.10 and the deformation comes as a result of large movements of the molecules and atoms rearrangement. Rubbery polymeric materials can sustain very large strains before failure. For material temperature, near to $T_{g}$ Figure 
2.10 the behavior is viscoelastic (time dependent) which means a combination of fluid and elastic properties. The rate of conformational change can be described by Arrhenius equation,

Rate $=A e^{-E / R T}$ where $\mathrm{A}$ is constant, $\mathrm{E}$ is the activation energy of the process, $\mathrm{R}$ is the gas constant $\left(\mathrm{R}=8.314 \mathrm{~J} / \mathrm{mol}^{\circ}{ }^{\circ} \mathrm{K}\right)$ and $\mathrm{T}$ is the temperature in Kelvins.

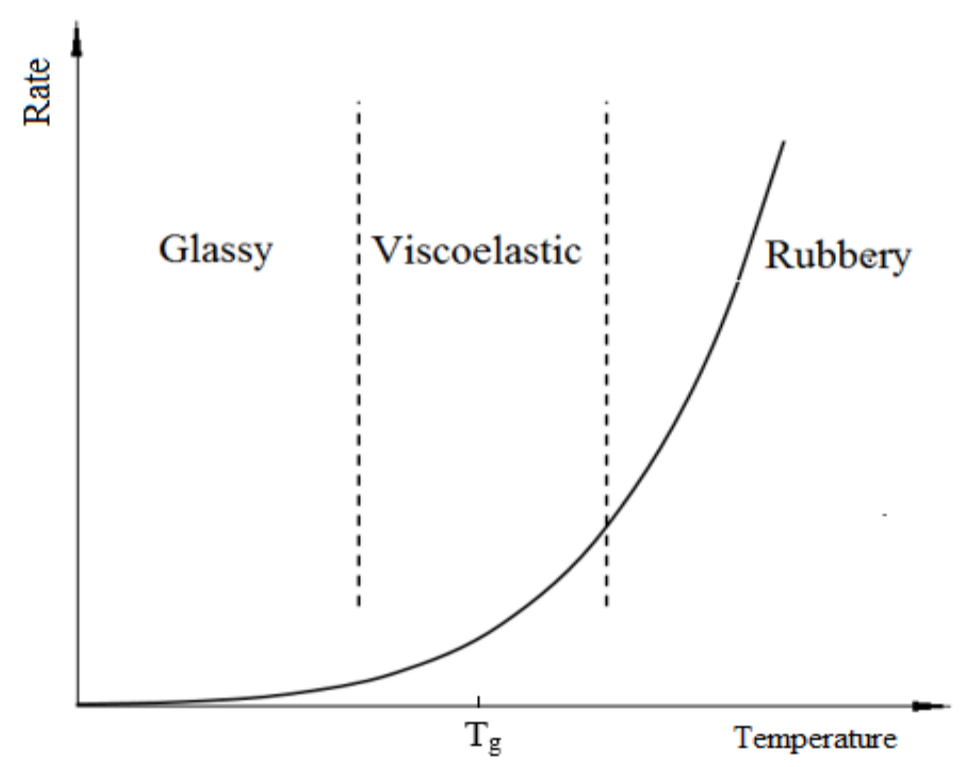

Figure 2.10: Conformational rate versus temperature.

Viscelastic materials have both fluid viscous and solid elastic properties. The behavior of viscoelastic materials depends on the time scale and temperature. Material is classified as viscoelastic if it satisfies any of the following conditions:

- Time dependent strain under constant load (creep).

- Time dependent stress under constant strain (stress relaxation).

- Hysteresis loop stress strain curve as a result of oscillatory (dynamic) loading.

- Stiffness depends on the rate of applying stress. 
Most of materials show some degree of viscoelastic behavior under load, even metals at elevated temperatures. Composite structures, especially with polymeric constituents, show time dependent viscoelastic behavior under load.

\subsubsection{Characterization of viscoelastic Materials Mechanical Properties}

Viscoelastic materials behavior is characterized by performing a uniaxial tensile test and monitoring the response of the material for a period of time. The most common tensile viscoelastic tests are: creep, stress relaxation and dynamic loading.

\section{- Creep}

Creep is a time dependent strain that occurs when the material is subjected to constant stress. Creep strain increases with stress, temperature, relative humidity and time. Polymeric materials may creep at room temperature. Typical creep curve consists of three stages: primary creep where the creep rate is high, secondary creep (steady state creep) where the creep rate is constant and the tertiary creep where the creep rate shows continuous increase until rupture Figure 2.11.
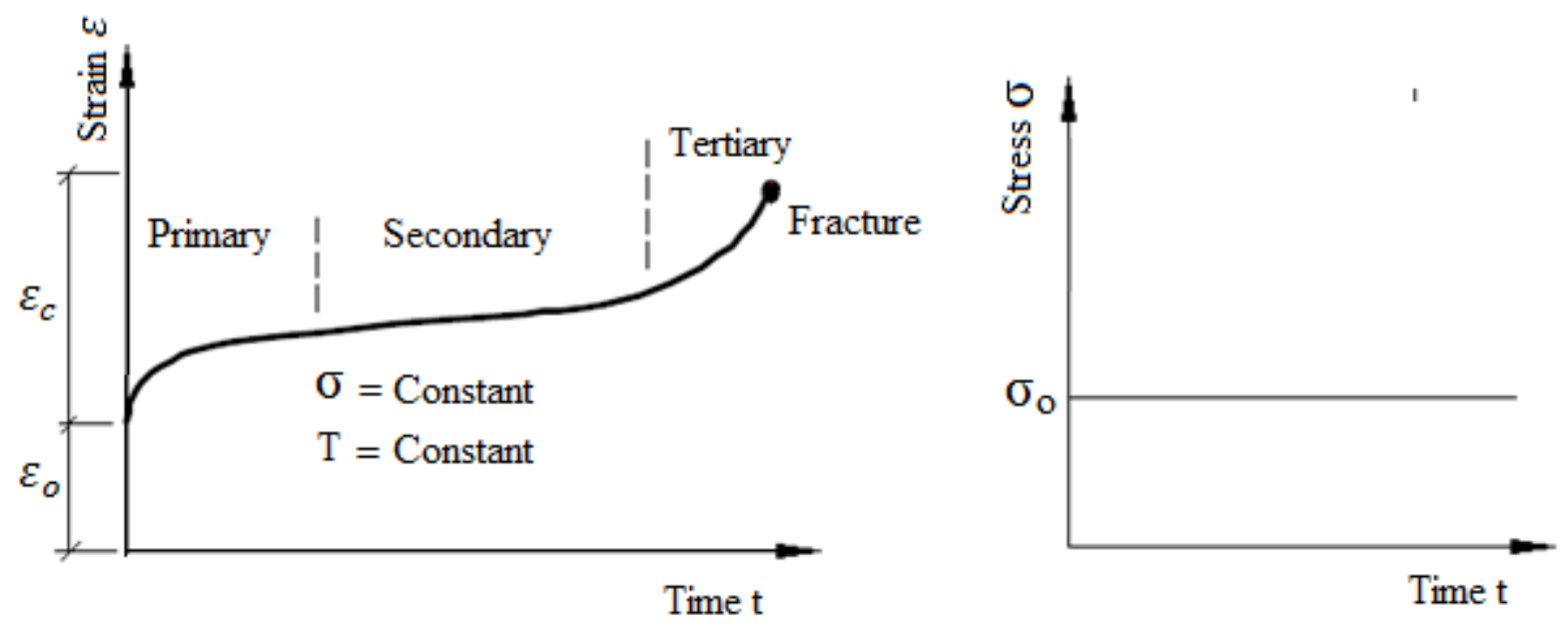

Figure 2.11:Typical creep curve, $\varepsilon_{o}$ is theinstantaneous elastic strain and $\varepsilon_{c}$ is the creep strain. 
- Stress Relaxation

Stress relaxation is a time dependent stress that occurs when the material is subjected to a constant strain.
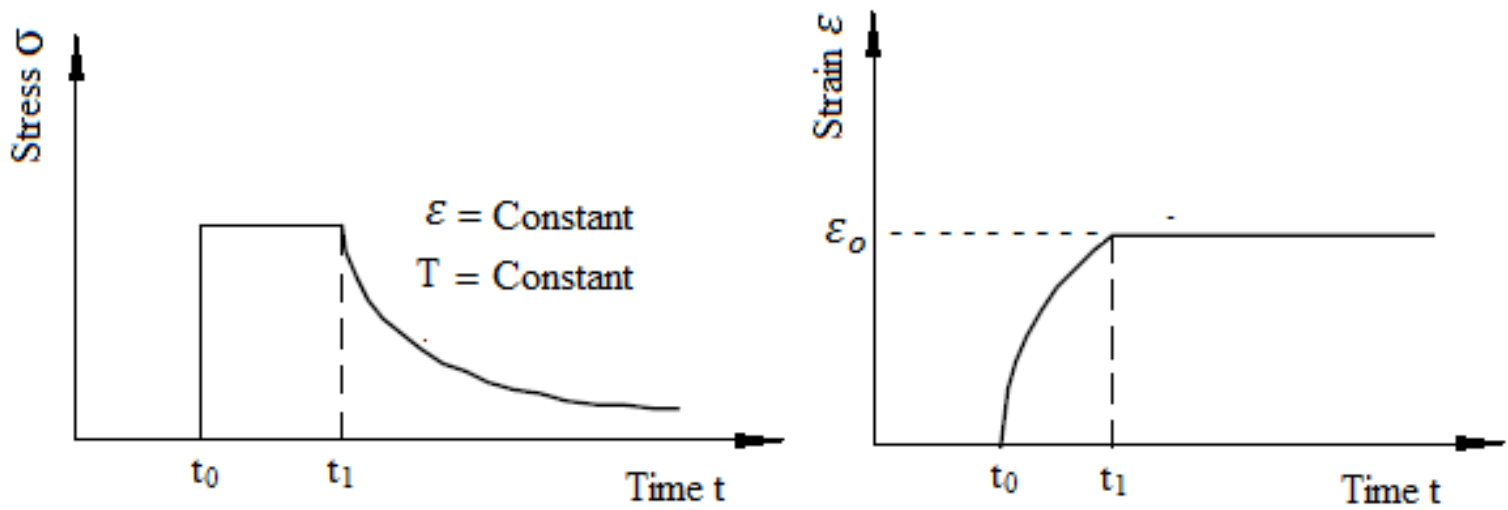

Figure 2.12: Stress relaxation under constant strain $\varepsilon_{0}$.

\section{- Dynamic Loading}

Creep and stress relaxation tests can be used to study the viscoelastic material response for long times, but for shorter times the dynamic test is used. In this test, the strain or (stress) as a result of dynamic stress or (strain) is monitored.

\subsubsection{Linear and Nonlinear Viscoelasticity}

For linear viscoelastic behavior, the creep compliance is constant at specific time and stress independent. The nonlinear behavior occurs at relatively high stresses Figure 2.13. 


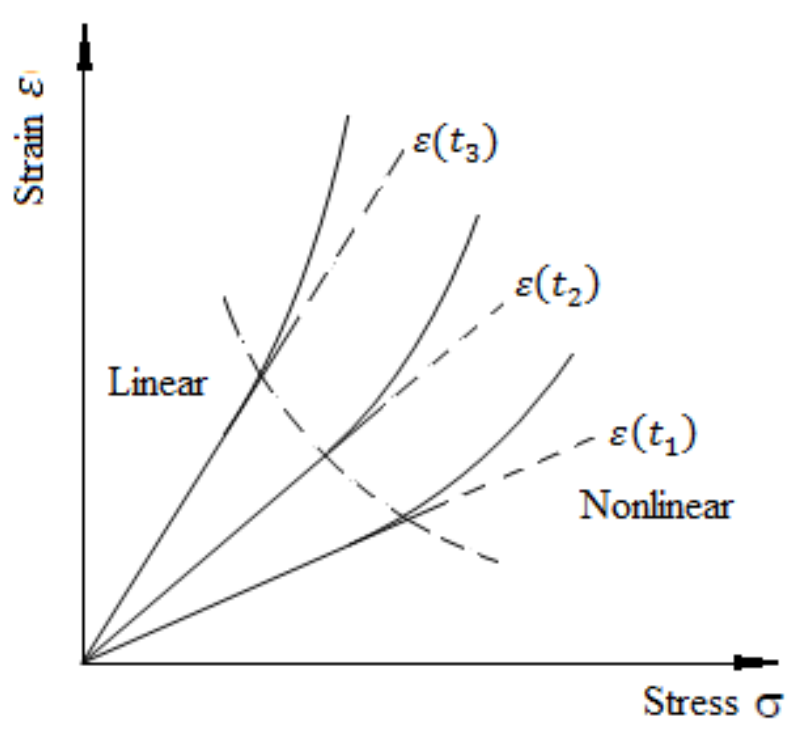

Figure 2.13: Linear and nonlinear viscoelastic behavior at different times $\left(t_{1}, t_{2}, t_{3}\right)$.

\subsubsection{Analytical Modeling of Viscoelastic Behavior}

Many viscoelastic material models were developed to fit experimental creep or stress relaxation data.In creep testing, a constant stress is applied and strain against time is measured $D(t)=\frac{\varepsilon(t)}{\sigma_{o}}$. In relaxation test, a constant strain is applied and stress against time is measured $E(t)=\frac{\sigma(t)}{\varepsilon_{o}}$.

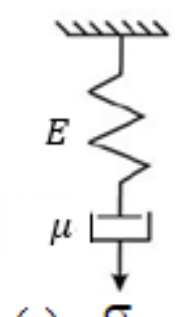

(a)

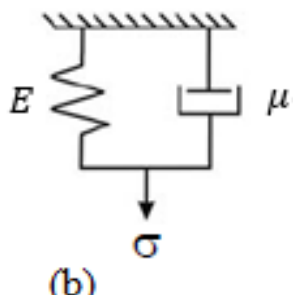

(b)

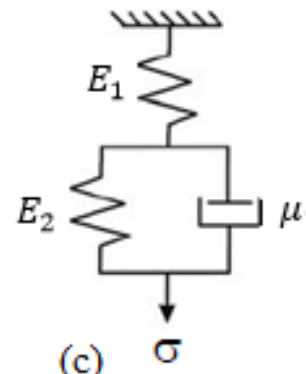

(c)

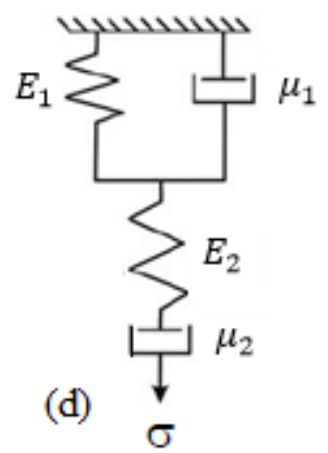

Figure 2.14: Viscoelastic models: (a) Maxwell, (b) Kelvin, (c) standard solid, and (d) MaxwellKelvin.

Viscoelastic materials have been modeled by a mixture of Maxwell and Kelvin models. These models consist of different spring and dashpot combinations. 


\subsubsection{Linear Viscoelastic Models}

- Maxwell model

It adequately describes relaxation but not creep response.

- Kelvin model.

- It does not describe well all features of creep and relaxation:

- Initial elastic response in creep is missing.

- Relaxation modulus should not be constant.

- Standard solid model.

Complete relaxation occurs in much less time required by real polymers.

- Generalized Maxwell model.

It consists of spring in parallel with $n$ Maxwell elements. The number of Maxwell elements increased to increase the number of relaxation times and broaden the range of relaxation time Figure 2.15(a).

(a)

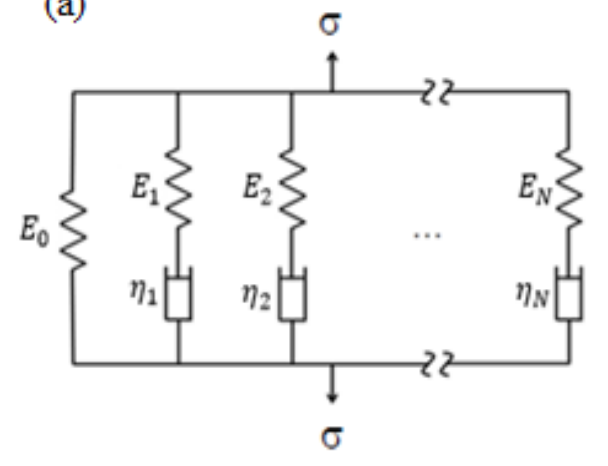

(b)

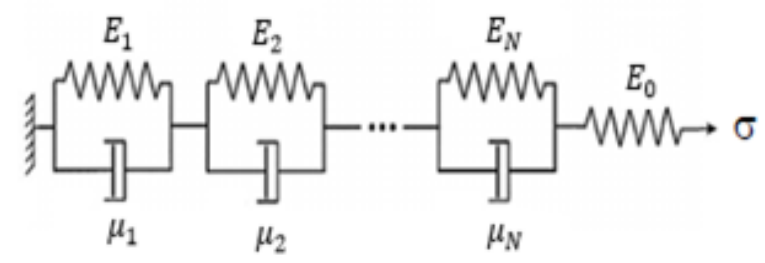

Figure 2.15: Viscoelastic models (a) Generalized Maxwell model; (b) Generalized Voigt (Kelvin) model.

Relaxation modulus for this model given by,

$C(t)=E_{o}\left[1-\sum_{i=1}^{N} c_{i}\left(1-e^{-\frac{t}{\tau_{i}}}\right)\right]$ 
Where,

$E_{0}$ Elastic modulus at $\mathrm{t}=0$.

$N$ Number of Maxwell elements.

$t$ Stress relaxation time.

$c_{i}, \tau_{i}$ Material constants.

- Generalized Voigt (Kelvin) model

It consists of spring in series with $n$ Voigt (Kelvin) elements. The number of Voigt (Kelvin) elements increased to increase the number of retardation times and broaden the range of creep time Figure 2.15(b).

Creep compliance for this model given by,

$D(t)=\frac{1}{E_{o}}\left[1+\sum_{i=1}^{N} D_{i}\left(1-e^{-\frac{t}{\lambda_{i}}}\right)\right]$

Where,

$E_{0}$ Elastic modulus att $=0$

$N$ Number of Voigt (Kelvin) elements.

$t$ Creep compliance time.

$D_{i}, \lambda_{i}$ Material constants.

- Power law (Findley and Khosla) [68].

Good for modeling short-term deformation of polymers.

$E(t)=A t^{-n}(2.15)$

Where $\mathrm{A}$ and $\mathrm{n}$ dimensionless material parameters. 


\subsubsection{Non-linear Viscoelastic Models}

All the previous models are for linear viscoelastic materials which mean that the parameters of the model are not function of stress.

- Nonlinear power law (HRZ) model

$\varepsilon(t)=\mathrm{a} \sigma^{b} t^{c \exp (\mathbf{e} \sigma)}$

Where $a, b, c, e$ nonlinear power law parameters, $\sigma$ creep stress.

This model was developed to simulate creep of injection molded thermoplastic composites [69].

- Schapery's nonlinear model

$\varepsilon_{\text {creep }}(t)=\sigma_{o}\left\{D_{o} g_{o}+g_{1} g_{2} \sum_{i=1}^{N} D_{i}\left(1-e^{-\left(\frac{t}{a_{\sigma}}\right) \lambda_{i}}\right)\right\}$

Where $\boldsymbol{g}_{\boldsymbol{o}}, \boldsymbol{g}_{\mathbf{1}}, \boldsymbol{g}_{2}, \boldsymbol{a}_{\sigma}$ are nonlinear parameters, $\boldsymbol{\sigma}_{\boldsymbol{o}}$ stress, $\boldsymbol{D}_{\boldsymbol{o}}$ instantaneous compliance, $\boldsymbol{D}_{\boldsymbol{i}}$ and $\boldsymbol{\lambda}_{\boldsymbol{i}}$ are prony series coefficents and retardation times respectively. [70-71]

\subsubsection{Superposition Principles}

\section{- Boltzmann Superposition Principle}

This principle can be used to describe the stress strain relationship in linear viscoelastic materials. It states that the response of a material to a given load is independent of the response of the material to any load which is already on the material. For linear viscoelastic material, the deformation at any specific time $\mathrm{t}$ is directly proportional to the applied stress Figure 2.16. 

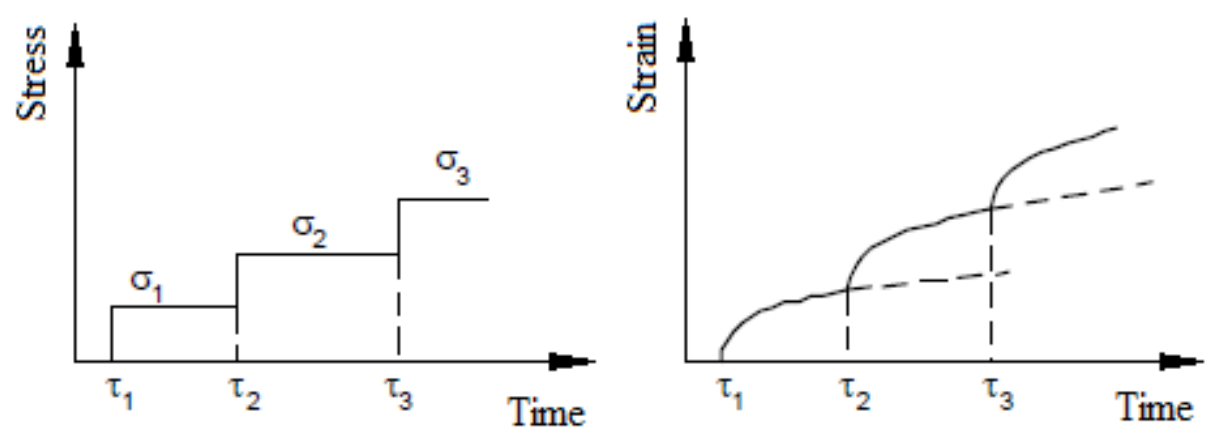

Figure 2.16: Boltzmann superposition principle.

\section{Creep}

$\varepsilon(\mathrm{t})=\Delta \sigma_{1} \mathrm{D}\left(\mathrm{t}-\tau_{1}\right)+\Delta \sigma_{2} \mathrm{D}\left(\mathrm{t}-\tau_{2}\right)+\Delta \sigma_{3} \mathrm{D}\left(\mathrm{t}-\tau_{3}\right)$

where $\mathrm{D}(\mathrm{t})$ is the creep compliance.

The above equation can be written in this form:

$\varepsilon(\mathrm{t})=\int_{-\infty}^{t} D(t-\tau) \frac{d \sigma(\tau)}{d \tau} d \tau$

\section{Stress relaxation}

$\sigma(\mathrm{t})=\Delta \varepsilon_{1} \mathrm{C}\left(\mathrm{t}-\tau_{1}\right)+\Delta \varepsilon_{2} \mathrm{C}\left(\mathrm{t}-\tau_{2}\right)+\Delta \varepsilon_{3} \mathrm{C}\left(\mathrm{t}-\tau_{3}\right)$

where $\mathrm{C}(\mathrm{t})$ is the relaxation modulus.

The above equation can be written in this form:

$\sigma(\mathrm{t})=\int_{-\infty}^{t} C(t-\tau) \frac{d \varepsilon(\tau)}{d \tau} d \tau$

Where $\mathrm{C}(\mathrm{t})$ is the stress relaxation modulus.

For linear viscoelastic materials, both creep compliance $\mathrm{D}(\mathrm{t})$ and stress relaxation modulus $\mathrm{C}(\mathrm{t})$ are stress independent and are constant for all stresses (or strains) at particular creep or stress relaxation time. 


\section{- Time Temperature Superposition Principle (TTSP)}

The instantaneous elastic modulus of viscoelastic material under constant load (creep) is function in time and temperature. Elastic modulus decreases with time and the increase in temperature accelerates this process. TTSP principle is used with linear viscoelastic materials to describe this relation. According to TTSP principle the viscoelastic behavior at any temperature could be related to that at other temperature by shifting the experimental data along the time scale [72]. Short-term creep or stress relaxation accelerating tests are performed at elevated temperatures and the resulted curves can be shifted to the selected reference temperature to construct "master curve" and shift factors. The generated master curve represents the expected long-term creep or stress relaxation of the viscoelastic material at the reference temperature.

\section{- Mathematical Formulation}

$E\left(T_{1}, t\right)=E\left(T_{2}, \frac{t}{a_{T}}\right) b_{T}$

Where $a_{T}$ and $b_{T}$ are horizontal and vertical shift factors. The temperature change has the same effect of shifting the $\log -\log \left(\mathrm{G}\right.$ versus time) curve a displacement of $\log a_{T}$ along the time scale. The horizontal shift factor $a_{T}$ could be determined from experimental creep or stress relaxation curves Figure 2.17. The vertical shift factor $b_{T}$ is a correction factor that accounts for the elastic modulus change due to change in temperature and could be neglected due to its small effect compared to $a_{T}$. 
(a)

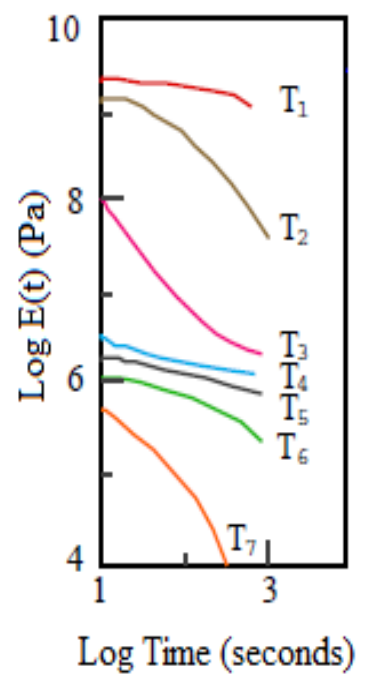

(b)

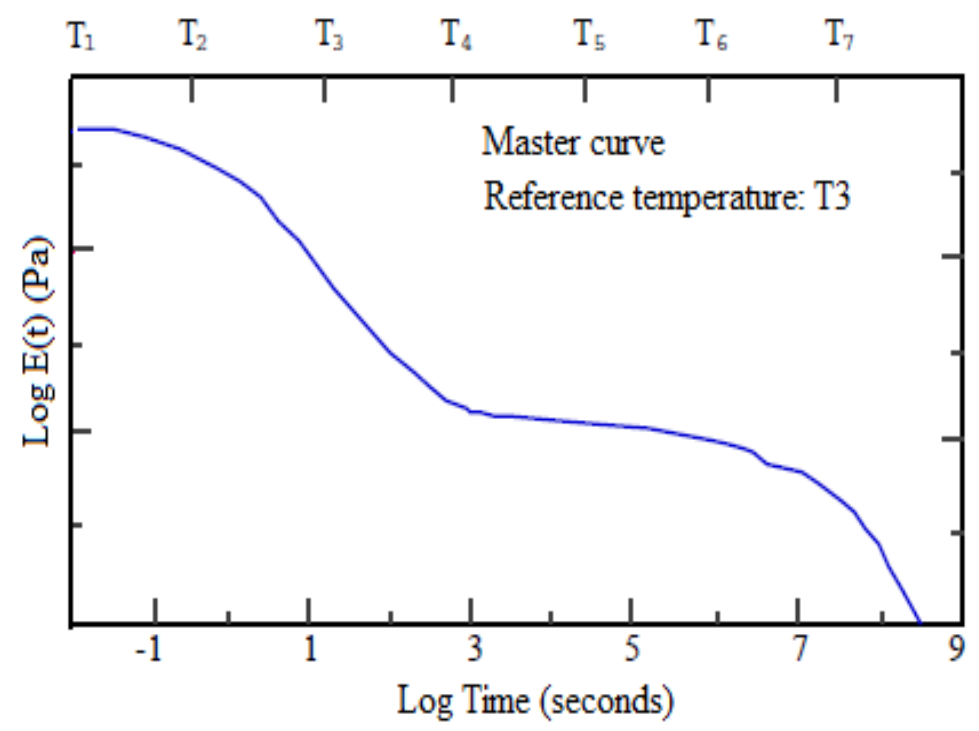

Figure 2.17: Construction of master curve (a) Experimental modulus curves at various temperatures, (b) Master curve.[73]

\section{- Shift Equations}

- Williams, Landel and Ferry equation (WLF) [74]

$$
\log a_{T}=\frac{-C_{1}\left(T-T_{r e f}\right)}{C_{2}+\left(T-T_{r e f}\right)}
$$

Where, $T_{\text {ref }}$ is the reference temperature, $C_{1}, C_{2}$ constants, for many polymers and for $T_{\text {ref }}=$ $T_{g}$ (glass transition temperature), $C_{1}=17.4$ and $C_{2}=51.6, T$ is the measurement temperature and $a_{T}$ is the horizontal shift factor.

\section{- Arrhenius relation}

$\log a_{T}=\frac{E}{R\left(T-T_{r e f}\right)}$

Where $E$ is activation energy, $R$ is the gas constant $\left(R=8.314 \mathrm{~J} / \mathrm{mole}^{O}\right), T_{\text {ref }}$ is the reference temperature, $T$ is the measurement temperature and $a_{T}$ is the horizontal shift factor. 
The shift factors determined can be fitted to mathematical model to permit shifting of the master curve to any temperature. This means that experimental data used to construct master curve at high $T_{r e f}$ can be easily shifted to low temperature and vice versa.

\subsection{Thesis objectives and contribution}

Adhesively bonded structures under load exhibit time dependent behavior as a result of continuous decrease with time of the adhesive stiffness. This leads to redistribution of stresses and strains within the structure resulting parts of the structure to exceed the allowed deformation limit or even premature failure of the structure. Some structures are designed to serve for decades of years which raise the need for predicting the long-term time dependent behavior of the structure. Accelerated three-point bending creep tests on two types of adhesively bonded beam specimens: specimens prepared by adhesively bonding two aluminum beams and specimens prepared by adhesively bonding two unidirectional carbon fiber laminated beams were performed at higher temperatures up to $60{ }^{\circ} \mathrm{C}$ and deflection was measured as a function of time for both types of specimens. Time temperature superposition principle TTSP based on time temperature equivalency was implemented to shift all creep curves into one master curve at reference temperature $T_{\text {ref. }}$ The resulted master curve covers much longer time span of the creep behavior of the structure. Prony series was used to model the master curve by non-linear least square fitting then finite element analyses were performed and ABAQUS software was used to validate the analytical and experimental results. In literature, most of the time dependent studies performed on adhesively bonded structures were done on lap joints where the specimen is subjected to axial load along the span. In this study, a different approach was followed where the adhesively bonded joints were subjected to flexural creep loading. The reason is that this kind of loading is quite common in structures and tends to appear in almost every structure under load 
even if the structure is not subjected to direct flexural load. In addition, current flexural creep work complements the scholarly work related to lap shear type creep response of adhesively bonded structures and offers a new dimension.

\subsubsection{Lap shear versus flexural time dependent behavior}

Lap shear time dependent tests are used to study the time dependent properties of adhesives and the response of the bonded joint as a whole to long-term loading. In this kind of testing the axial load is applied and the response of the lap joint is monitored against time. Even though the lap joint is subjected to one type of loading, the stresses developed in the adhesive bond line are a combination of shear, peel and normal stresses. In addition, these stresses are not uniform along the bond line. For all these reasons, the analytical solutions proposed are generally complicated and need to be solved numerically. Flexural time dependent test is much easier to perform and requires simple test set up. For low adhesive to adherend thickness, the adhesive is assumed under shear stress only which makes the analysis less complicated. Also, flexural loading is quite common in structures under load and it is better to study the time dependent behavior of adhesively bonded joints under flexural loading by direct application of flexural load on the structure. 


\section{CHAPTER 3 THEORETICAL AND ANALYTICAL CONSIDERATIONS}

\subsection{Introduction}

There are three distinct creep stages: primary, secondary, and tertiary creep Figure 3.1. Primary stage is characterized by steady creep rate decrease. During secondary stage, the creep rate is almost constant and this stage covers most of the creep time frame. Tertiary stage shows rapid increase in creep rate and covers a shorter period of time. This study covers the primary and secondary stages of adhesively bonded structure flexural creep.

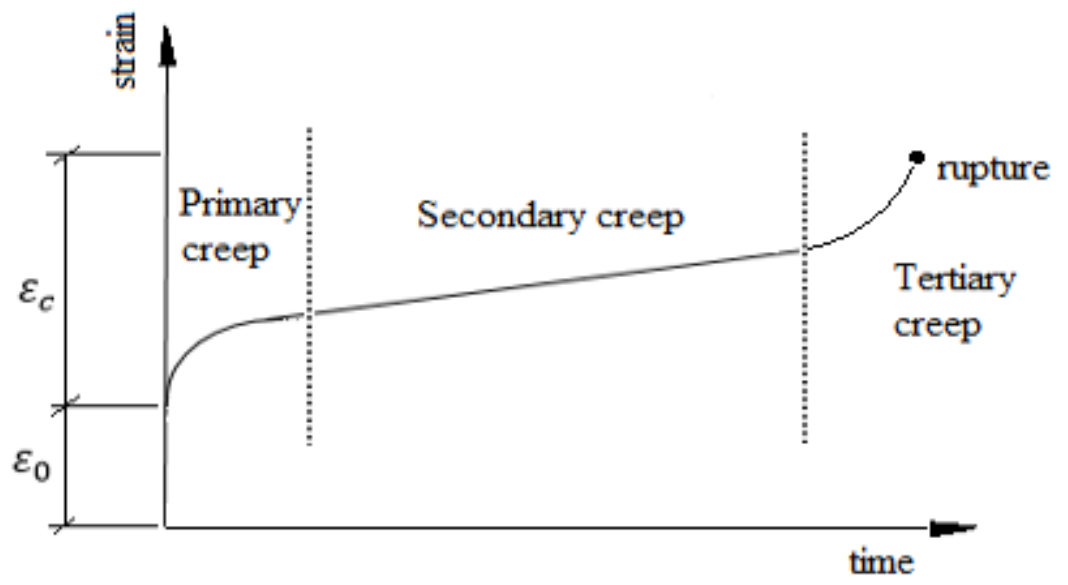

Figure 3.1: Typical creep curve $\varepsilon_{o}$ is theinstantaneous elastic strain and $\varepsilon_{c}$ is the creep strain.

The flexural creep stiffness $S(t)$ of the adhesively bonded beam under dead weight is represented in terms of $(w / \delta)$ where $w$ is the applied dead weight at mid-span and $\delta$ is the resulting mid-span deflection of the adhesively bonded beam Figure 3.2. For linear viscoelastic behavior, the ratio $(w / \delta)$ at any creep time $\left(t_{1}, t_{2}, t_{3}, \ldots\right)$ is constant and load independent Figure 3.3. 

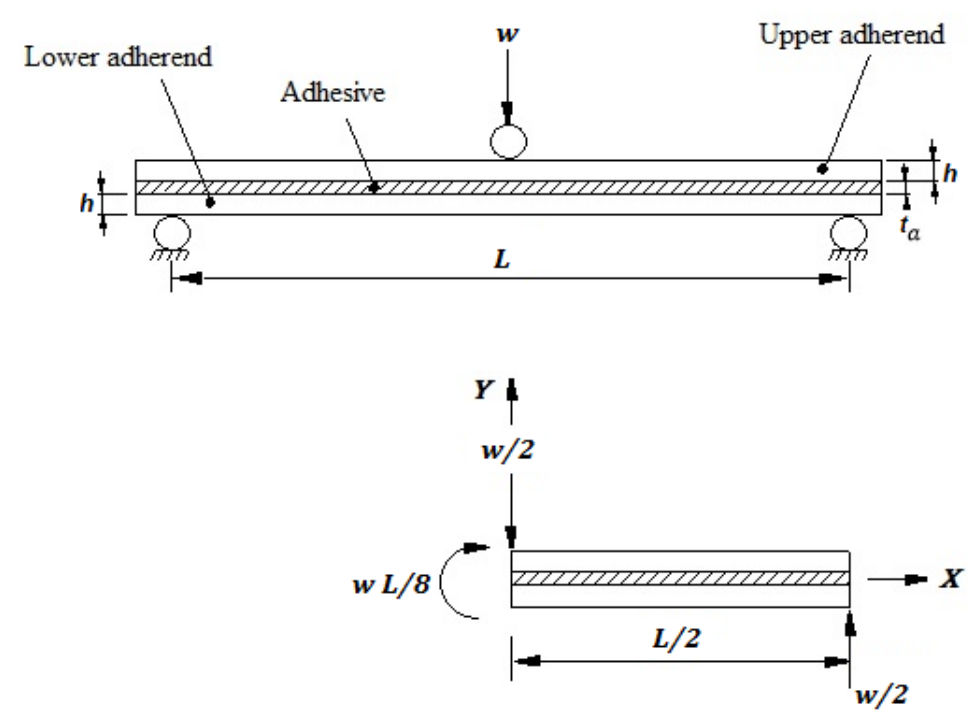

Figure 3.2: Three point bending of adhesively bonded beam.

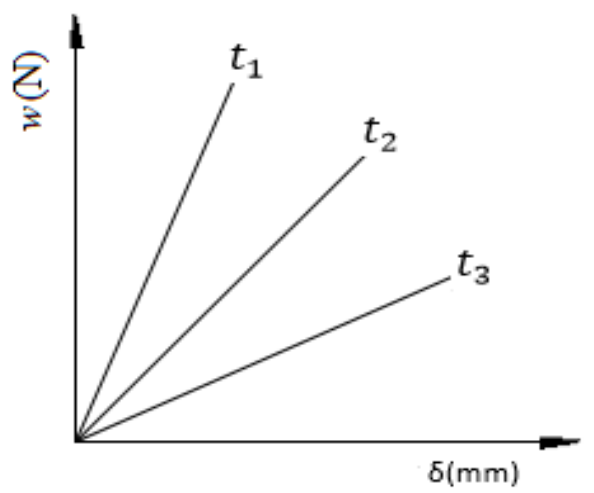

Figure 3.3: Linear viscoelastic adhesives creep behavior.

Moussiaux et al. [75] in their solution for the deflection of the adhesively bonded beam under three-point bending assumed that the adhesive is under pure shear for low adhesive to adherend thickness ratio $\left(t_{a} / h<0.4\right)$ and the Euler-Bernoulli beam theory could be applied for $(L / h>$ 20).

\subsection{Mathematical Formulation}

When the mid span dead weight is applied, the adhesively bonded beam will deflect and as a result there will be a relative movement between the upper and lower adherends. The adhesive 
will resist this relative movement and as a result will be subjected to shear stress. The amount of adhesively bonded beam deflection depends on the stiffness of both the upper and lower adherends and the shear modulus of the adhesive which is assumed under pure shear stress as the adhesive thickness is very small compared to the adherends and the location of the adhesive bond line along the neutral axis of the adhesively bonded beam where the bending stress is very small. Moussiaux et al. [75] proposed a solution of the adhesively bonded beam where a cantilever beam under end load w/2 was analogized to three-point bending beam under mid-span load (w) Figure 3.4. The analysis included shear stress distribution along the adhesive bond line and the deflection of the adhesively bonded beam. The basic idea of their approach is to cut the adhesive bond line along the beam mid-plane to free the adhesive shear stress Figure 3.5. To preserve the continuity of the adhesive, the total relative displacements of the adhesive in both cut sides that resulted from both external and internal loads should equal to zero. These relative displacements are: adhesive displacement as a result of adherend bending, displacement as a result of shear deformation of the adhesive and displacement as a result of normal deformation of the adherend. The resulted continuity equation was used with Euler-Bernoulli deflection equation for the adherend to form a differential equation where the adhesive shear stress is the only unknown. This equation was then solved using the proper boundary conditions equation (3.3). The shear stress is assumed constant through the thickness of the adhesive layer. Three assumptions were made in this analysis:

- The adhesive is under pure shear stress (adhesive thickness to adherend thickness is very low).

- Euler-Bernoulli beam deflection applicable for adherends.

- Elastic behavior of both adhesive and adherends. 
It is important to note that the adhesives in their bulk form have properties that differ from their properties when used as a thin film in actual bonding joint.

The mid-span deflection equation was derived by integrating modified Euler-Bernoulli beam deflection equation where another term was added to account for the moment generated on the adherends as a result of adhesive shear stress. In this equation, the effect of the adhesive on beam deflection is seen through the parameter $\beta$ which includes the adhesive shear modulus $G_{a}$. For viscoelastic adhesive, the mid-span creep deflection is given by:

$\delta(\mathrm{t})=\frac{w L^{3}}{32 E_{f} b\left(h+\frac{t_{\mathrm{a}}}{2}\right)^{3}} \beta(\mathrm{t})$

Where,

$\beta(t)=\left(1+\frac{t_{a}}{2 h}\right)^{3}\left[4\left(1-\frac{1}{\gamma^{2}}\right)+\frac{6 E_{1}}{G}\left(\frac{h}{L}\right)^{2}+\frac{12}{\gamma^{2}}\left(\frac{1}{\bar{\alpha}^{2}}-\frac{\tanh \bar{\alpha}^{2}}{\bar{\alpha}^{3}}\right)\right]$

$\gamma^{2}=1+\frac{1}{3\left(1+t_{a} / h\right)^{2}}$

$\alpha(t)^{2}=\frac{3 G_{a}(t)}{4 E_{1}}(L / h)^{2} \frac{\left(1+t_{a} / h\right)^{2}}{\left(t_{a} / 2 h\right)}$

$\bar{\alpha}(t)=\alpha(t) \gamma$

$E_{f}$ adherend flexural modulus, $E_{1}$ adherend tensile modulus, $G$ dherend shear modulus, $G_{a}$ is the adhesive shear modulus and $h, t_{a}, L$ are the geometrical parameters of the specimen Figure 3.2 and $b$ is the beam width. 


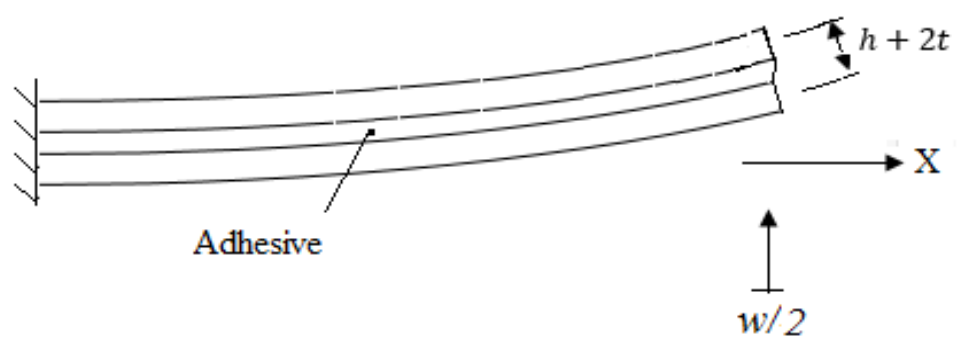

Figure 3.4: Three-point bending-cantilever beam analogy.

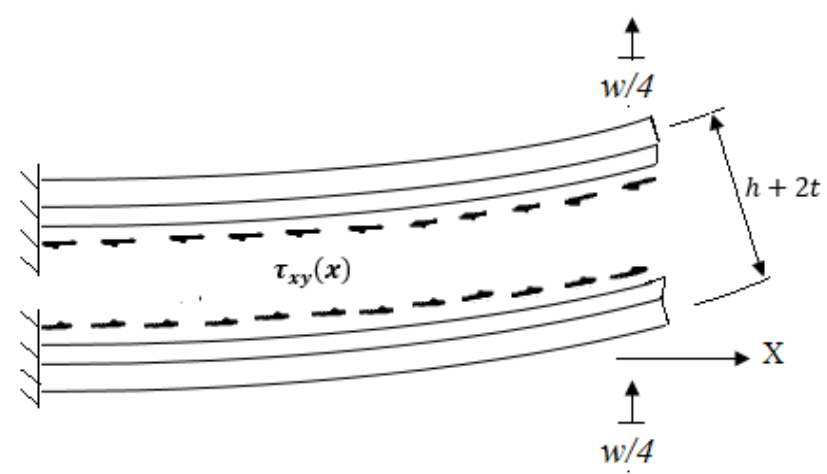

Figure 3.5: Cantilever beam cut along the mid-plane of the adhesive layer.

In equation (3.1) the constant term $w L^{3} / 32 E_{f} b\left(h+t_{\mathrm{a}} / 2\right)^{3}$ accounts for the mid-span deflection with perfect adhesion (monolithic beam) and the adhesion factor $\beta$ accounts for the effect of adhesive- adherends interaction on the adhesively bonded beam deflection. The adhesion factor $\beta$ consists of three terms: the first term is constant and related to the adherends bending and depends only on geometry. The second term is adherends shear deflection term which is also constant and related to the adherends and geometry. This term is very small compare to other deflection terms except for very short beams and high $E / G$ ratio like composite adherends. The third term which is the most important one depends on the adhesive shear modulus, $G_{a}$. The value of this term increases with time due to the decrease in adhesive shear modulus in case of viscoelastic adhesives.

Equation (3.1) can be written in the form: 
$\beta(t)=\frac{32 E_{f} b\left(h+\frac{t_{a}}{2}\right)^{3}}{L^{3} S(t)}$

Where $S(\mathrm{t})$ is the bonded beam stiffness and equal to $w / \delta(t)$.

The adhesive shear stress distribution along mid-span of the adhesive is given by:

$\tau_{x y}(t)=\frac{w}{2 b \gamma^{2}\left(h+t_{a}\right)}(1-\cosh \bar{\alpha} \zeta+\tanh \bar{\alpha} \cdot \sinh \bar{\alpha} \zeta)$

Where $\zeta=x /(L / 2)$.

In this study, the bonded beam stiffness $S(\mathrm{t})$ was recorded every time interval of the experimental creep test, then these experimental values were used with equation (3.2) to evaluate the adhesion factor $\beta(t)$ in that specific step of creep time. The next step is to use these adhesion factor values $\beta(t)$ with the expressionsfor $\beta(t)$ in equation (3.1) and numerically solving for adhesive shear modulus at every time interval of the creep test. 


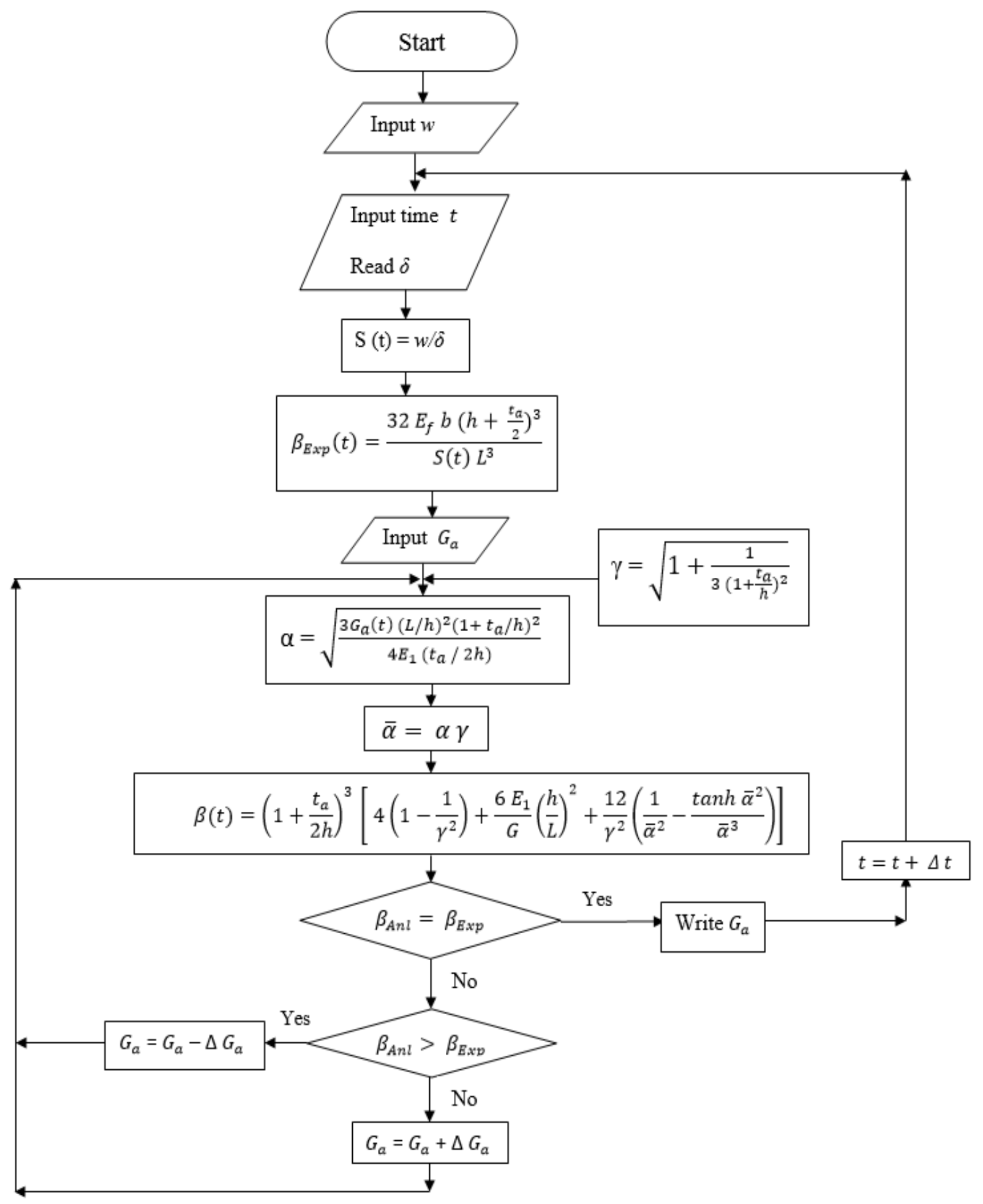

Figure 3.6: Analysis flow chart. 


\subsection{Sensitivity of Adhesively Bonded Beam to Adhesive Shear Modulus}

The graph in Figure 3.7 shows the sensitivity of the adhesively bonded beam to the change in the adhesive shear modulus $G_{a}$ and can be divided into three zones: The first zone (zone1) is a high deformability adhesive zone where the bonded beam behaves like two separate beams each loaded by mid-span force of $w / 2$ and $(\beta \approx 4.0)$.

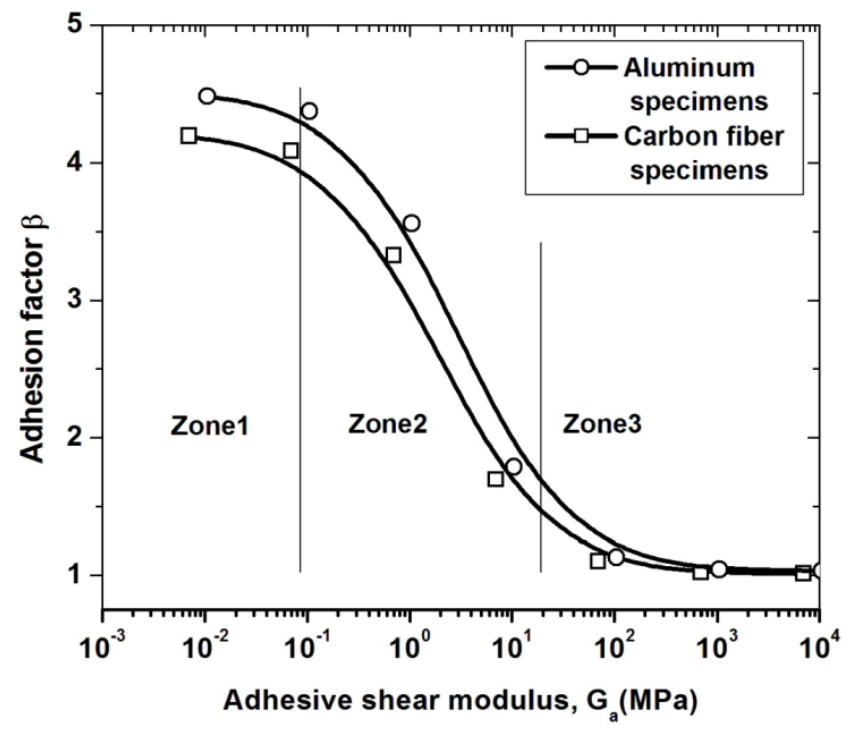

Figure 3.7: Adhesion factor $\beta$ versus adhesive shear modulus $G_{a}(M P a)$.

The third zone (zone3) is the perfect adhesion zone in which the bonded beam behaves as an isotropic beam and $(\beta \approx 1.0)$. Zone1 and zone 3 are connected by zone 2 which is high sensitivity zone. In this zone, the bonded beam is very sensitive to adhesive shear modulus. The sensitivity of the beam to the adhesive shear modulus depends on the beam geometry $\left(t_{a} / h\right.$ and $\left.L / h\right)$ and can be increased by increasing the thickness of the adhesive or decreasing the beam length. In both cases the requirements for the assumptions of pure adhesive shear and long beam (EulerBernoulli beam theory) should not be violated. 


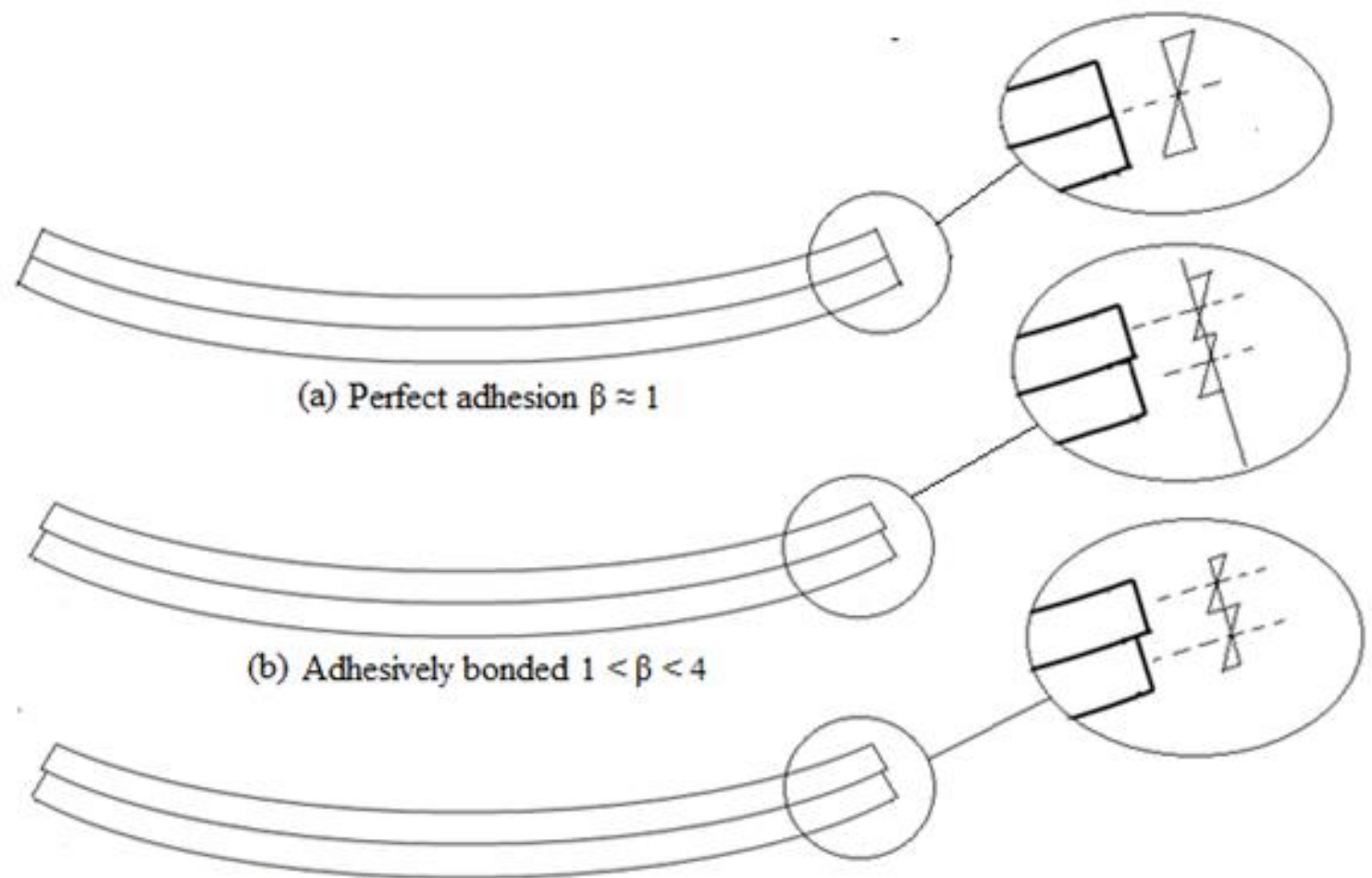

(c) No adhesion $\beta \approx 4$

Figure 3.8: The composite action between adhesive and adherends.

The three-point deflection of adhesively bonded beam Figure 3.8(b) subjected to mid-span load $(w)$ is somewhere between the deflection of monolithic beam Figure 3.8(a) (perfect adhesion $\beta \approx$ 1) and the deflection of one adherend subjected to mid-span load (w/2) Figure 3.8(c) (No adhesion $\beta \approx 4$ ). Cases (a) and (c) are not sensitive to changes in adhesive shear modulus. 


\section{CHAPTER 4 MATERIALS AND SPECIMENS}

\subsection{Material Description}

Two types of specimens were prepared:

- Adhesively bonded aluminum specimens where the upper and lower adherends were prepared from aluminum alloy (6063-T52). Aluminum alloy 6063 is widely used in many structural applications such as products used in architecture and building, electrical components, furniture and aerospace applications. When heat treated it becomes good resistant to corrosion and easily welded or brazed by different methods. Due to its heat treatability, its strength can be reduced in the weld area. Aluminum alloy 6063 selected for this study because of the wide use of aluminum alloys in many aerospace applications.

- Adhesively bonded carbon fiber specimens where the upper and lower adherends were prepared from unidirectional carbon fiber laminate. Carbon fiber has unique technical properties and used in many structural applications due to its high strength to weight ratio. Carbon fiber is excellent fatigue resistant, light in weight, thermally and electrically conductive and has low thermal expansion coefficient.

- The same kind of epoxy adhesive was used with both types of adhesively bonded specimens.

Before applying the adhesive and creep testing, cut adherends were subjected to tensile and

flexural testing to determine their tensile and flexural properties. These properties were presented in Table 4.1 and used later in the analytical and finite element analysis. 


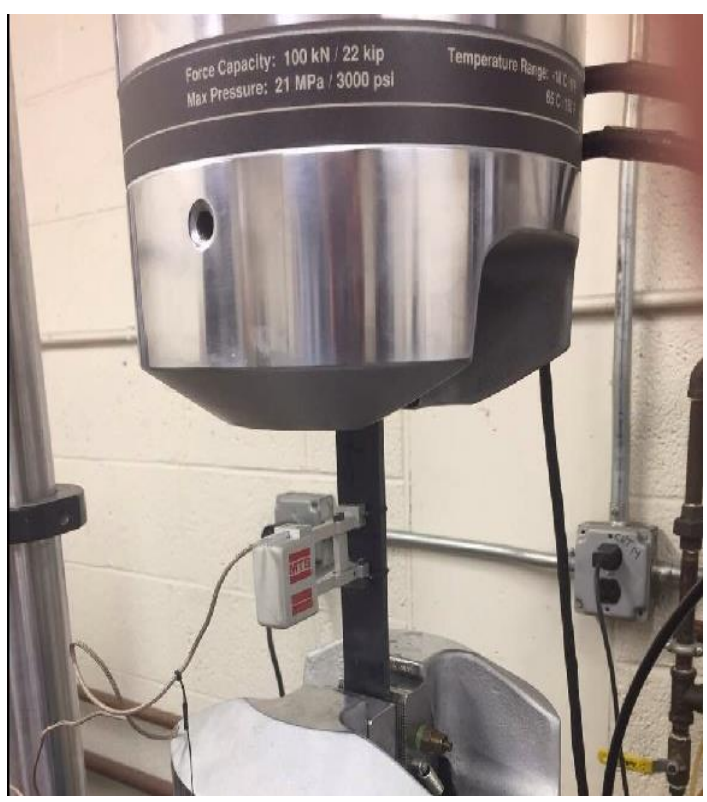

Figure 4.1: Tensile testing machine.

The tensile tests were performed according to ASTM D3039/D3039 M standard test where five strips of unidirectional carbon fiber material, for both $0^{\circ}$ and $90^{\circ}$ orientation and with constant cross section were tested. The experimental data recorded in the form of force and displacement then changed to stress and strain by dividing the force by the specimen cross sectional area and the displacement by the initial specimen length (extensometer initial opening). Tensile modulus is the tangent of the linear initial part of the stress strain curve. 


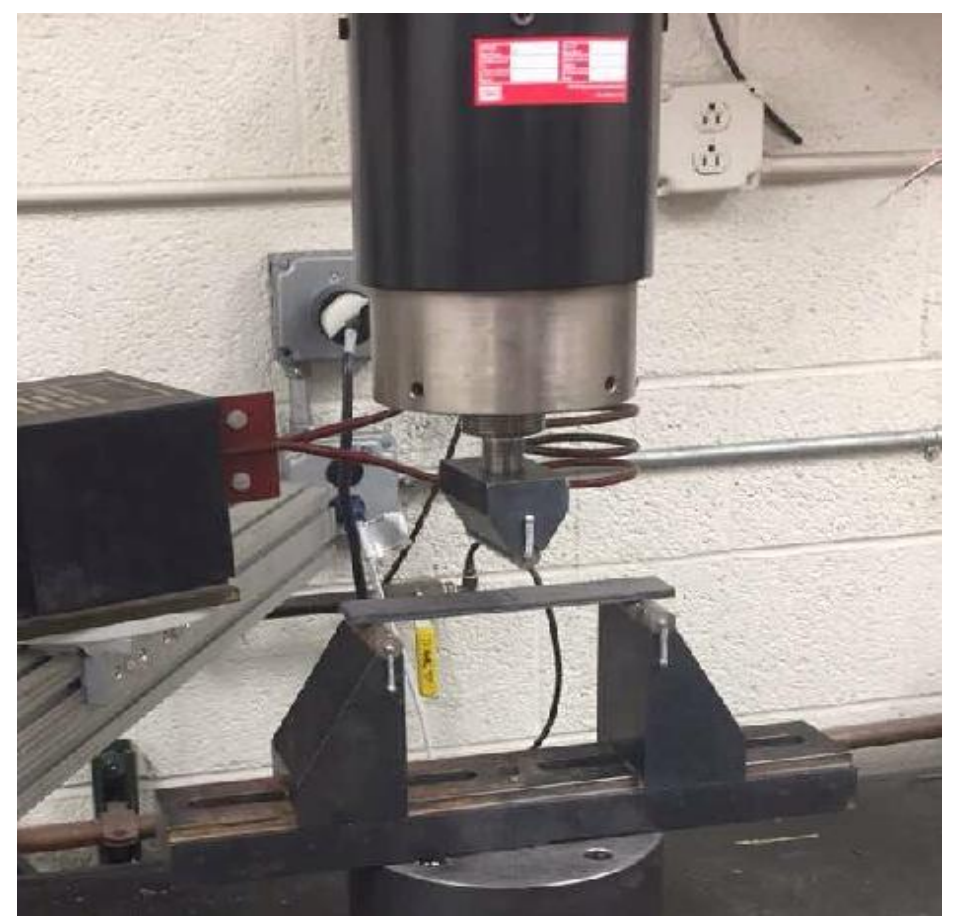

Figure 4.2: Three-point bending testing machine.

The three-point bending tests were performed according to ASTM D790 standard test where five specimens of unidirectional carbon fiber material with $0^{\circ}$ orientation and constant cross section were tested. The modulus of elasticity in bending was calculated by the formula,

$E_{b}=\frac{L^{3} m}{4 b h^{3}}$

Where $m$ is the slope of the linear initial part of the mid-span loaddeflection curve. 
Table 4.1 Tensile, flexural and shear properties of adherends.

\begin{tabular}{|l|c|c|}
\hline Mechanical property & Carbon fiber specimens & Aluminum specimens \\
\hline Tensile modulus, $E_{1}(G P a)$ & 105.0 & 68.9 \\
\hline Tensile modulus, $E_{2}(G P a)$ & 2.9 & 68.9 \\
\hline Flexural modulus, $E_{f}(G P a)$ & 107.0 & 68.9 \\
\hline Shear modulus, $G_{12}=G_{13}(G P a)$ & 6.9 & 25.8 \\
\hline Poisson's ratio, $v$ & 0.30 & 0.33 \\
\hline
\end{tabular}

\subsection{Specimens and dimensions}

Two types of specimens were prepared, five specimens of adhesively bonded aluminum beams and five specimens of adhesively bonded unidirectional carbon fiber laminated beams. Water jet machine was used to precisely cut the carbon fiber specimens from ten ply unidirectional carbon fiber laminate that was prepared in a vacuum press machine.

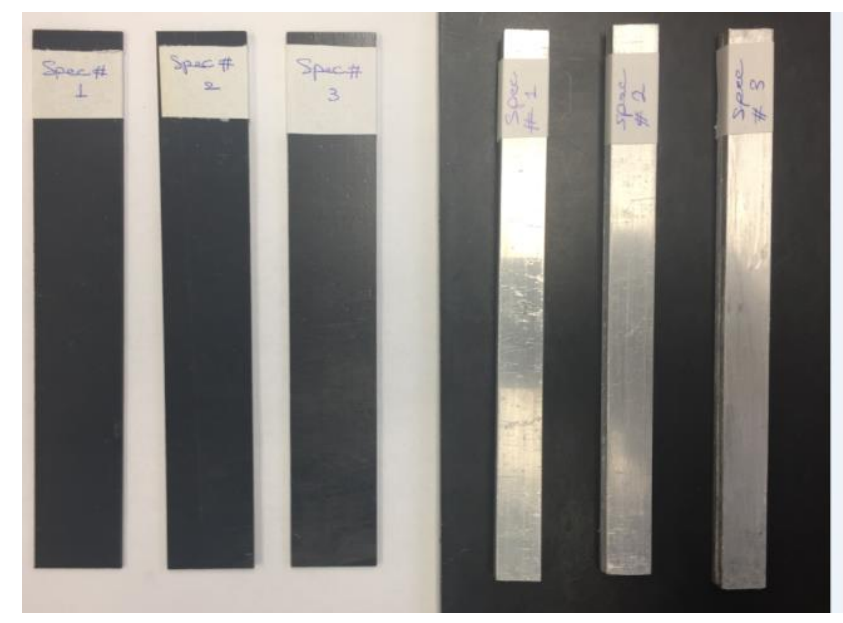

Figure 4.3: Aluminum and carbon fiber specimens. 


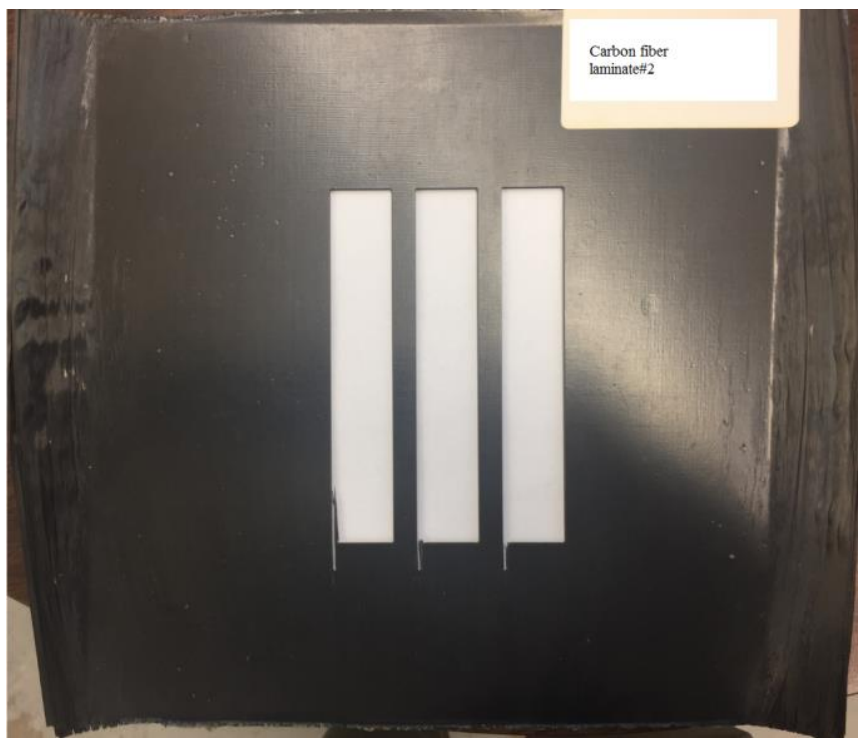

Figure 4.4: Waterjet cut carbon fiber laminate.

The dimensions of the specimens were presented in Table 4.2.

Table 4.2 Specimens dimensions.

\begin{tabular}{|c|c|c|}
\hline & $\begin{array}{c}\text { Aluminum-adhesive- aluminum } \\
\text { Carbon fiber-adhesive- } \\
\text { carbon fiber }\end{array}$ \\
\hline Upper adherend thickness & $3.175 \mathrm{~mm}$ & $1.35 \mathrm{~mm}$ \\
\hline Lower adherend thickness & $3.175 \mathrm{~mm}$ & $1.35 \mathrm{~mm}$ \\
\hline Adhesive thickness & $0.1 \mathrm{~mm}$ & $0.1 \mathrm{~mm}$ \\
\hline Bonded specimen thickness & $6.45 \mathrm{~mm}$ & $2.8 \mathrm{~mm}$ \\
\hline Length & $152.4 \mathrm{~mm}$ & $152.4 \mathrm{~mm}$ \\
\hline Width & $12.7 \mathrm{~mm}$ & $25.4 \mathrm{~mm}$ \\
\hline
\end{tabular}




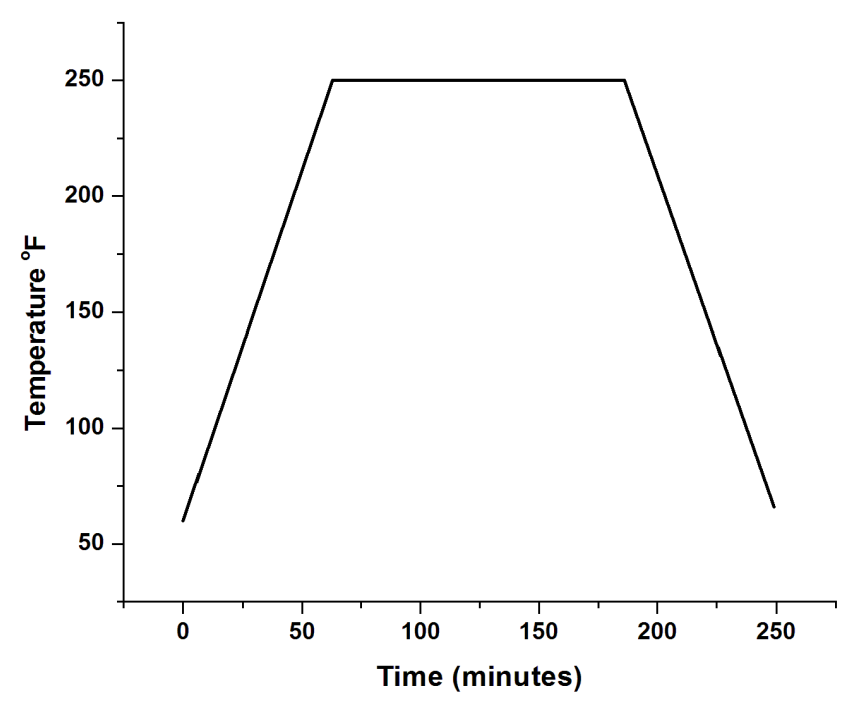

Figure 4.5: Curing cycle of the carbon fiber laminate.

In both aluminum and carbon fiber specimens the bonding epoxy adhesive is properly mixed with small amount of glass bubbles filler to ensure constant adhesive thickness $\left(t_{a}=0.1 \mathrm{~mm}\right)$. To have good adhesive to surface bonding strength and before applying the adhesive, the contact surfaces should be clean and dry. Platen pressure of $100 \mathrm{KPa}$ was applied and specimens were left to cure at room temperature for $72 \mathrm{hrs}$. 


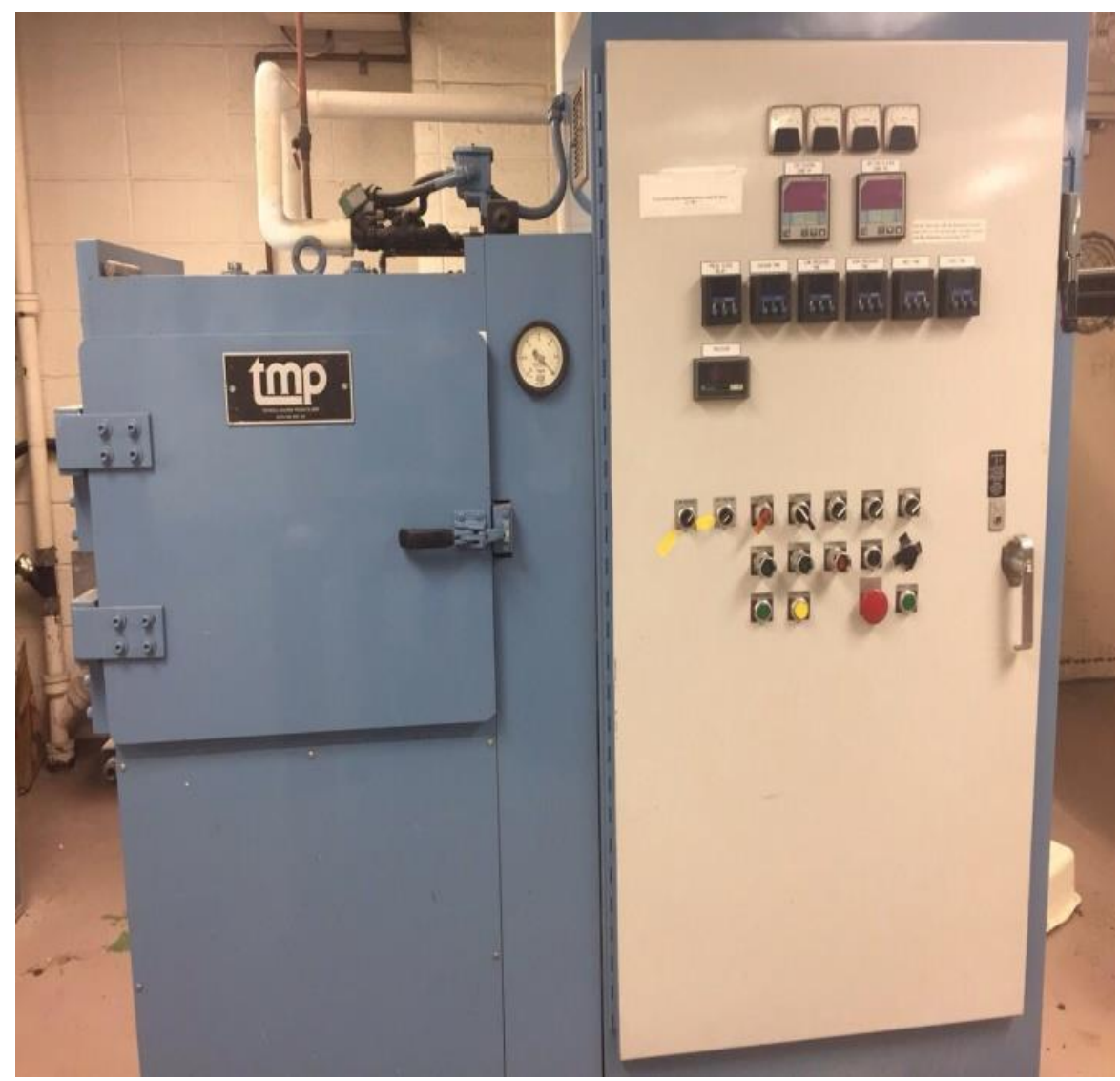

Figure 4.6: Vacuum press machine.

\subsection{Experimental thin adhesive description}

According to literature, the adhesive is considered thin if adhesive thickness to adherend thickness ratio is less than 0.4 . In this study, this ratio is 0.0315 for adhesively bonded aluminum specimens and 0.074 for adhesively bonded carbon fiber specimens. Since the adhesive layer is very thin compare to adherend thickness and the adhesive is located at the neutral plane of the adhesively bonded beam, the bending stresses on adhesive are very small and the dominant factor is the in plane pure shear stress acting on the adhesive. The resulting adhesive shear strain increases with time due to time dependent decrease in bonding adhesive shear stiffness. As a 
result of this, more flexural load is transferred to the adherends causing more time dependent deflection of the adhesively bonded beam.

\subsection{Preparation of adherends surfaces for adhesive bonding}

- Degreasing

To remove contaminants and dirt from the surface of the adherends. Solvent trichloroethylene was used.

\section{- Abrasion}

To remove heavy deposits from the adherend surface, sand paper was used for aluminum adherend and fine emery cloth for carbon fiber adherend. The adherend surface was degrease again to remove any debris or contaminants from the abrasion processes.

- Chemical treatment

To improve the adhesion ability of the adherend surface, the adherends were first immersed for about 10 minutes in a solution of $96 \%$ sulfuric acid (10 parts), dichromate ( 3 parts) and distilled water (20 parts). The adherends then rinsed in tap water at room temperature followed by rinse in distilled water at temperature $\approx 70{ }^{\circ} \mathrm{C}$. At the final step, adherends were left to dry in the oven at about $70{ }^{\circ} \mathrm{C}$ and for about 30 minutes.

\subsection{Experimental setup}

The testing fixture as shown in Figures 4.7 and 4.8 was prepared according to ASTM D-2990 and ASTM D790 standard [76-77]. It consists of stainless steel loading roller of $6.35 \mathrm{~mm}$ diameter and two stainless steel support rollers of $3.175 \mathrm{~mm}$ diameter. 


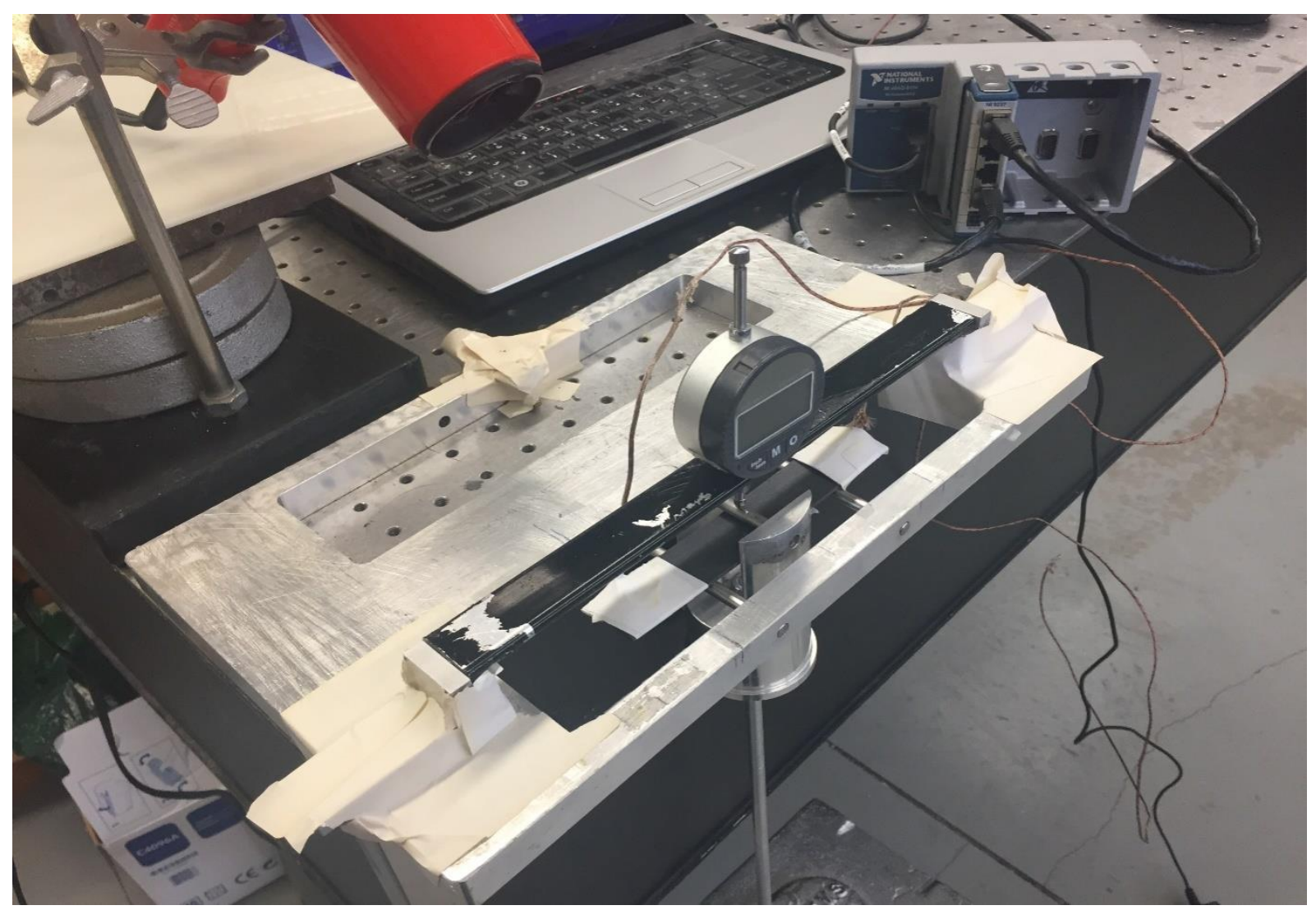

Figure 4.7: Flexural creep test stand.

The loading span, beam thickness and adhesive thickness were selected to ensure that the adhesively bonded beam is within the sensitive range (zone 2, Figure 3.7). The dead weight $w$ was applied at the mid-span of the specimen through the loading assembly of stainless steel rod and flat weight plates in multiples of $5.0 \mathrm{~kg}$. A linear variable displacement transducer LVDT was coaxially fixed in the loading assembly Figure 4.7 to measure the mid-span deflection during the creep test period. 


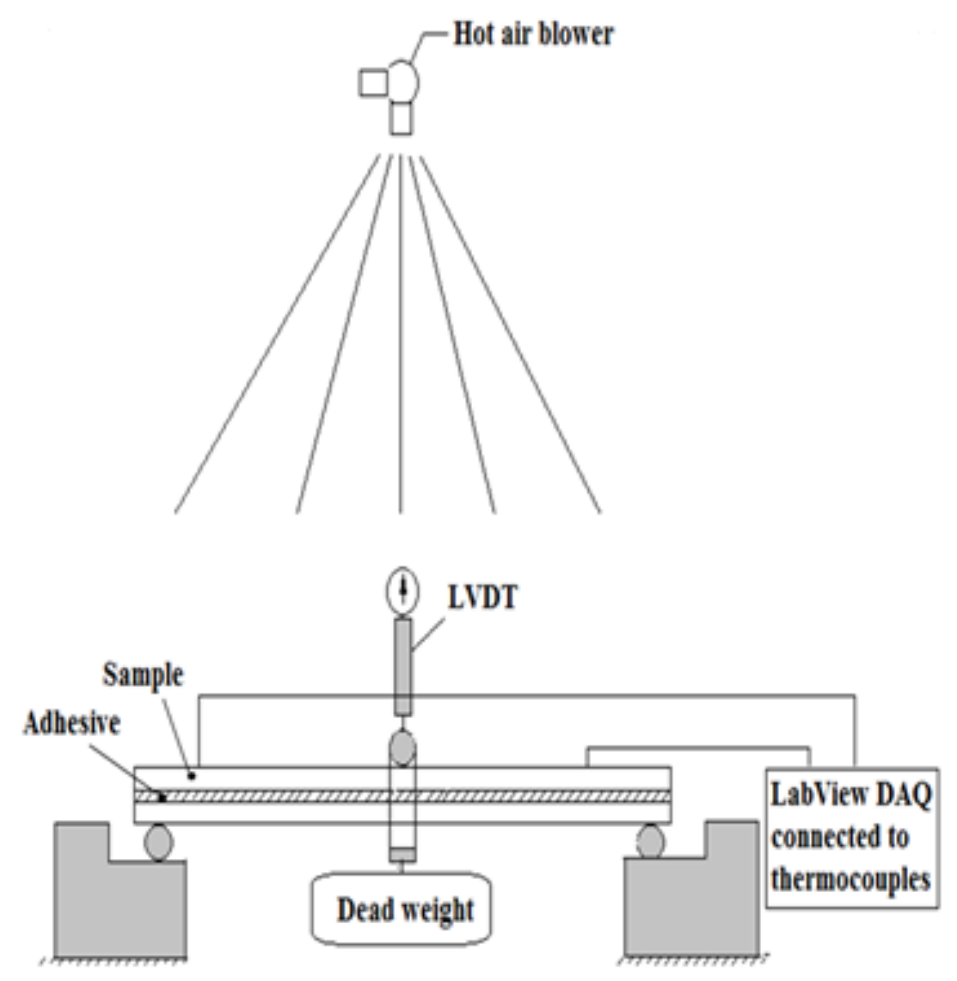

Figure 4.8: Flexural creep testing setup drawing

\subsection{Testing}

The two sets of adhesively bonded beams were tested for flexural creep. The creep tests were performed at different temperatures ranging from $25^{\circ} \mathrm{C}$ to $60^{\circ} \mathrm{C}$. Isothermal flexural creep tests were performed on the specimens within this temperature range and with a stepwise temperature increment of $5^{\circ} \mathrm{C}$. The specimen is heated up by blowing it with a stream of air at constant temperature. Two thermocouples were fixed to the specimen and the temperature is monitored with the use of LabView data acquisition system [78], Figures 4.7and 4.8. Before starting the test, each specimen was equilibrated for 5 minutes then the dead load $w$ was applied at mid-span of the specimen where, $w=250 \mathrm{~N}$ for aluminum specimens and $200 \mathrm{~N}$ for carbon fiber specimens. The beam mid-span deflection was registered against creep time for 60 minutes with every 2.0 minutes interval of time at the primary stage and every 5.0 minutes at the secondary creep stage. 


\section{CHAPTER 5 RESULTS AND DISCUSSION}

\subsection{Construction of Master Curve (TTSP shifting)}

From the accelerated experimental flexural creep tests and for both aluminum and carbon fiber specimens, the variation of bonding adhesive shear modulus with creep time at different temperatures is shown in Figure 5.1(a) and (b). From the curves, it is clear that the adhesive is viscoelastic and thermo-rheologically simple. According to the time temperature superposition
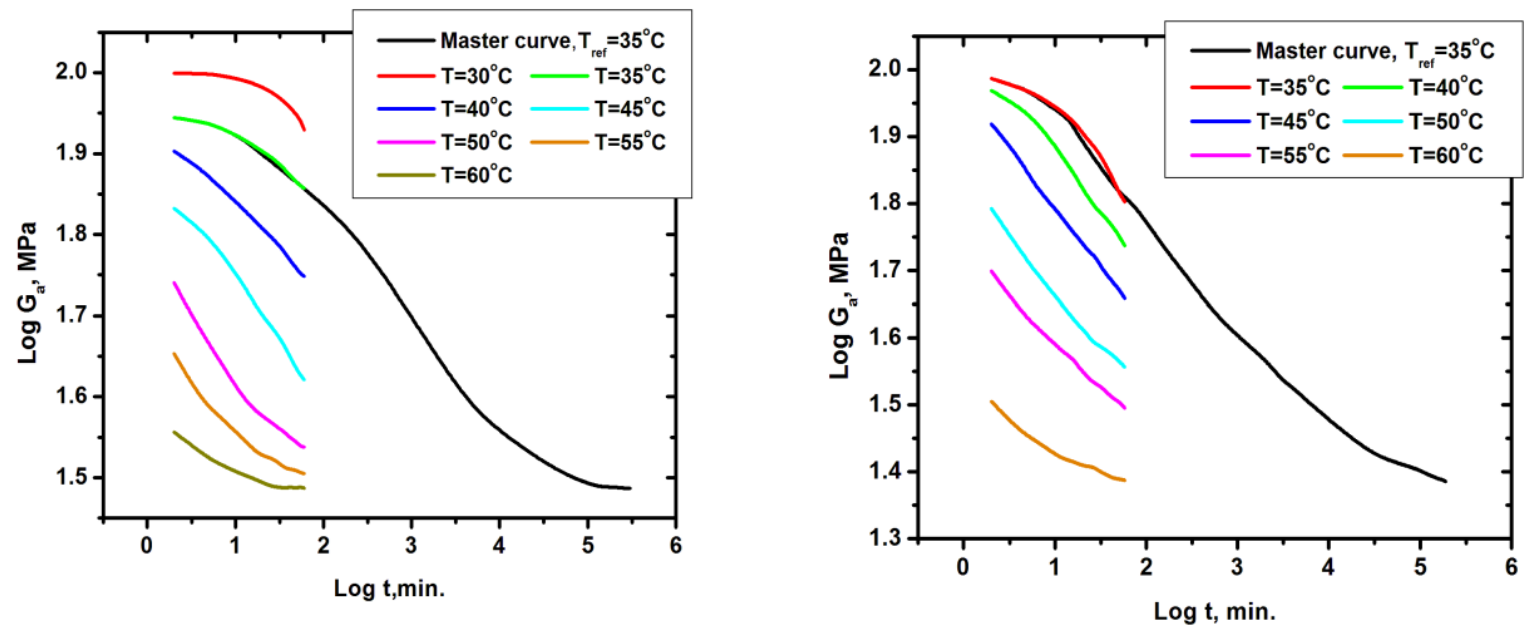

Figure 5.1: Individual creep curves and master curve at $\mathrm{T}_{\text {ref }}=35^{\circ} \mathrm{C}$

(a) aluminum specimens, (b) carbon fiber specimens.

Principle [79] the viscoelastic behavior at one temperature can be related to that at other temperature by applying change in the time scale. This means that changing the temperature of any of the creep curves has the same effect of applying a horizontal time shift factor $\log a_{T}$ on a logarithmic scale plot of adhesive shear modulus versus time. In this study, the horizontal time shift factors were determined directly from the experimental creep curves Figure 5.1 (a) and (b). There is also the vertical shift factor $b_{T}$ which is also a function in temperature. The value of the 
vertical shift factor is very small compared to the horizontal shift factor and can be neglected. The horizontal shift factor is given by,

$\log \left(t^{\prime}\right)=\log (t)+\log \left(a_{T}\right)$

The experimentally determined horizontal shift factors are presented in Table 5.1 and Figure 5.2 shows a plot of horizontal shift factor versus temperature. This curve can be used to determine the shift factor at any intermediate temperature.

Table 5.1 Horizontal shift factor versus temperature.

\begin{tabular}{|c|c|c|c|}
\hline \multicolumn{2}{|c|}{ Aluminum specimens, $\mathrm{T}_{\text {ref }}=35^{\circ} \mathrm{C}$} & \multicolumn{2}{c|}{ Carbon fiber specimens, $\mathrm{T}_{\text {ref }}=35^{\circ} \mathrm{C}$} \\
\hline Temperature $\mathrm{T},{ }^{\circ} \mathrm{C}$ & $\begin{array}{c}\text { Horizontal shift factor } \\
\log \left(a_{T}\right)\end{array}$ & Temperature $\mathrm{T},{ }^{\circ} \mathrm{C}$ & $\begin{array}{c}\text { Horizontal shift factor } \\
\log \left(a_{T}\right)\end{array}$ \\
\hline 35 & 0 & 35 & 0 \\
\hline 40 & .95 & 40 & .4 \\
\hline 45 & 1.7 & 45 & .86 \\
\hline 50 & 2.5 & 50 & 1.6 \\
\hline 55 & 3.0 & 55 & 2.1 \\
\hline 60 & 3.7 & 60 & 3.5 \\
\hline
\end{tabular}

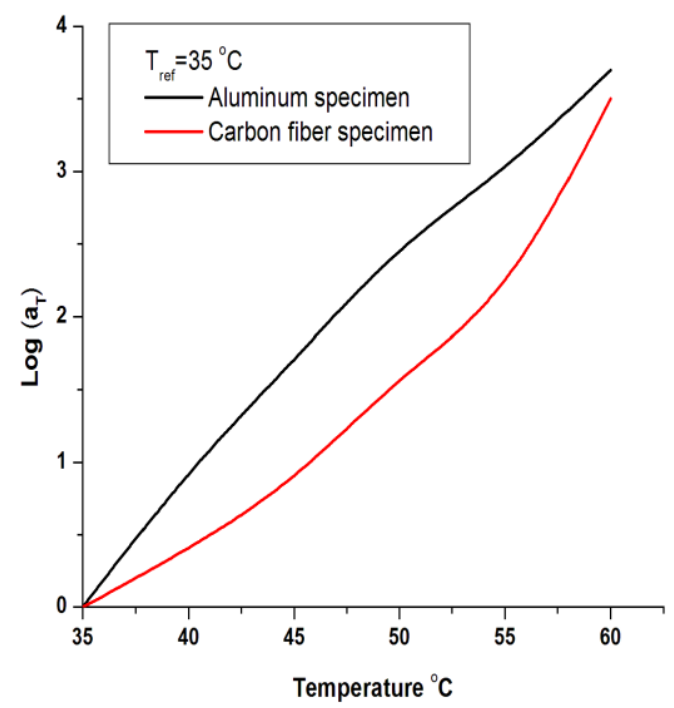

Figure 5.2: Horizontal shift factor versus temperature. 
The result is a single master curve that allows the prediction of longer term beam stiffness and adhesive shear modulus Figure 5.1 (a) and (b).

\subsection{Modeling of Master Curve}

Master curves Figures 5.1(a, b) represent the creep response of both composite systems for longer period of time (208 days for aluminum specimens and for 131 days for carbon fiber composite specimens). Figure 5.3 shows the long-term change of composite beam stiffness $(w / \delta)$ for both aluminum and carbon fiber specimens. As disused in chapter two, generalized Maxwell model Figure 2.14(a) that consists of one spring in parallel with $N$ Maxwell elements used to model the long-term viscoelastic behavior of the adhesive (master curve) due to its ability to cover broader range of the adhesive viscoelastic behavior.

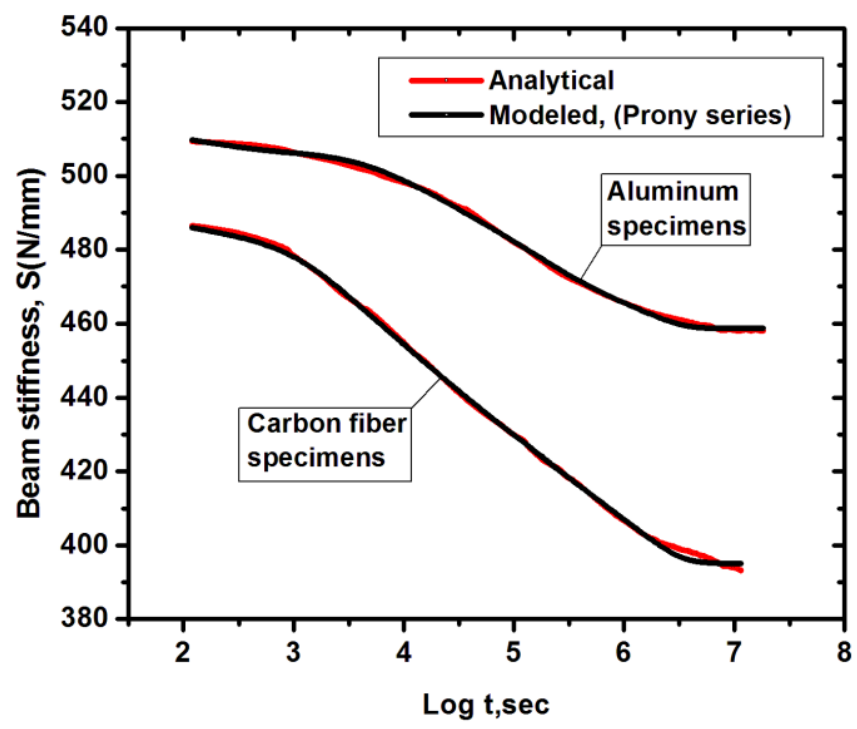

Figure 5.3: Long-term bonded beam stiffness versus creep time.

$G_{a}\left(t, T_{g}\right)=G_{\infty}+\sum_{i=1}^{N}\left(G_{i-1}-G_{i}\right) \exp \left(-\frac{t}{\tau_{i}}\right)$ 
Where $G_{\infty}$ is the adhesive shear modulus at equilibrium state $(\mathrm{t}=\infty), G_{i}$ and $\tau_{i}$ are Prony series parameters.

Let $G_{N}=G_{\infty}$ then,

$G_{o}=\lim _{t \rightarrow 0} G\left(t, T_{g}\right)=G_{\infty}+\sum_{i=1}^{N}\left(G_{i-1}-G_{i}\right)$

From equation (1) and for $N=1$,

$G_{a}\left(t, T_{g}\right)=G_{\infty}+\left(G_{o}-G_{\infty}\right) \exp \left(-\frac{t}{\tau_{i}}\right)(5$

From equations (5.3) and (5.4),

$G_{a}\left(t, T_{g}\right)=G_{o}[1-e]\left(1-\exp \left(-\frac{t}{\tau_{i}}\right)\right)$

Where, $e=\left(G_{o}-G_{\infty}\right) / G_{O}$

Equation (5.5) is one Maxwell element viscoelastic model which is not sufficient to model all the features of the long-term viscoelastic adhesive behavior represented by the constructed master curve. Generalized Maxwell model Figure 2.14(a) with $N$ Maxwell elements and with different spring constants were used.

$G_{a}\left(t, T_{g}\right)=G_{o}\left[1-\sum_{i=1}^{N} e_{i}\left(1-\exp \left(-\frac{t}{\tau_{i}}\right)\right)\right]$

Where $e_{i}=\left(G_{i-1}-G_{i}\right) / G_{O}=\Delta G / G_{O}$

Equation (5.6) can be written in the form:

$G_{a}(t)=G_{o}-\sum_{i=1}^{N} g_{i}\left[1-\exp \left(-\frac{t}{\tau_{i}}\right)\right]$

Where, 
$G_{a}(t)$ Adhesive shear relaxation modulus, $G_{o}$ instantaneousadhesive shear modulus, $g_{i}$ and $\tau_{i}$ Prony series parameters and $N$ is the number of Prony series terms. Prony series equation 5.7 was used both analytically and FEM to model the long-term creep of adhesively bonded aluminum and carbon fiber composite beams [80-81].

In the analytical analysis, Prony series with $\mathrm{N}$ number of terms was used to model the experimental data by least square fitting. The number of Prony series terms $\mathrm{N}$ and initial values for Prony series parameters $g_{i}, \tau_{i}$ were selected then optimization performed to determine Prony parameters $\mathrm{g}_{\mathrm{i}}, \tau_{\mathrm{i}}$ Table (5.2) by minimizing the least squares differences. If the result is not accurate enough, the number of Prony series terms $\mathrm{N}$ need to be increased and the process is repeated until good agreement between the experimental and modeled values are reached.

In the FEM analysis, Abaqus software was used to model the long-term creep behavior by directly specifying the analytically determined Prony series parameters to Abaqus. In Abaqus, long-term creep can be modeled by directly using creep experimental data and Abaqus will generate Prony series parameters or as followed in this study by assigning analytically determined Prony series parameters to Abaqus. Using the same Prony parameters analytically and FEM to compare the long-term behavior in both cases. There is a good agreement between analytical and FEM results in simulating the long-term creep of both types of adhesively bonded specimens. 
Table 5.2 Bonding adhesive Prony series parameters $g_{i}$ and $\tau_{i}$.

\begin{tabular}{|c|l|c|c|c|}
\hline \multirow{2}{*}{$\begin{array}{l}\text { Prony } \\
\text { series } \\
\begin{array}{l}\text { Term } \\
\text { Number } \\
(n)\end{array}\end{array}$} & $\begin{array}{l}\text { Norbon fiber composite beam } \\
\text { shear } \\
\text { relaxation } \\
\text { modulus }\left(g_{i}\right)\end{array}$ & $\begin{array}{l}\text { Relaxation time } \\
\left(\tau_{i}\right)\end{array}$ & $\begin{array}{l}\text { Normalized } \\
\text { shear } \\
\text { relaxation } \\
\text { modulus }\left(g_{i}\right)\end{array}$ & Relaxation time $\left(\tau_{i}\right)$ \\
\hline 1 & 0.0057 & 75456.29 & 0.0281 & 103286.2 \\
\hline 2 & 0.0100 & 103306 & 0.0387 & 100006.5 \\
\hline 3 & 0.0162 & 100004.7 & 0.0393 & 100039.7 \\
\hline 4 & 0.0163 & 100038.6 & 0.0393 & 100040 \\
\hline 5 & 0.0165 & 100038.1 & 0.0399 & 997662.3 \\
\hline 6 & 0.0173 & 100050.2 & 0.0976 & 142.9589 \\
\hline 7 & 0.0264 & 96843.14 & 0.1568 & 11314.93 \\
\hline 8 & 0.1013 & 997722.8 & 0.2443 & \\
\hline 9 & 0.2048 & 12258.37 & & \\
\hline 10 & 0.3320 & 1758.702 & & \\
\hline
\end{tabular}

(a)

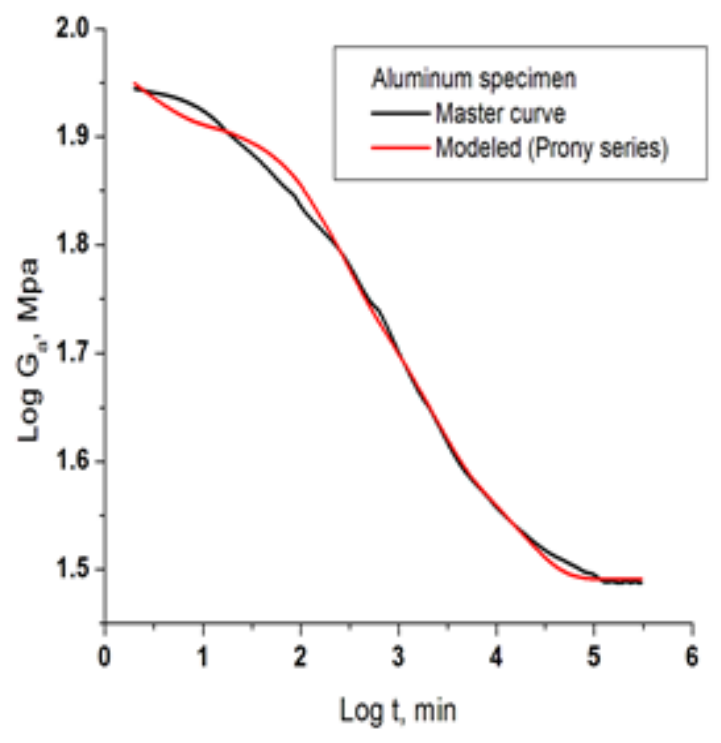

(b)

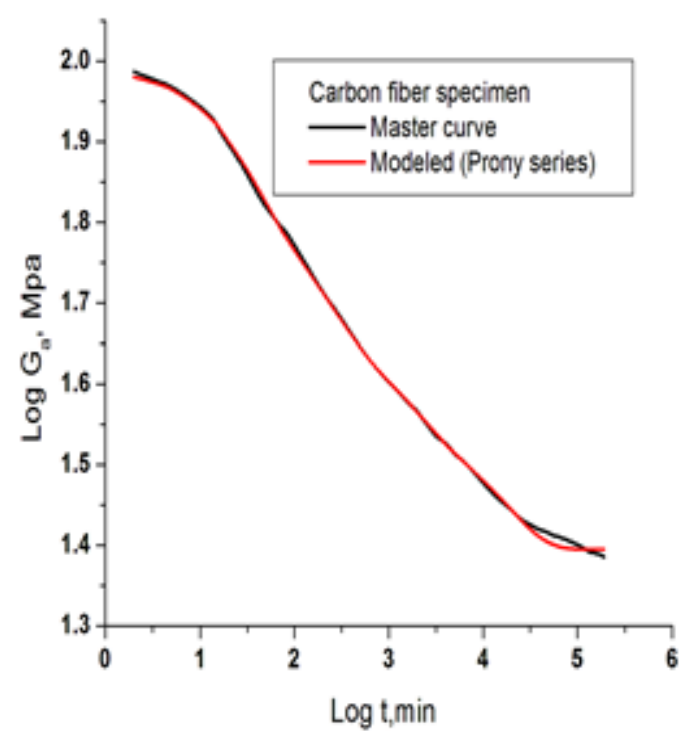

Figure 5.4: Analytical modeling of master curve (a) aluminum specimens, (b) carbon fiber specimens. 
Once the long-term creep of the adhesively bonded beams was modeled, this model is used with equations (3.1-3.3) to find out the variation with creep time of the bonded beam stiffness or (mid-span deflection), adhesion factor, bonded beam edge shear stress and the variation of adhesive shear stress along the bond line for both composite systems as shown in figures 5.5-5.9.

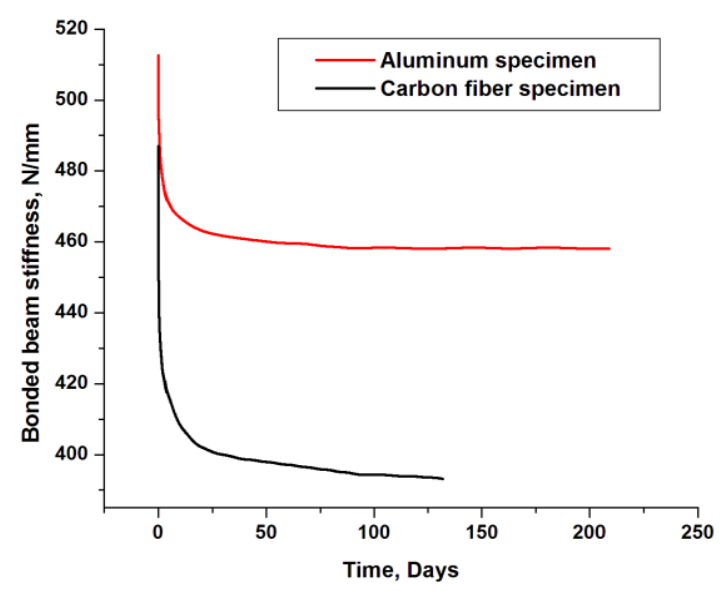

Figure 5.5: Variation of bonded beam stiffness versus creep time.

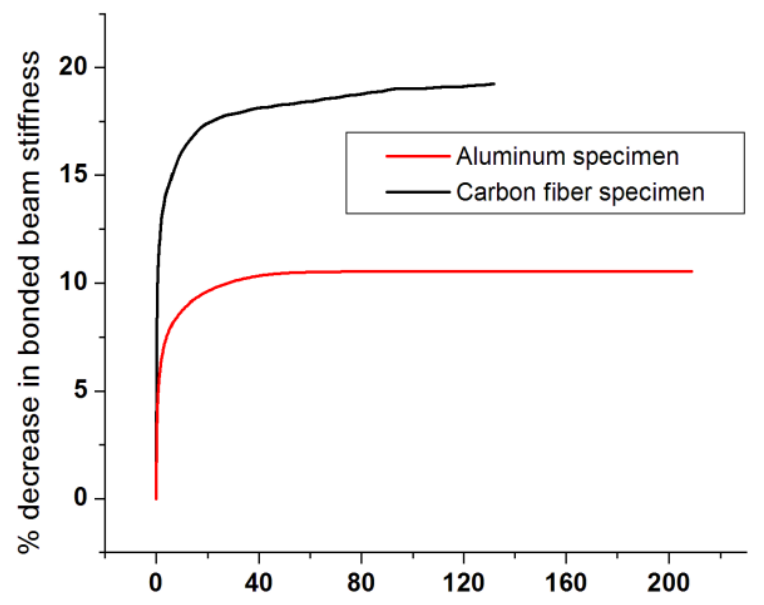

Figure 5.6: Percentage decrease in bonded beam stiffness versus creep time. 


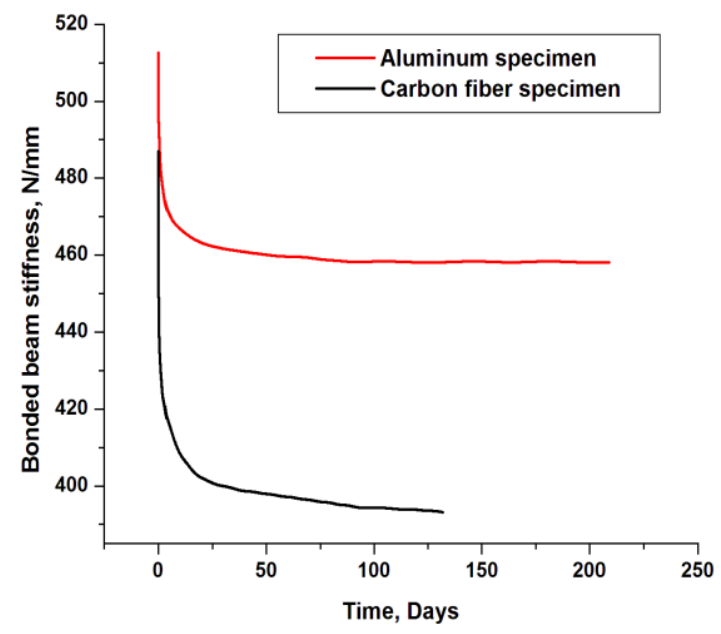

Figure 5.7: Adhesion factor versus creep time.

(a)

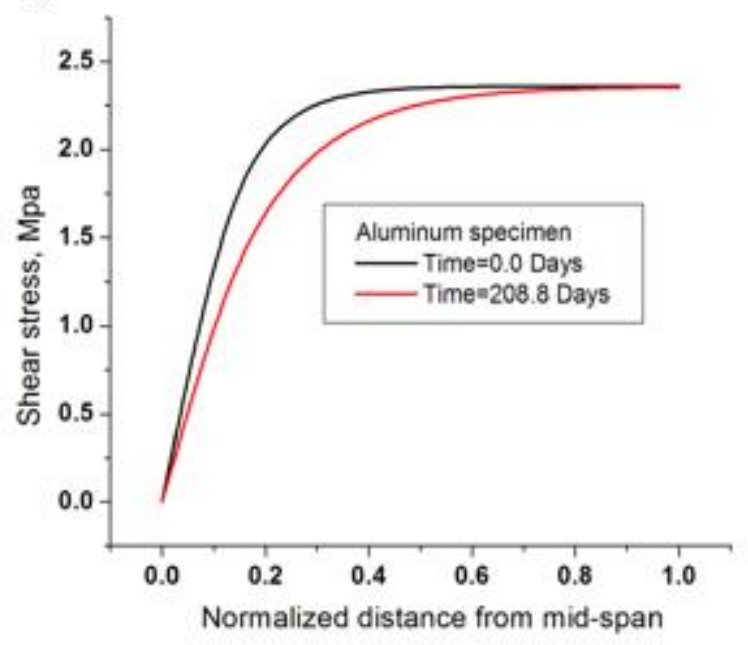

(b)

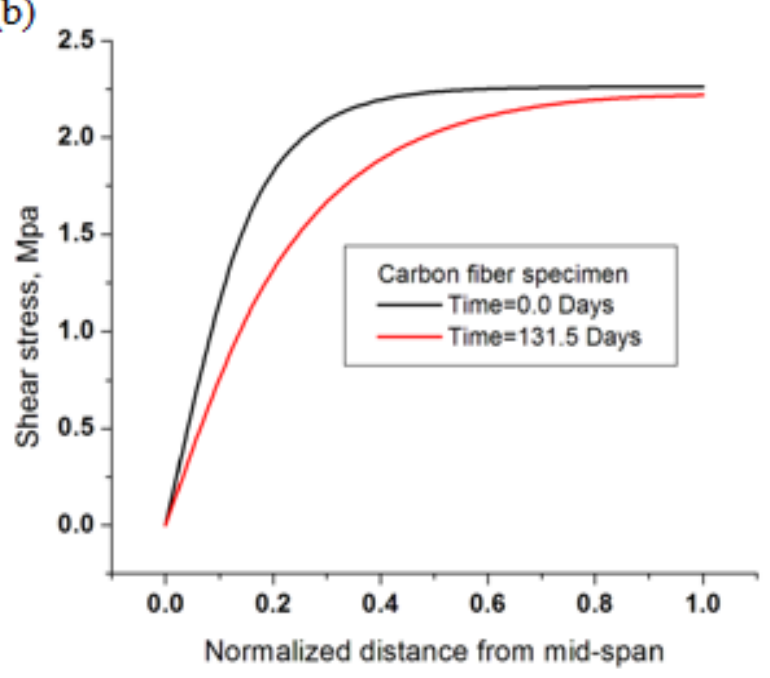

Figure 5.8: Shear stress variation along the adhesive bond line(a) aluminum specimens, (b) carbon fiber composite specimens.

As shown in Figures 5.5-5.9, there is an instantaneous response to the application of the load at mid-span of the composite beam which is the elastic part of the deflection and not related to the viscoelastic adhesive behavior. The viscoelastic response is high in rate at the beginning and gradually decreases to a low rate steady state viscoelastic behavior. 


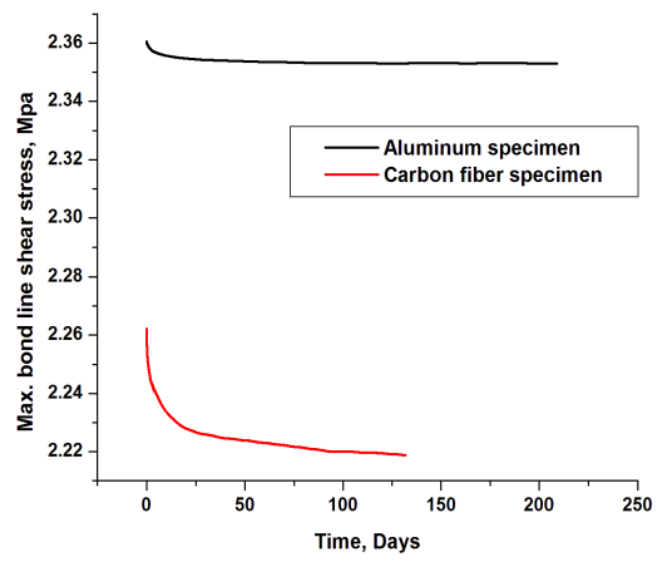

Figure 5.9: Max. adhesive shear stress versus creep time.

The adhesive shear stress starts zero at the mid-span and at a certain distance from the mid-span, it is almost constant value. Adhsive shear stress reaches its maximum value at the support. Figure 5.8shows the distribution of the in plane adhesive shear stress along the bond line. As we see in Figure 5.9, the adhesive shear at the edge slightly decreased but there is a substantial decrease in the shear stress at a certain region between the mid-span and the support Figure 5.8.

\subsection{Adherends Stress Analysis}

A differential section dx was cut from the composite beam Figure 5.10. It is assumed that the adherends materials are linear elastic and the adhesive is linear viscoelastic and the stresses in the adhesive layer are constant across the thickness. The adhesive is ability to transfer stresses between adherends changes with creep time. 

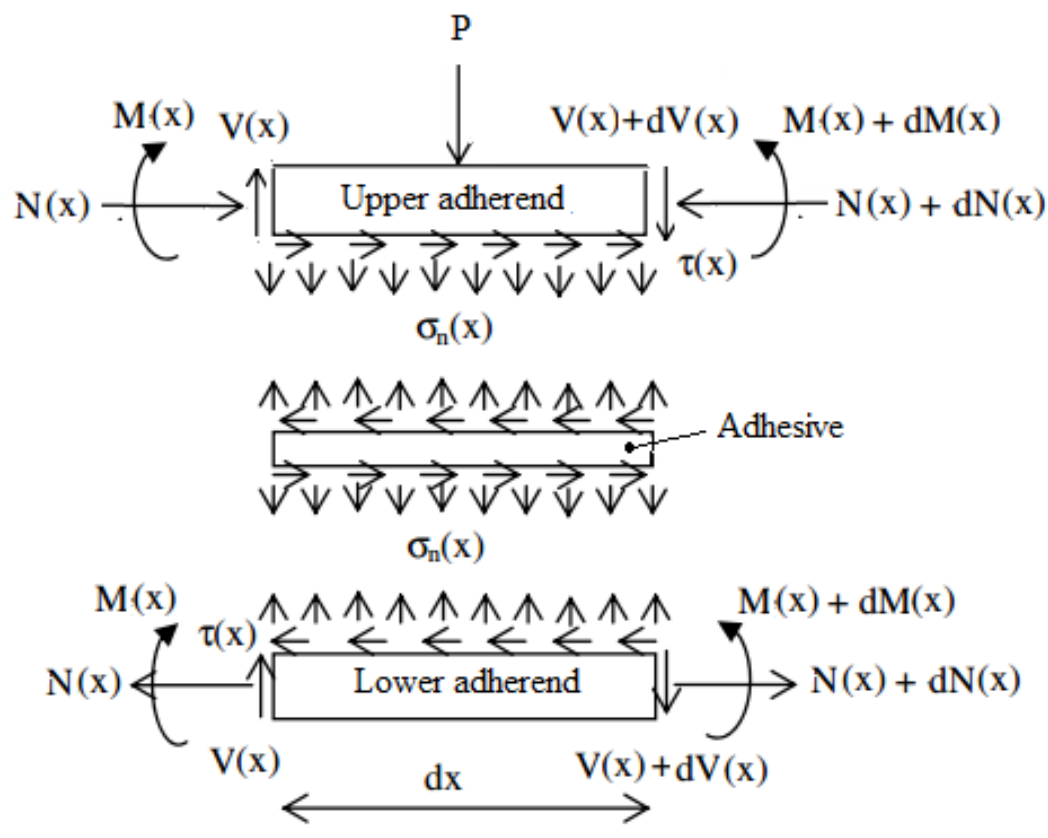

Figure 5.10: Infinitesimal element of adhesively bonded joint.

Equilibrium condition along $\mathrm{x}$-axis of the adherends,

$\frac{d N}{d x}=\tau(x) b$

$N(x)=b \int_{0}^{x} \tau(x) d x(5.9)$

Where $N$ is the axial force at the adherends. The moments on both adherends are equal assuming the same curvature for both upper and lower adherends as both have the same material and geometry.

$M_{u}(x)=M_{l}(x)=M(x)$

Where $M(x)$ the bending moment acting at the adherend. The moment equilibrium of the adherend differential segment Figure 5.10 gives,

$M_{T}(x)=M_{u}(x)+M_{l}(x)+N(x)\left[\frac{h}{2}+t_{a}+\frac{h}{2}\right]$ 
Where $M_{T}(x)$ the total moment acting at the composite beam. The last equation can be written in the form:

$M(x)=\frac{M_{T}(x)-N(x)\left[h+t_{a}\right]}{2}(5.12)$

From equations 5.9 and 5.12 the distribution of axial stress along the span at the upper and lower surfaces of the composite beam is given by,

$\sigma(x)=\frac{N(x)}{b h}+\frac{6 M(x)}{b h^{2}}(5.13)$

Where $N(x)$, the axial force and $M(x)$, the bending moment are changing along the composite beam span. The normal stress distribution $\sigma(x)$ resulted from equation 5.13 was compared with FEM results Figure 5.11 (a) and (b) and 5.12 (a) and (b) at time $=0$ and at the end of creep test time. The results are very similar except at the mid-span and boundary where Saint Venant effect makes some difference. The normal stress increase in adherends is a direct result of adhesive shear stiffness decrease with creep time.

(a)

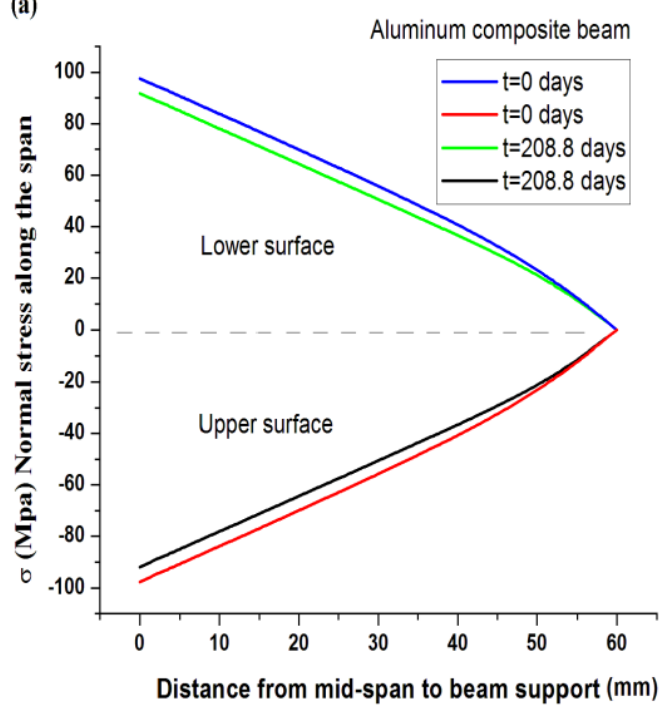

(b) Aluminum composite beam

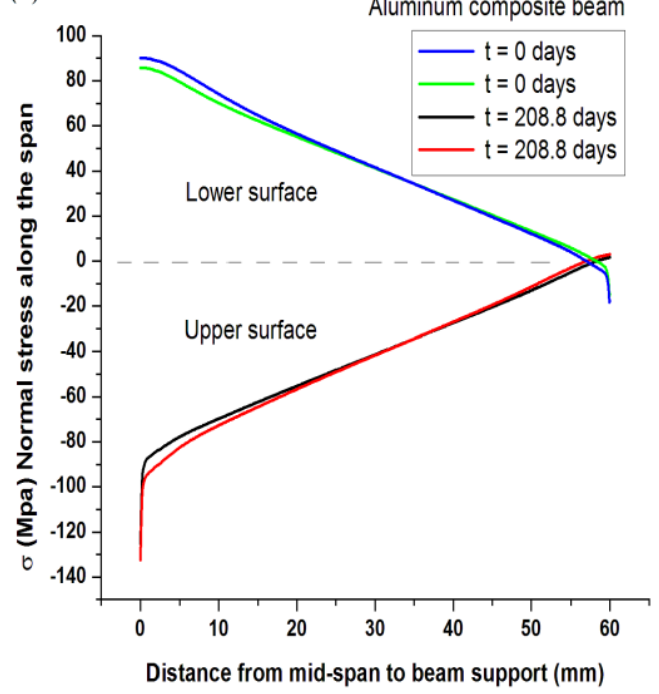

Figure 5.11: Variation of normal stress along the span at upper and lower aluminum composite beam surfaces (a) analytical, (b) FEM. 

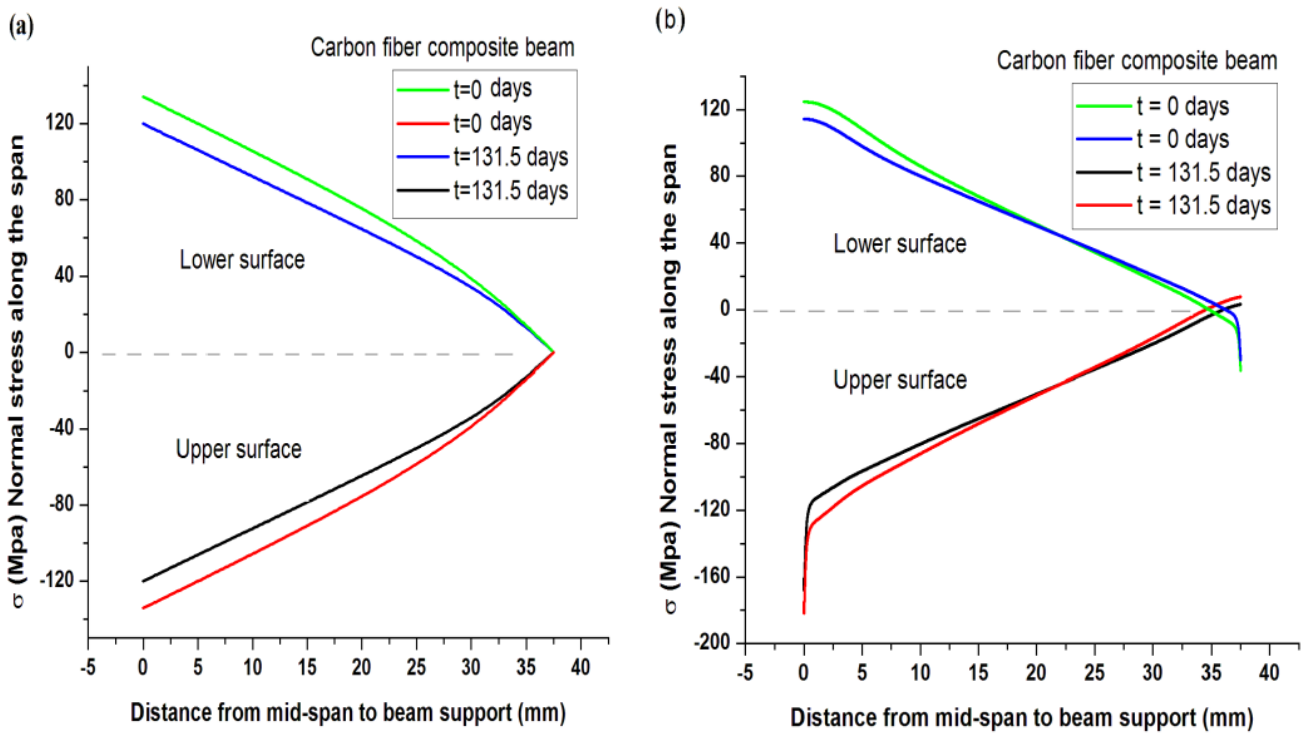

Figure 5.12: Variation of axial stress along the span at upper and lower carbon fiber composite beam surfaces (a) analytical, (b) FEM.

Figure 5.13 shows the variation of axial stress across the bonded beam thickness at mid-span. There is discontinuity in the variation of stress at the adhesive region. The discontinuity increased with creep time.
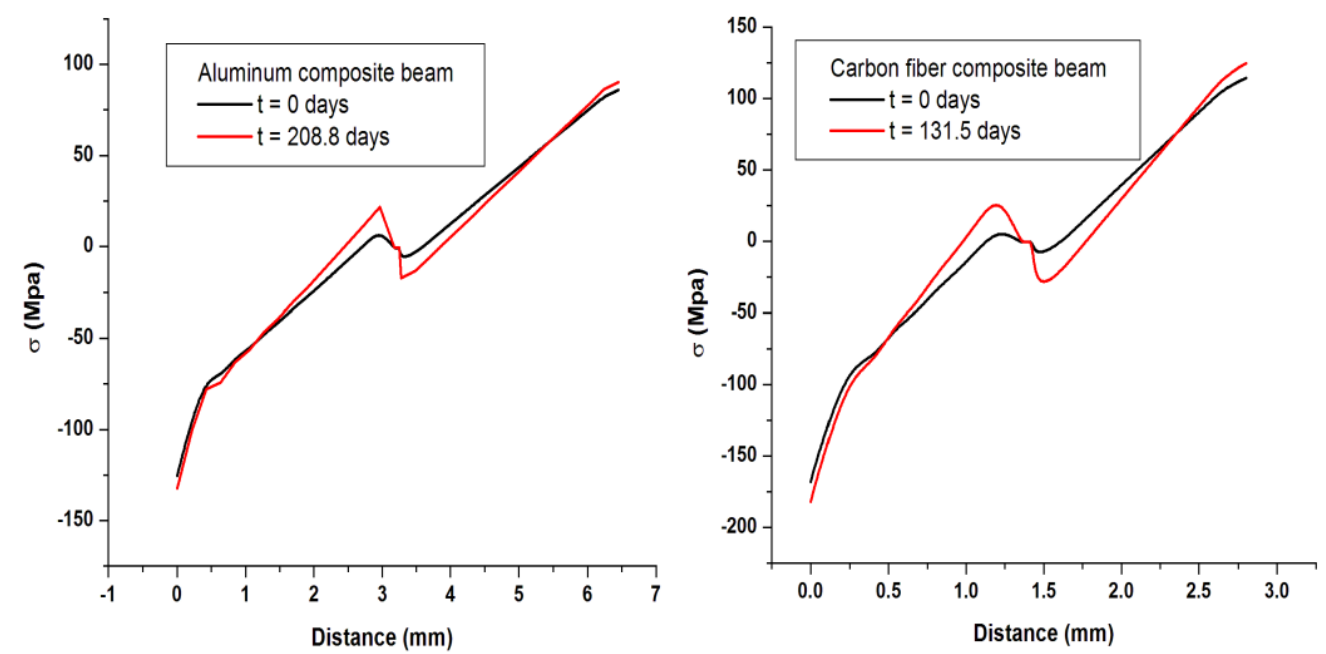

Figure 5.13: Variation of axial stress across composite beam thickness at mid-span (FEM). 


\subsection{Finite Element Analysis}

Finite element analysis was performed as part of the study to predict the long-term creep behavior of adhesively bonded aluminum and carbon fiber composite beams under flexural three-point loading. This includes simulation of: long-term mid-span creep deflection, variation with creep time of the adhesive in plane shear and normal stresses along the bond line and adherends creep time dependent stresses and strains. In this static finite element analysis, Hypermesh v 11.0 was used as a pre-processor and ABAQUS/Standard 2D was used as a solver. HyperView was used as post-processor to process the results from ABAQUS analysis.

\subsubsection{Preprocessing (Hypermesh v 11.0)}

In this step, the ABAQUS input file was created and the material properties, geometry and boundary conditions for both aluminum and carbon fiber composite beams were defined. The adherends material properties (aluminum and carbon fiber) were determined from experimental tests. In the aluminum composite beam, only isotropic material properties including elastic moduli and Poisson's ratio have been assigned to each aluminum adherend. The carbon fiber adherends in the model has been defined as a unidirectional carbon fiber laminate and the lamina properties such as $E_{1}, E_{2}, G_{12}, G_{13}, G_{23}$ and $v_{12}$ have been specified for the carbon fiber. The used material properties in the model documented in Table 4.1.In both aluminum and carbon fiber composites the adhesive properties were given in the form of the instantaneous shear modulus to represent the elastic part Table 4.1 and previously determined Prony series coefficients to represent the viscous creep part Table 5.2.The material properties then assigned to the material component of the finite element model which is the adhesively bonded beam model that was created for finite element analysis. The grid geometry of the adhesively bonded aluminum beam has been meshed using a very fine mesh of 41480 elements. While 15 elements have been 
utilized through thickness of each aluminum adherend, there have been 4 elements used through the thickness of the adhesive. The problem has been considered as a 2-dimensional plane stress problem; therefore, the reduced integration plane stress element formulation (CPS4R) with hourglass control commercially available in Abaqus/Standard 2D has been used in this numerical analysis. This type of element formulation with hourglass control has been found well suitable for such a specific numerical modeling of engineering problems where a structure is subjected to a bending load. The adhesively bonded aluminum beam has been loaded at the center of the midspan with the magnitude of $250 \mathrm{~N}$. Moreover, the simply supported boundary conditions have been successfully assigned to the model.

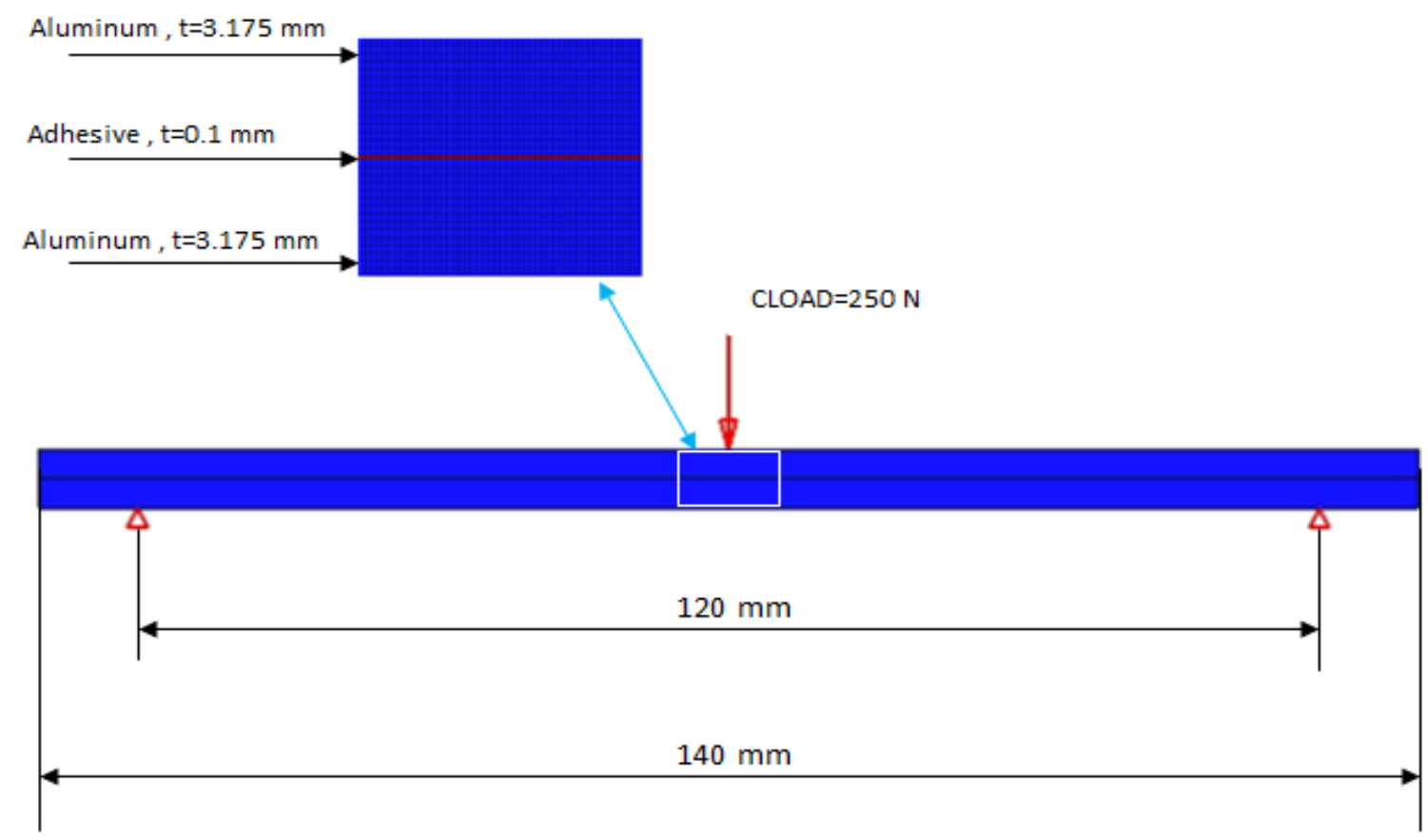

Figure 5.14: Two-dimensional finite element model for adhesively bonded aluminum beam.

Very fine mesh of 19200 reduced integration plane stress elements (CPS4R) with hourglass control has been used in the meshing of adhesively bonded carbon fiber beam. While 10 elements have been used in through thickness of each carbon fiber beam, 4 elements have been 
utilized in through the thickness of the adhesive. The bending load of $200 \mathrm{~N}$ has been applied to the center of the beam. Also, the simply supported boundary conditions have been assigned. Figures 5.14-5.15 show the finite element model mesh for both aluminum and carbon fiber composite beams.

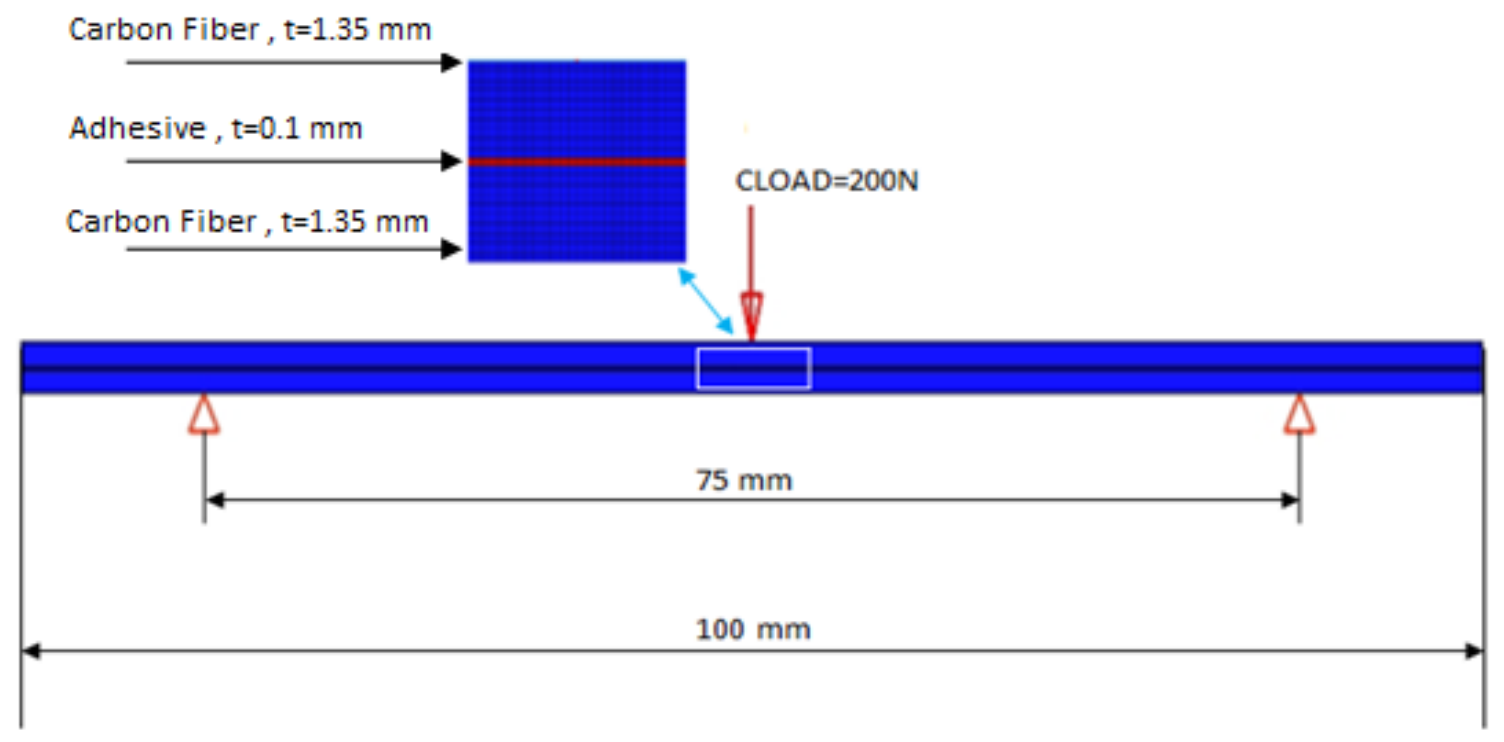

Figure 5.15: Two-dimensional finite element model for adhesively bonded carbon fiber beam.

\subsubsection{Simulation (ABAQUS/Standard 2D)}

In this study ABAQUS/Standard was used to simulate the long-term creep response of aluminum and carbon fiber adhesively bonded beam composite. This is the stage where the numerical problem was solved by ABAQUS/Standard software and a number of different files generated. The generated output result file was used in the next post-processer stage. The required time for solving the problem depends on the power of the computer used for the analysis, complexity of the problem and the number of elements. 


\subsubsection{Post-Proceeding (HyperView)}

Hypermesh v 11.0 was used in the present study as a post-processor where the results were presented in a graphical form. The generated (. fil) file from the simulation stage was converted into Hypermesh result (.res) file. The result file then imported to the Hypermesh v11.0 environment where various results such as stresses, strains and displacements were presented. There are many ways to display the results of finite element analysis with Hypermesh v 11.0, including animation, colored contour and deformed shape plots. For both aluminum and carbon fiber adhesively bonded composites, analytical approach was followed to predict the long-term, adhesive in plane shear stress variation along the bond line and the bonded beam mid-span deflection. Finite element analyses were performed to validate the analytical results.

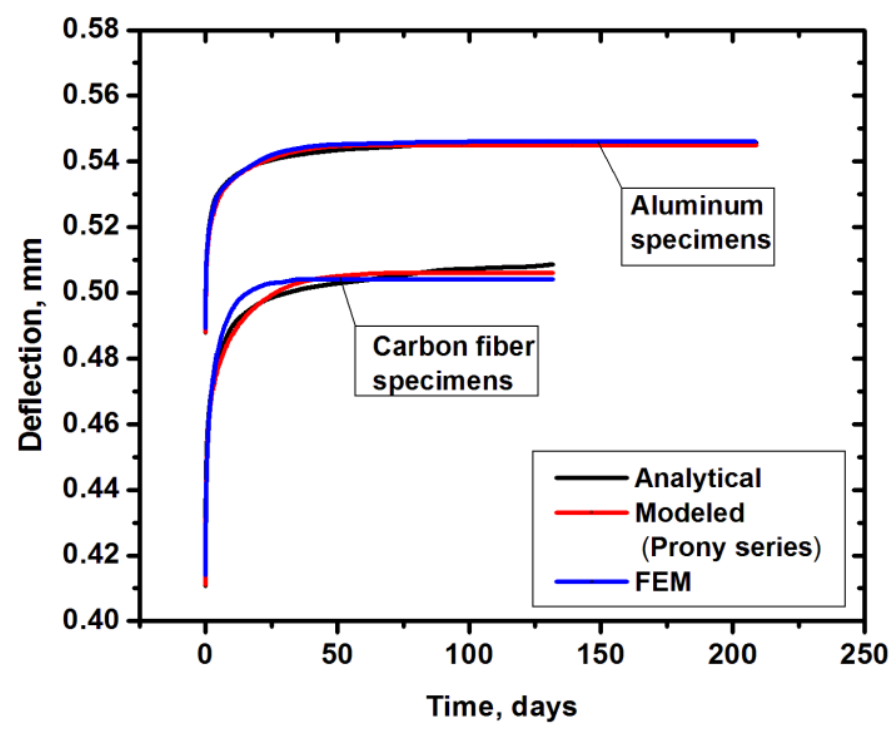

Figure 5.16: Long-term creep deflection. 

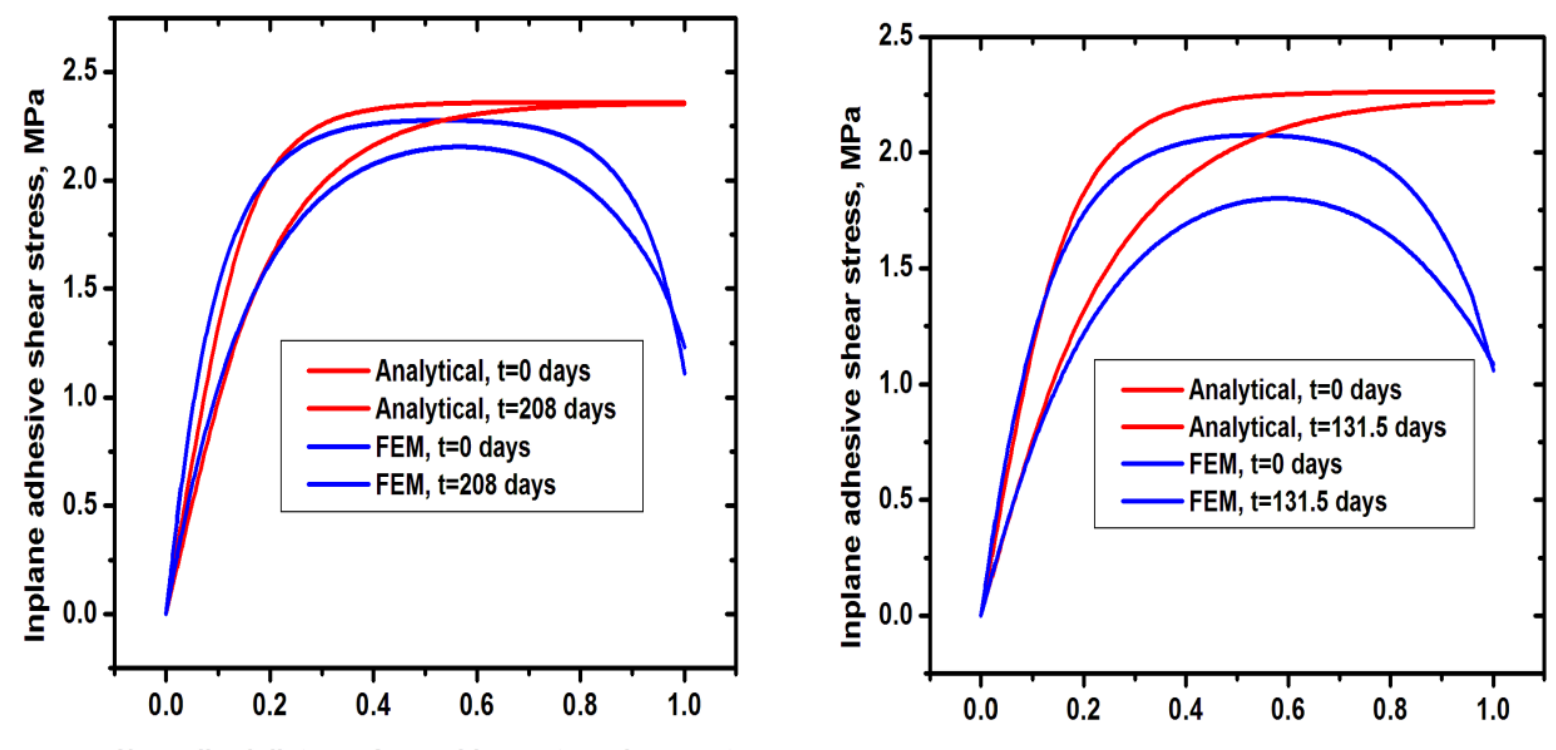

Normalized distance from mid-span to end support

Normalized distance from mid-span to end support

Figure 5.17: In plane shear stress versus adhesive bond line (a) aluminum specimens, (b) carbon fiber composite specimens.

Figure 5.17shows the in-plane adhesive shear stress distribution along the half span of the adhesively bonded beam at $t=0$ and at the end of the creep time for both analytical and FEM.

The results show a good match between the analytical and FEM in the in plane adhesive shear stress distribution along the bonded beam except in the region near to the supporters where FEM showed a steep decline in the shear stress near to the bonded beam supporters due to (SaintVenant) effect. The match between the analytical and FEM results in the carbon fiber composite beam is not as strong as the aluminum beam Figures 5.16-5.17. This can be because of the less accurcy in the values of the carbon fiber composite beam mechanical properties that used in analytical and FEM simulation. 

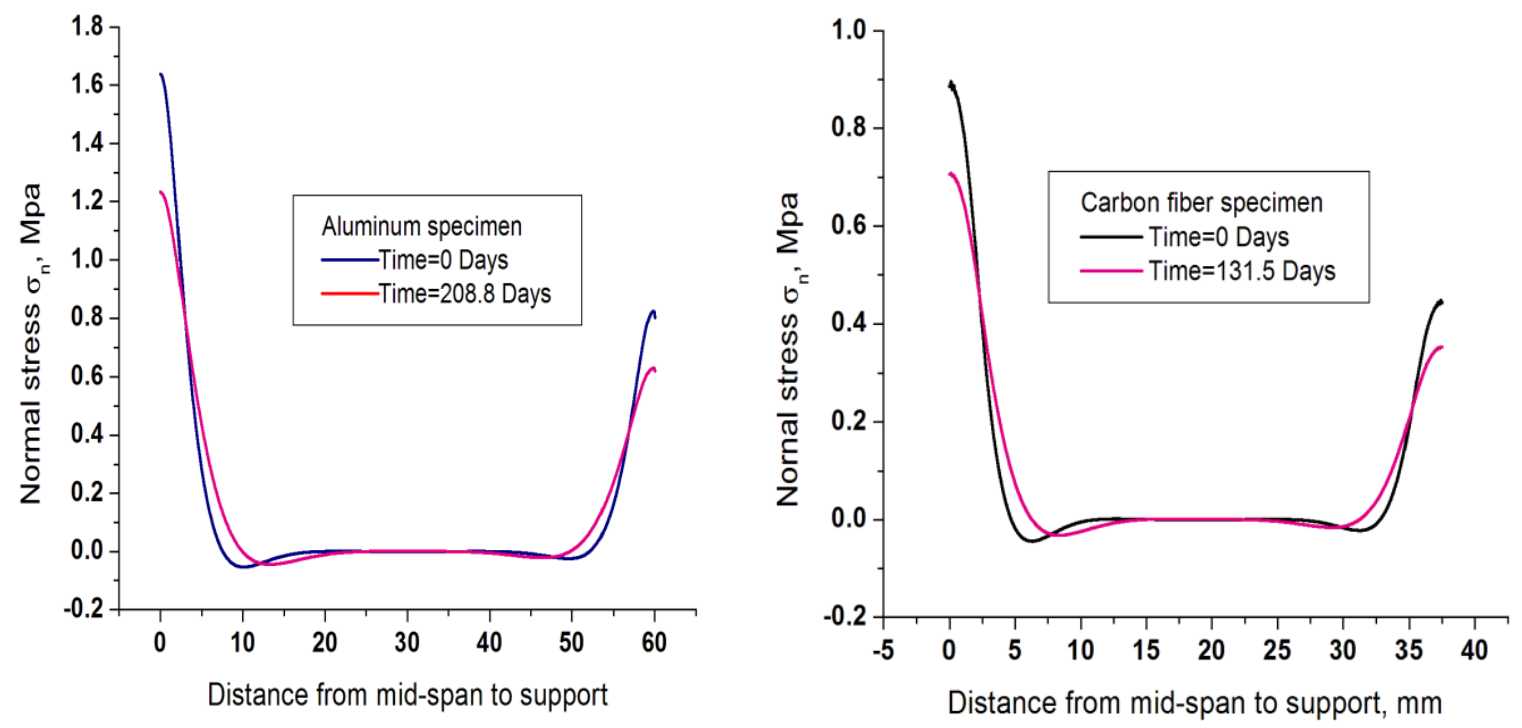

Figure 5.18: FEM, normal (compressive) adhesive stress distribution along the bond line(a) aluminum specimens, (b) carbon fiber composite specimens.

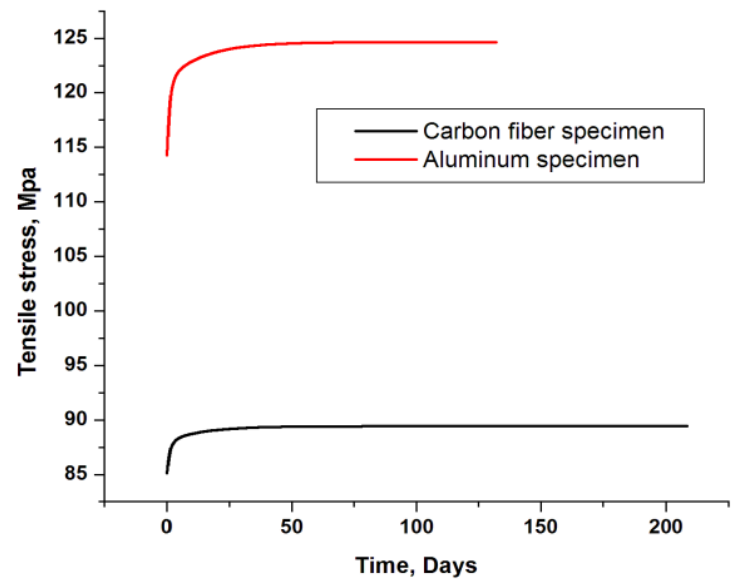

Figure 5.19: Mid-span lower adherend lower surface tensile stress versus creep time.

FEM also used to simulate the variation of the adhesive normal stress along the bond line at time $=0$ and at the end of creep time Figure 5.14. The effect of the loading rollers is strong at midspan and at the beam end. There is no strong variation with time of the normal stress especially for the region away from the loading supporters. FEM results showed gradual increase with time 
in the maximum tensile stress at mid-span lower adherend lower surface due to decrease in adhesive shear modulus Figure 5.15. 


\section{CHAPTER 6 CONCLUSION AND RECOMMENDATIONS}

In literature, axially loaded single and double lap joints testing is the most common way to predict the long-term behavior of adhesively bonded structures under constant load. In this study, a new approach was followed where a flexural creep testing fixture was prepared and a series of short-term three-point creep bending tests at different temperatures were performed on two types of specimens: Adhesively bonded aluminum composite specimens and adhesively bonded unidirectional carbon fiber specimens. In previous studies, three-point bending tests were performed to characterize the elastic mechanical properties of adhesives. In this study, the testing and analysis were extended to cover the viscoelastic behavior of the adhesive and the entire bonded structure where master curve was constructed by shifting all the resulted individual creep curves (TTSP) Figure 5.1 (a, b) and Prony series was used to model the long-term creep behavior of the structure.

\subsection{Conclusions}

- A three-point flexural creep testing fixture was prepared to study the long-term linear viscoelastic behavior of adhesively bonded structures. Three-point bending test was selected because of the simplicity of the experimental setup and the fact that bending stresses are quite common in real structural loading. The proposed solution extended the analytical approach followed by Moussiaux et al. [75] to cover the viscoelastic range and permits the study of long-term creep behavior. Specimens' dimensions and adhesive thickness should be properly selected for the composite beam to be sensitive to the adhesive shear modulus change with creep time.

- Accelerated creep tests were performed at higher temperatures and mid-span deflection was measured as a function of time for both types of specimens. Time temperature 
superposition principle (TTSP) based on the equivalency between time and temperature was used to construct the master curve by proper horizontal shifting of all experimentally recorded creep curves at different temperatures. All the shifted creep curves were transformed into a single reference curve (master curve) at reference temperature $\left(\mathrm{T}_{\mathrm{ref}}\right)$ which is a good indication of the linear viscoelastic behavior of the bonding adhesive.

- The generated master curve is very important because it covers viscoelastic behavior times much higher than the range that can be covered experimentally. Also, master curve can be shifted to any desired temperature rather than the reference temperature by fitting the experimentally determined shift factors to a mathematical model.

- Prony series was successfully used to model the master curve where Excel solver 2007 used to perform non-linear least square fitting of the master curve to $\mathrm{N}$ terms Prony series. Prony series parameters were identified for best fit between master curve and the selected viscoelastic model.

- ABAQUS software was used to model the flexural creep response of the adhesively bonded beams and the analytical and finite element analysis results were in good agreement for both types of specimens Figure 5.16. Once the difference in the instantaneous deflection between the aluminum and carbon fiber composite systems is directly related to the difference in the flexural stiffness of the specimens and the midspan dead weight load applied, the difference in creep response Figure 5.3 is due to the difference in residual thermal stresses as a result of thermal and mechanical properties mismatch between adherends and adhesives during the cure processes. There is also the difference in response to thermal loading between the two systems that resulted difference in their viscoelastic behavior. 
- The mechanical properties of the adhesive in the bonded joint are affected by adherends contact. The thin adhesive layer may exhibit different properties in its bulk form.

- Bonded structure viscoelastic behavior depends on the mechanical and thermal properties of both adherends and adhesive. The difference in mechanical properties and material mismatch are the main source of resulting creep response influenced by the adhesive/ adherend interface.

\subsection{Recommendations for future work}

- Better understanding of the time dependent behavior of adhesively bonded structures requires more understanding of the effect of many environmental factors such as temperature, moisture content and aging on the molecular structure of the adhesive and how the mechanical properties of the adhesive are affected by this change in adhesive molecular structure.

- The time dependent behavior and durability of the adhesively bonded joints is highly affected by the region of interface between the adhesive and adherends. This region, which is very thin, is affected by temperature, moisture content and other environmental factors in a different way than the adhesive and adherends. More sensitive tests may be required.

- Creep tests were performed at different temperatures where a hot air blower were used to heat up the specimen under test. Use of an environmental box, where the experimental setup is put inside controlled environment box, will be better and more convenient to control the sample condition.

- It is recommended to use FEM in analyzing the stresses and predicting the long-term behavior of adhesively bonded structures due to the complicated state of stress, material 
and geometrical nonlinearity. Also, the viscoelastic behavior of the adhesive may become nonlinear at higher stresses. The available numerical models are complicated and not commonly used in industrial application. This rise the need for more simple approach. 


\section{REFERENCES}

1. Kinloch, A., Adhesion and adhesives: science and technology. 2012: Springer Science \& Business Media.

2. Plecnik, J.M., et al., Temperature effects on epoxy adhesives. Journal of the structural division, 1980. 106(1): p. 99-113.

3. McMurray, M. and S. Amagi, The effect of time and temperature on flexural creep and fatigue strength of a silica particle filled epoxy resin. Journal of materials science, 1999. 34(23): p. 59275936.

4. Gardner, D.J., C.E. Frazier, and A.W. Christiansen, Characteristics of the wood adhesion bonding mechanism using hydroxymethyl resorcinol. 2006.

5. Curley, A., et al., The fatigue and durability behaviour of automotive adhesives. Part III: predicting the service life. The Journal of Adhesion, 1998. 66(1-4): p. 39-59.

6. Lodeiro, M., W. Broughton, and G. Sims, Understanding limitations of through thickness test methods. Plastics, rubber and composites, 1999. 28(9): p. 416-424.

7. Broughton, W., R. Mera, and G. Hinopoulos, Environmental Degradation of Adhesive Joints. Single-Lap Joint Geometry. NPL Report CMMT (A), 1999. 196.

8. Broughton, W., R. Mera, and G. Hinopoulos, Cyclic Fatigue Testing of Adhesive Joints: Test Method Assessment. NPL Report CMMT (A), 1999. 191: p. 1996-1999.

9. Broughton, W. and G. Hinopoulos, Evaluation of the single-lap joint using finite element analysis. 1999: National Physical Laboratory. Great Britain, Centre for Materials Measurement and Technology.

10. Hinopoulos, G. and W. Broughton, Evaluation of the T-peel joint using the Finite Element method. NPL Report CMMT (A), 1999. 207. 
11. Broughton, W. and R. Mera, Environmental degradation of adhesive joints, accelerated testing. NPL Report CMMT (A), 1999. 197.

12. Broughton, W., R. Mera, and G. Hinopoulos, Cyclic fatigue testing of adhesive joints: environmental effects. NPL Report CMMT (A), 1999. 192.

13. Broughton, W., Creep Testing of Adhesive Joints Analysis of Creep Rupture Data. NPL Report CMMT (A), 1999. 195.

14. Roy, S. and J. Reddy, Nonlinear viscoelastic analysis of adhesively bonded joints. 1986, DTIC Document.

15. Delale, F., F. Erdogan, and M. Aydinoglu, Stresses in adhesively bonded joints: a closed-form solution. Journal of Composite Materials, 1981. 15(3): p. 249-271.

16. Botha, L., R.M. Jones, and H. Brinson, Viscoelastic Analysis of Adhesive Stresses in Bonded Joints. 1983, DTIC Document.

17. Henriksen, M., Nonlinear viscoelastic stress analysis-a finite element approach. Computers \& structures, $1984.18(1)$ : p. 133-139.

18. Yadagiri, S. and C.P. Reddy, Viscoelastic analysis of nearly incompressible solids. Computers \& structures, $1985.20(5):$ p. 817-825.

19. Carver, D. and G. Wooley, Stress concentration factors for bonded lap joints. Journal of Aircraft, 1971. 8(10): p. $817-820$.

20. Adams, R. and N. Peppiatt, Effect of Poisson's ratio strains in adherends on stresses of an idealized lap joint. The journal of strain analysis for engineering design, 1973. 8(2): p. 134-139.

21. Adams, R. and N. Peppiatt, Stress analysis of adhesive-bonded lap joints. Journal of strain analysis, 1974. 9(3): p. 185-196.

22. Volkersen, O., D.N.i.Z.m.K. Laschenquerschritten, and Luftfahrtforschung, pp. 41-47, 1938: p. 41.

23. Goland, M. and E. Reissner, The Stress in Cemented Joint. Trans. ASME, 1944. 66: p. A17. 
24. Hart-Smith, L., Adhesive-bonded double-lap joints.[analytical solutions for static load carrying capacity]. 1973.

25. Bigwood, D. and A. Crocombe, Elastic analysis and engineering design formulae for bonded joints. International journal of Adhesion and Adhesives, 1989. 9(4): p. 229-242.

26. Bigwood, D. and A. Crocombe, Non-linear adhesive bonded joint design analyses. International journal of adhesion and adhesives, 1990. 10(1): p. 31-41.

27. Allman, D.J., THEORY FOR ELASTIC STRESSES IN ADHESIVE BONDED LAP JOINTS. Quarterly Journal of Mechanics and Applied Mathematics, 1977. 30(NOV): p. 415-436.

28. Wah, T., Trans. ASME J. Eng. Mater. Technol., 1973. 95: p. 174.

29. Pirvics, J., Two dimensional displacement-stress distributions in adhesive bonded composite structures. The Journal of Adhesion, 1974. 6(3): p. 207-228.

30. Renton, W.J. and J.R. Vinson, The Efficient Design of Adhesive Bonded Joints. The Journal of Adhesion, 1975. 7(3): p. 175-193.

31. Renton, J. and J. Vinson, On the behavior of bonded joints in composite material structures. Engineering Fracture Mechanics, 1975. 7(1): p. 41IN153-52IN660.

32. Srinivas, S., NASA technical note. NASA TN D-7855, 1975.

33. Cheng, S., D. Chen, and Y. Shi, Analysis of Adhesive-Bonded Joints with Nonidentical Adherends. Journal of engineering mechanics. 117(3): p. 605.

34. Cheng, S., D. Chen, and Y. Shi, Analysis of adhesive-bonded joints with nonidentical adherends. Journal of Engineering Mechanics, 1991. 117(3): p. 605-623.

35. Yang, C. and S.-S. Pang, Stress-Strain Analysis of Single-Lap Composite Joints Under Tension. Journal of Engineering Materials and Technology, 1996. 118(2): p. 247-255. 
36. Sawa, T., et al., A two-dimensional stress analysis of single-lap adhesive joints of dissimilar adherends subjected to tensile loads. Journal of adhesion Science and Technology, 2000. 14(1): p. $43-66$.

37. Zou, G.P., K. Shahin, and F. Taheri, An analytical solution for the analysis of symmetric composite adhesively bonded joints. Composite Structures, 2004. 65(3-4): p. 499-510.

38. Lee, J. and H. Kim, Stress analysis of generally asymmetric single lap adhesively bonded joints. Journal of Adhesion, 2005. 81(5): p. 443-472.

39. Adams, R. and V. Mallick, A method for the stress analysis of lap joints. The Journal of Adhesion, 1992. 38(3-4): p. 199-217.

40. Rao, B.N., Y.S. Rao, and S. Yadagiri, Analysis of composite bonded joints. Fibre Science and Technology, 1982. 17(2): p. 77-90.

41. Yadagiri, S., C.P. Reddy, and T.S. Reddy, Viscoelastic analysis of adhesively bonded joints. Computers \& structures, 1987. 27(4): p. 445-454.

42. Reddy, J. and S. Roy, Non-linear analysis of adhesively bonded joints. International journal of non-linear mechanics, 1988. 23(2): p. 97-112.

43. Amijima, S. and T. Fujii, A simple stress analysis method for adhesive bonded tapered joints. International Journal of Adhesion and Adhesives, 1989. 9(3): p. 155-160.

44. Carpenter, W.C., Viscoelastic analysis of bonded connections. Computers \& Structures, 1990. 36(6): p. 1141-1152.

45. Li, G. and P. Lee-Sullivan, Finite element and experimental studies on single-lap balanced joints in tension. International journal of adhesion and adhesives, 2001. 21(3): p. 211-220.

46. Chien-Chang, L. and L. Yee-Shown, A finite element model of single-lap adhesive joints. International journal of solids and structures, 1993. 30(12): p. 1679-1692. 
47. Edlund, U. and A. Klarbring, A geometrically nonlinear model of the adhesive joint problem and its numerical treatment. Computer Methods in Applied Mechanics and Engineering, 1992. 96(3): p. 329-350.

48. Tong, L. and X. Sun, Nonlinear stress analysis for bonded patch to curved thin-walled structures. International journal of adhesion and adhesives, 2003. 23(5): p. 349-364.

49. Andruet, R.H., D.A. Dillard, and S.M. Holzer, Two-and three-dimensional geometrical nonlinear finite elements for analysis of adhesive joints. International Journal of Adhesion and Adhesives, 2001. 21(1): p. 17-34.

50. Goncalves, J., M. De Moura, and P. De Castro, $A$ three-dimensional finite element model for stress analysis of adhesive joints. International Journal of Adhesion and Adhesives, 2002. 22(5): p. 357-365.

51. Dean, G., et al., Prediction of deformation and failure of rubber-toughened adhesive joints. International journal of adhesion and adhesives, 2004. 24(4): p. 295-306.

52. Brinson, H.F. and L.C. Brinson, Polymer engineering science and viscoelasticity. 2008: Springer.

53. Feng, C.-W., et al., Modeling of long-term creep behavior of structural epoxy adhesives. International journal of adhesion and adhesives, 2005. 25(5): p. 427-436.

54. Dean, G., Modelling non-linear creep behaviour of an epoxy adhesive. International journal of adhesion and adhesives, 2007. 27(8): p. 636-646.

55. Yu, X., A. Crocombe, and G. Richardson, Material modelling for rate-dependent adhesives. International journal of adhesion and adhesives, 2001. 21(3): p. 197-210.

56. Majda, P. and J. Skrodzewicz, A modified creep model of epoxy adhesive at ambient temperature. International Journal of Adhesion and Adhesives, 2009. 29(4): p. 396-404. 
57. $\mathrm{Yu}, \mathrm{H} ., \mathrm{Z}$. Li, and Q.J. Wang, Viscoelastic-adhesive contact modeling: Application to the characterization of the viscoelastic behavior of materials. Mechanics of Materials, 2013. 60: p. $55-65$.

58. Roseley, A.S., et al., Creep response of thixotropic ambient temperature cure adhesives measured by DMTA in static tension and shear. International Journal of Adhesion and Adhesives, 2011. 31(6): p. 575-582.

59. Chiu, W. and R. Jones, Unified constitutive model for thermoset adhesive, FM73. International journal of adhesion and adhesives, 1995. 15(3): p. 131-136.

60. Duncan, B. and A. Maxwell, Measurement methods for time-dependent properties of flexible adhesives. 1999: NPL Middlesex.

61. Dean, G.D. and W. Broughton, A review of creep modelling for toughened adhesives and thermoplastics. 2005: Citeseer.

62. Pandey, P., H. Shankaragouda, and A.K. Singh, Nonlinear analysis of adhesively bonded lap joints considering viscoplasticity in adhesives. Computers \& structures, 1999. 70(4): p. 387-413.

63. Ramberg, W. and W.R. Osgood, Description of stress-strain curves by three parameters. 1943.

64. Mortensen, F. and O.T. Thomsen, Analysis of adhesive bonded joints: a unified approach. Composites Science and Technology, 2002. 62(7): p. 1011-1031.

65. Adams, R.D., Adhesive bonding: science, technology and applications. 2005: Elsevier.

66. Banea, M. and L.F. da Silva, Adhesively bonded joints in composite materials: an overview. Proceedings of the Institution of Mechanical Engineers, Part L: Journal of Materials Design and Applications, 2009. 223(1): p. 1-18.

67. Brinson, H.F., Durability (Lifetime) Predictions Adhesively Bonded Structures. 1987, DTIC Document. 
68. Findley, W. and G. Khosla, An equation for tension creep of three unfilled thermoplastics. SPE Journal, 1956. 12(12): p. 20-25.

69. Hadid, M., S. Rechak, and A. Zouani, Empirical nonlinear viscoelastic model for injection molded thermoplastic composite. Polymer composites, 2002. 23(5): p. 771-778.

70. Schapery, R.A., A theory of non-linear thermoviscoelasticity based on irreversible thermodynamics. 1966: American Society of Mechanical Engineers.

71. Schapery, R.A., On the characterization of nonlinear viscoelastic materials. Polymer Engineering \& Science, 1969. 9(4): p. 295-310.

72. Ferry, J.D., Viscoelastic properties of polymers. 1980: John Wiley \& Sons.

73. Aklonis, J. and W. MacKnight, Introduction to Polymer Viscoelasticity. 1983. A Wiley-Interscience Publication: New York.

74. Williams, M.L., R.F. Landel, and J.D. Ferry, The temperature dependence of relaxation mechanisms in amorphous polymers and other glass-forming liquids. Journal of the American Chemical society, 1955. 77(14): p. 3701-3707.

75. Moussiaux, E., H. Brinson, and A. Cardon, Bending of a bonded beam as a test method for adhesive properties. 1987, DTIC Document.

76. ASTM D-2990 Standard Test Methods for Tensile, Compressive, and Flexural Creep and CreepRupture of Plastics. 2009, ASTM International.

77. ASTM D-790 Standard Test Methods for Flexural Properties of Unreinforced and Reinforced Plastics and Electrical Insulating Materials. 2015, ASTM International.

78. LabVIEW Software.

79. Alwis, K. and C. Burgoyne, Time-temperature superposition to determine the stress-rupture of aramid fibres. Applied Composite Materials, 2006. 13(4): p. 249-264. 
80. Soussou, J., F. Moavenzadeh, and M. Gradowczyk, Application of prony series to linear viscoelasticity. Transactions of the Society of Rheology, 1970. 14(4): p. 573-584.

81. Pacheco, J.E.L., C.A. Bavastri, and J.T. Pereira, Viscoelastic relaxation modulus characterization using Prony series. Latin American Journal of Solids and Structures, 2015. 12(2): p. 420-445. 


\begin{abstract}
FLEXURAL CREEP BEHAVIOR OF ADHESIVELY BONDED METAL AND COMPOSITE LAMINATES
\end{abstract}

by

\title{
HASAN NUWAYER
}

August 2017

\section{Advisor: Dr.Golam Newaz}

Major: Mechanical Engineering

Degree: Doctor of Philosophy

Adhesively bonded structures exhibit time dependent behavior when subjected to constant load (creep). The aim of this study is to predict the long-term creep behavior of adhesively bonded metal and composite structures under load. Three-point bending test is selected because of its simplicity and the fact that bending stresses are quite common. In this study, two types of adhesively bonded beam specimens were tested: specimens prepared by adhesively bonding two aluminum beams and specimens prepared by adhesively bonding two unidirectional carbon fiber laminated beams. Accelerated creep tests were performed at higher temperatures and deflection was measured as a function of time for both types of specimens. Time temperature superposition principle (TTSP) used to construct the master curve to predict longer term creep of the adhesively bonded beams under load at reference temperature. Prony series was used to model the master curve by non-linear least square fitting. The analytical results showed good agreement with finite element results where ABAQUS software was used to model the flexural creep response of the adhesively bonded beams. 


\section{AUTOBIOGRAPHICAL STATEMENT \\ HASAN NUWAYER}

\section{EDUCATION:}

- Ph.D., Mechanical Engineering, Wayne State University, Detroit, Michigan, 2017.

- M.S, Mechanical Engineering, Kazan State Technical University, Kazan, Russia, 2001.

- BSME, Garyounis University, Bengahzi, Libya, 1988.

\section{EXPERIENCE:}

- Mechanical Engineer, Center of production and development, Tripoli-Libya 1988-2006.

- Teacher Assistant, Aljabal Algharbi University, Gharyan-Libya 2007-2010. 